\title{
WORKING
}

paper

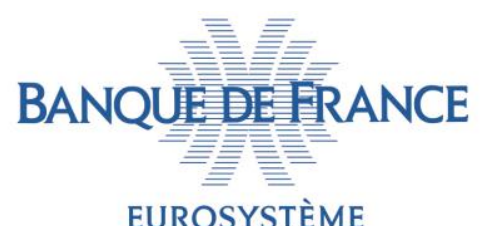

EUROSYSTÈME

\section{This Town Ain't Big Enough? Quantifying Public Good Spillovers}

\author{
Nicolas Jannin ${ }^{1}$, Aurélie Sotura ${ }^{2}$
}

December 2020, WP 796

\begin{abstract}
Despite long-standing theoretical interest, empirical attempts at investigating the appropriate level of decentralization remain scarce. This paper develops a simple and flexible framework to test for the presence of public good spillovers between fiscally autonomous jurisdictions and to investigate potential welfare gains from marginal fiscal integration. We build a quantitative spatial equilibrium model with many local jurisdictions, mobile households and endogenous local public goods causing spillovers across jurisdictional boundaries. We show how one can exploit migration and housing price responses to shocks in local public goods at different geographic scales to reveal the intensity of spillovers. Applying our framework to the particularly fragmented French institutional setting, we structurally estimate the model using a unique combination of municipal administrative panel datasets. Estimation relies on plausibly exogenous variations in government subsidies to instrument changes in the supply of public goods. We find that public goods in a municipality account for $4--11 \backslash \%$ of the local public good bundle enjoyed by its residents, and that public goods in each neighbor municipality account for an average 3.2--3.5 $\backslash \%$ of this bundle. Finally, we simulate the effect of a reform increasing fiscal integration and find substantial welfare gains ${ }^{3}$.
\end{abstract}

Keywords: Local Public Service, Spillover Effect, Spatial General Equilibrium, Tiebout, Welfare Economics, State Government Subsidies.

JEL classification: D16, H41, H71, H72, H73, R13

\footnotetext{
1 Banque de France, aurelie.sotura@banque-france.fr

2 Direction Générale du Trésor, nicolas.jannin@dgtresor.gouv.fr

${ }^{3}$ We thank Antoine Bozio, Jan K. Brueckner, Pierre-Philippe Combes, Gilles Duranton, Gabrielle Fack, Stéphane Gauthier, Laurent Gobillon, Stéphane Guibaud, Philipp Ketz, Miren Lafourcade, Thomas Piketty, Emmanuel Saez, Benoit Schmutz, Daniel Sturm, Etienne Wasmer and seminar participants at Amsterdam 2019 UEA European Meeting, Philadelphia 2019 UEA Meeting, UC Berkeley, Panthéon-Assas CRED and PSE for helpful comments and discussions. All remaining errors are our own.
}

Working Papers reflect the opinions of the authors and do not necessarily express the views of the Banque de France. This document is available on publications.banque-france.fr/en 


\section{NON-TECHNICAL SUMMARY}

Take an economy divided into geographically distinct jurisdictions. Who should be providing local public goods? Local governments or the central government? On the one hand, decentralization may be inefficient because of spatial spillovers, i.e., the extent to which a jurisdiction's local public goods also benefit its neighbours. When spillovers are strong, local jurisdictions may under-provide local public services as they do not internalize their benefits to neighbour jurisdictions. In addition, jurisdictions may actively free-ride on neighbour jurisdictions' public goods, worsening the under-provision problem. On the other hand, the political economy of centralized decision-making may misallocate local public services.

Despite long-standing theoretical interest, empirical attempts at investigating the intensity of local public good spillovers and henceforth the appropriate level of decentralization remain scarce.

This paper develops a simple and flexible framework to test for the presence of public good spillovers between fiscally autonomous jurisdictions and to investigate potential welfare gains from marginal fiscal integration.

We build a quantitative spatial equilibrium model with many local jurisdictions and mobile households that choose in which jurisdiction they live in. Local amenities, rents, wages, and local public good characterize jurisdictions. Inhabitants of jurisdiction vote for local public good quantity and taxes that maximize their utility. Wages and rents clear labour and housing markets. Inhabitants of a jurisdiction may value local public goods of neighbouring jurisdiction; hence, there might be local public good spillovers across jurisdictional boundaries. We show how one can exploit population and housing price responses to shocks in local public goods at different geographic scales to reveal the intensity of spillovers. We interpret a stronger response, in terms of population, housing consumption and housing prices, at a greater geographic level, as evidence of stronger public good spillovers within the smaller geographic level.

We apply our framework to the particularly fragmented French institutional setting. Here the greater geographic level are municipal federation and the smaller are municipalities. We structurally estimate the model using a unique combination of municipal administrative panel datasets.

Estimation relies on plausibly exogenous variations in government subsidies that we use to instrument changes in the supply of public goods.

We find that public goods in a municipality account for $4--11 \backslash \%$ of the local public good bundle enjoyed by its residents, and that public goods in each neighbour municipality account for an average $3.2--3.5 \backslash \%$ of this bundle. Finally, we simulate the effect of a reform increasing fiscal integration and find substantial welfare gains.

\section{Population and housing prices municipalities responses to local public good shocks within and} between municipal federation

Population
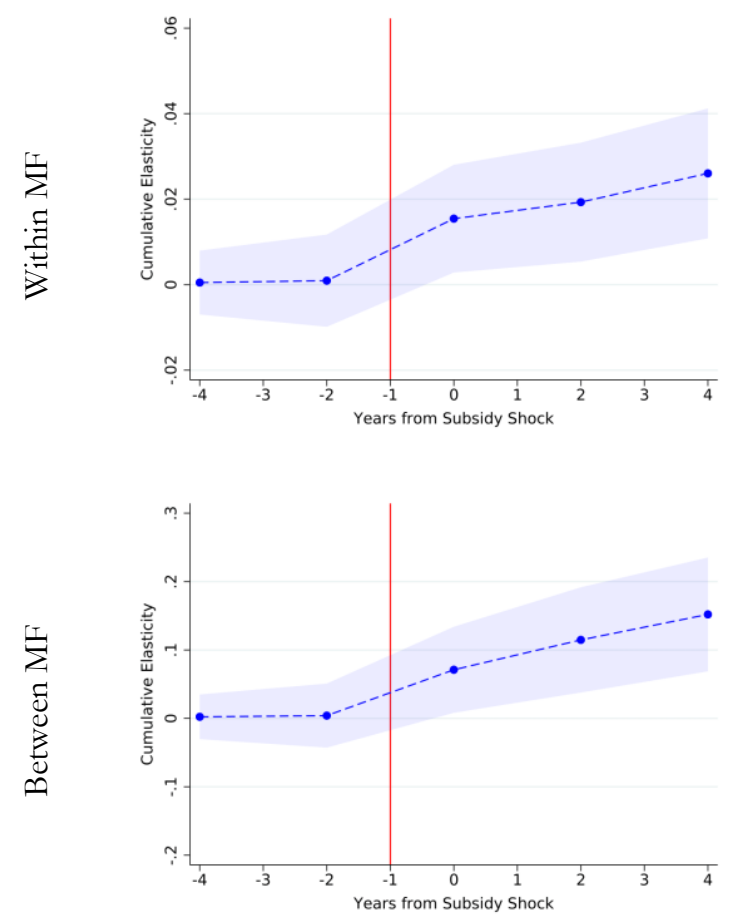

Housing prices
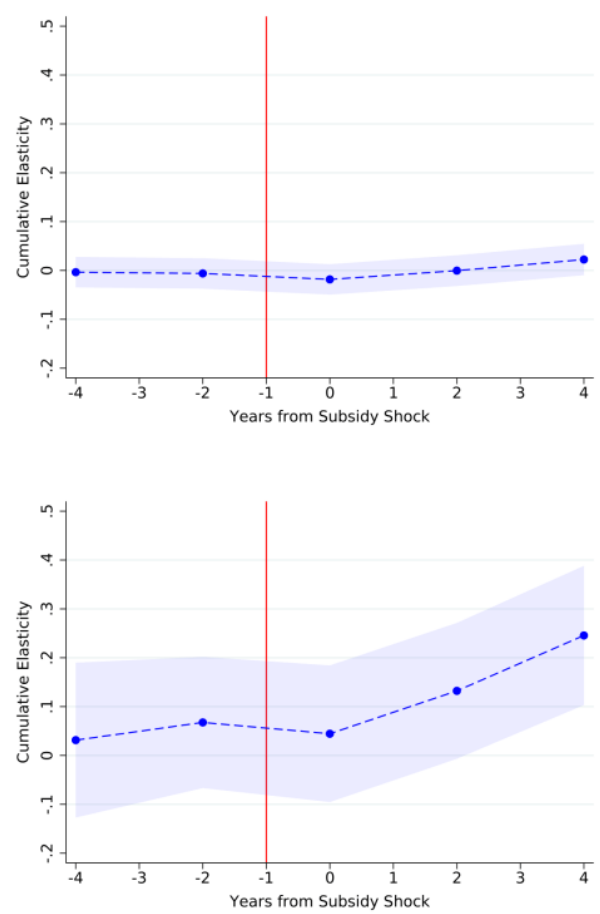
Note: These graphs show the effect of changes in a municipality's subsidy stock, that proxy local public good changes, on cumulative changes in population and housing prices starting 6 years prior to the shock year. First line graphs are relative to within municipal federation mean changes, the second line are relative to between municipal federation mean changes. Standard errors are clustered at the MF level. We report the $5 \backslash \%$ confidence bands. Sources: Administrative database, Notaries database, Authors' calculations.

\title{
Cette ville n'est pas assez grande? Quantifier les effets de débordements des biens publics locaux
}

\begin{abstract}
RÉSUMÉ
Quel est le niveau géographique optimal de production des biens publics ? Malgré un intérêt persistent parmi les décideurs publics et les économistes, cette question a fait l'objet de relativement peu de travaux empiriques. Ce papier développe un méthodologie simple et flexible permettant de tester la présence d'effets de débordements des biens publics locaux entre collectivités avec autonomie fiscale, et d'estimer les potentiels effets positifs d'une réforme qui fusionnerait les collectivités à un échelon géographique supérieur. On appelle effets de débordement le fait qu'un bien public produit et financé par une collectivité peut être valorisé et utilisé par des habitants d'autres collectivités. On construit un modèle quantitatif d'équilibre spatial où les individus choisissent dans quelles collectivités ils veulent habiter, et où leur choix dépend de la quantité de bien public produit par les collectivités, ces biens publics pouvant faire l'objet d'effets de débordement en dehors de leurs frontières juridiques. On montre comment il est possible d'utiliser les variations de la population et des prix de l'immobilier des collectivités en réponse à des chocs de biens publics, à différents niveaux de collectivités, pour mettre en évidence l'intensité des effets de débordements. En appliquant la méthodologie développée au cas des communes et communautés de communes françaises, on estime structurellement le modèle grâce à une riche combinaison de données administratives. L'estimation repose sur des variations plausiblement exogènes des subventions de l'État aux communes qui nous permettent d'instrumenter les variations de biens publics locaux. On trouve que les biens publics de la commune de résidence d'un habitant représente environ 4--11\% du panier de biens publics qu'il valorise et que les biens publics des communes de la même communauté de communes représentent, chacun, en moyenne $3.2--3.5 \%$ de ce panier. Dans un dernier exercice on simule les effets d'une réforme qui fusionnerait les communes au niveau de leur communauté de communes et on trouve des effets positifs substantiels.
\end{abstract}

Mots-clés : Bien public local, Effets de débordements, Équilibre spatial général, Tiebout, Économie du Bien-être, Subventions de l'État 


\section{Introduction}

Take an economy divided into geographically distinct jurisdictions. Who should be providing local public goods? Local governments or the central government? If local jurisdictions are tasked with providing public goods, what should be their boundaries? Since the seminal works of Tiebout (1956) and Oates (1972), academics have investigated the optimal balance of power between local and more centralized forms of government. Simply put, the political economy of centralized decision-making misallocates local public services. On the other hand, decentralization may be inefficient because of spatial spillovers, i.e., the extent to which a jurisdiction's local public goods also benefit its neighbors. ${ }^{1}$ When spillovers are strong, local jurisdictions may under-provide local public services as they do not internalize their benefits to neighbor jurisdictions. In addition, jurisdictions may actively free-ride on neighbor jurisdictions' public goods, worsening the under-provision problem.

In practice, there seems to be no consensus about the optimal size and autonomy of local jurisdictions. There remains substantial variation in institutional geography across western countries. Average town population is 4,300 in the EU compared to 16,000 in the US. Within the EU itself, there are large disparities between otherwise comparable countries. Average town density is similar in Germany (179 inhabitants per $\left.\mathrm{km}^{2}\right)$, France (154 inh. per $\mathrm{km}^{2}$ ) and Spain (177 inh. per $\mathrm{km}^{2}$ ). However, with mean jurisdiction population of respectively 7,100 and 5,800, German and Spanish towns are much larger than the average French town only home to 1,753 inhabitants.

Depending on the magnitude of decentralization and centralization inefficiency costs, jurisdictional fragmentation may have important welfare consequences. Policy and institutional solutions to remedy spillover inefficiencies typically include Pigovian subsidies and boundary redefinition. While the former solution requires the tailoring of subsidies to spillover intensity, one simply needs knowledge of the presence of spillovers between jurisdictions belonging to a given geographic area to implement the latter. However, while a rich theoretical literature studies efficient fiscal federalism (see Oates 2005 for a review), there are few empirical attempts at structurally quantifying local public good spillovers. Indeed, there are empirical and theoretical challenges to disentangling public good spillovers from other general equilibrium mechanisms. For example, spillovers may worsen migration externalities when public goods are subject to agglomeration or scale economies. ${ }^{2}$

Our paper revisits the local public good provision debate in a quantitative spatial equilibrium

\footnotetext{
${ }^{1}$ Decentralization may be inefficient for other reasons, e.g., tax competition between local governments (see for example Brueckner 2000, Brueckner 2003 and Boadway and Tremblay 2012 for reviews). In this paper, we focus on local public good spillovers in the tradition of the early literature on decentralization. Our results are however robust to the presence of tax competition.

${ }^{2}$ When public goods are not fully rival, the costs of providing residents with a given level of public good benefits increase less than one for one with population. Denser jurisdictions typically provide more public goods for less taxes, which creates an agglomeration force.
} 
model. Our contribution is twofold. First, we develop a simple framework to test for potential welfare gains from arbitrary increases in the level of centralization of public goods provision. We ground it on a location choice model borrowed from the urban economics literature that allows us to isolate public good spillovers from other mechanisms at play in equilibrium. The key ingredient is the nesting of fiscally autonomous jurisdictions in geographic areas within which one suspects there are cross-border spillovers. By studying migration and housing price responses to local public good shocks first between jurisdictions within nests, then between such nests, one can reveal the presence of spillovers. Because these nesting areas can be made to encompass an arbitrary number of jurisdictions, our framework allows to repeatedly test for the presence of spatial spillovers until finding the jurisdictional fragmentation for which they vanish. To the best of our knowledge, this paper is the first attempt at taking a structural approach to fiscal decentralization. Second, we apply our framework to French data and provide new estimates for structural parameters that are key to the local public finance debate. In the much fragmented French context, we estimate strong spatial spillovers and public good scale economies.

Our approach has two limitations. First, assessing the inefficiency cost of centralization is beyond the scope of the present paper. These costs typically stem from the interaction between centralized political frictions that tend to create winners and losers, and heterogeneous local needs. ${ }^{3}$ As such, we abstract from the taste heterogeneity motivating the standard Tiebout literature and do not account for interactions between local and central governments. Second, structural parameters may themselves be endogenous to local public goods, e.g., to the development of regional transport.

We first develop a spatial equilibrium model that draws on the seminal framework of Rosen (1974) and Roback (1982) and allows for endogenous wages, rents and local public good provision. We let households be potentially infra-marginal in their migration choices by introducing heterogeneous preferences for jurisdictions. Agents are otherwise homogeneous in skills and have identical preferences for public goods over private consumption. They vote for local taxes and a level of public goods that in turn affects equilibrium demand for jurisdictions. Most importantly, we allow for cross-border public good spillovers in a simple flexible structure that keeps the model amenable to reduced-form empirical analysis. Our model pinpoints key structural parameters related to spillovers, local public good agglomeration economies, preference for public goods, household mobility and housing supply elasticity.

Home to around 35,000 autonomous local jurisdictions accounting for 38\% of EU's total, France is a natural context in which to apply our framework. We first provide difference-in-differences (DiD) evidence on the impact of public good supply shocks on migration, housing consumption and housing prices using comprehensive administrative datasets on French municipalities. We combine data cov-

\footnotetext{
${ }^{3}$ See for example Carbonnier et al. (2008) for an attempt at assessing both the costs of centralization and decentralization.
} 
ering local taxes and public spending, population, housing consumption, wages and housing prices from 2000 to 2016. Our identification strategy exploits plausibly exogenous variation in public investment subsidies coming from higher layers of government-e.g., regions or the central government - to instrument changes in local public goods. Overall, we find significant migration responses and housing price capitalization which we interpret as evidence that households are mobile, enjoy local public services and that housing supply is not inelastic in the medium run. However, we find that migration responses to public good shocks within municipal federations - which are administrative groups of close-by municipalities - are smaller than when comparing these groups between them. We also estimate significant housing price capitalization in the latter case and not in the former. In line with our theoretical framework, a candidate mechanism to explain these reduced-form results is the presence of spatial spillovers, rendering location decisions less relevant for the enjoyment of publicly provided amenities within groups of close-knit jurisdictions.

We take our theoretical framework to the data and use a Generalized Method of Moments (GMM) to estimate the model's parameters. We express moments conditions in terms of the model's structural residuals and investment subsidy shocks. We combine moment conditions related to demand for municipalities and average demand for municipal federations. Importantly, the model is identified using the same subsidy shocks that we exploit in our DiD analysis. Different variations in subsidy shocks differently affect demand for municipalities and local housing supply and demand, in particular as we allow for local housing supply elasticities to vary across municipalities.

We find significant cross-border spillovers. Our results suggest that for the average municipal federation size, public spending in a French municipality accounts for $4-11 \%$ of the bundle of local public goods enjoyed by its residents, and that public spending in its average neighbor municipality - belonging to the same municipal federation - accounts for 3.2-3.5\% of this bundle. These high estimates for cross-border spillovers suggest that residents in a given municipality benefit from neighbor municipalities' public goods almost as much as their own municipality's. This may be because French municipalities are in general very small, and because there is almost no legal restriction such as zoning to benefiting from other municipalities' public goods. In a simple application of our method, we simulate the impact of redefining French jurisdictions' boundaries along pre-existing administrative lines and find strong welfare gains.

Our paper is related to the vast literature on fiscal decentralization. In his seminal paper, Tiebout (1956) argues that decentralized public good provision is efficient because people "vote with their feet" to choose their optimal bundle of taxes and public goods. However, Bewley (1981) provides a formal treatment of Tiebout's ideas and concludes that this efficiency result only holds when assuming away interesting features such as spatial spillovers and agglomeration externalities. Following Oates (1972), a rich theoretical literature investigates the consequences of spillovers on local public good provision 
and efficient federalism (e.g., Gordon 1983; Wellisch 1994; Conley and Dix 1999; Lockwood 2002; Besley and Coate 2003; Bloch and Zenginobuz 2007; Cheikbossian 2008; Bloch and Zenginobuz 2015).

Some empirical work tests the presence of spatial spillovers. Solé-Ollé (2006) investigates benefits spillovers - when households enjoy public goods of neighbor jurisdictions - and congestion spillovers - when households congest such public goods - in the case of local public spending in Spain. The author finds significant evidence of both in equal magnitude. Case et al. (1993) offer a test when local public goods of neighbor jurisdictions are complements and conclude to the existence of spillovers.

On the methodological side, our paper relates to the canonical spatial equilibrium framework of Rosen (1974) and Roback (1982). Drawing on the seminal logit choice setup of McFadden (1973), this workhorse model has since been extended to account for heterogeneous mobility frictions both for households and firms (e.g., Fajgelbaum et al. 2015; Suárez Serrato and Zidar 2016). We also relate to the large literature studying Tiebout type models with endogenous public good provision (Konishi 1996; Epple and Sieg 1999; Brueckner 2000; Bloch and Zenginobuz 2006). Our work is also related to recent research in urban economics modeling endogenous amenities such as Ahlfeldt et al. (2015), Diamond (2016) or Fajgelbaum and Gaubert (2018). In our setup, amenities take the form of public goods and taxes that are endogenous both because of household mobility and the local voting process.

Related empirical work has investigated Tiebout type drivers of migration decisions. Early work such as Oates (1969) studies the impact of local fiscal amenities on housing price capitalization. His estimates show that property values are positively affected by public spending on schools and negatively affected by local taxes. Banzhaf and Walsh (2008) look at the impact of a particular residential amenity, air quality, on jurisdiction density using large plant openings. The authors find that location choices are environmentally motivated. Lutz (2015) estimates significant effects of lower property taxation on residential investment and housing prices, with magnitudes depending on the elasticity of housing supply.

The rest of the paper proceeds as follows. Section 2 provides background on French local public finance and presents some empirical regularities. In Section 3, we develop our spatial equilibrium model of jurisdictions with endogenous fiscal amenities. Section 4 describes our data. Section 5 presents reduced-form evidence on the impact of local public good supply shocks on different economic outcomes. In Section 6, we use these shocks to structurally estimate our model with GMM. Section 7 presents welfare implications. Section 8 concludes.

\section{Institutional Background}

In this section we provide background on the French local institutional context and give some historical elements on the early acknowledgement by politicians of the existence of cross-border public good 
spillovers and of the potential gains from coordination. We then present some stylized facts that highlight the prevalence of municipalities in France in the provision of local public goods and lay the foundation for our empirical analysis by discussing municipalities' finances.

French local institutions belong to a four-tier system. As of 2016, the territory is divided into 35,352 municipalities (communes), nested in 2,000 municipal federations (intercommunalités), henceforth MF, 100 counties (départements) and 13 provinces (régions). Following a series of decentralization laws starting in the early 1980's, France's local authorities increasingly gained autonomy regarding local public services. Each layer of local government has the autonomy to levy taxes and is in charge of providing some public goods. The 35,352 French municipalities represent around 38\% of EU's total. ${ }^{4}$ This large number of municipalities means that most of them are home to very few residents - 383 in the median municipality.

The French government long acknowledged that this large number of jurisdictions may be a source of inefficiency in the provision of local public goods because of unexploited economies of scale, tax competition and poor public service coordination. ${ }^{5}$ Central authorities hence created financial incentives to encourage municipalities to merge into larger jurisdictions (see Leprince and Guengant 2002). Local officials however, supported by their constituents, have traditionally opposed such mergers. As a result, the number of municipalities has been fairly stable over time. There were around 38,000 municipalities in the late $18^{\text {th }}$ century, compared to roughly 35,000 in 2016 . To bypass political obstacles to mergers, central authorities introduced the possibility for neighbor municipalities to group into municipal federations. This new tier of local government, made up of elected officials from member jurisdictions, would allow municipalities to coordinate without loosing autonomy. Initially optional, being part of a municipal federation became compulsory in 2013. As a result, the share of federated municipalities jumped from 74\% in 2002 to 100\% in 2016, with an average 27 member municipalities per federation.

Despite the creation of this new layer, municipalities are still the largest providers of local public goods and local cooperation beyond basic services remains limited. In 2015, the local public sectormunicipalities, counties and provinces - spent $€ 229$ billion, representing 9.4\% of GDP. Municipalities accounted for $41 \%$ of the total, followed by counties (35\%), municipal federations (14\%) and provinces $(11 \%)$. When looking at local infrastructure investments alone, totalling $€ 47$ billion in 2015 , the relative weight of municipalities is even greater. Municipalities' investments represented $41 \%$ of the total, twice as much as counties $(21 \%)$, provinces $(20 \%)$ or municipal federations $(18 \%)$.

Municipalities are responsible for urban planning, transport and environmental policies (19\% of

\footnotetext{
${ }^{4}$ See data on local administrative areas by Eurostat https://ec.europa.eu/eurostat/fr/web/nuts/ local-administrative-units.

${ }^{5}$ See report by the French Senate https://www.senat.fr/rap/r05-193/r05-1931.html.
} 
their budget in 2009). They are also responsible for kindergartens and primary schools (13\% of the budget) which includes school creation, location decision, management and financing, i.e., everything except teachers' hiring and payroll. Finally, they are also in charge of sports, tourism and culture (17\% of their budget) including the construction and maintenance of public libraries, museums, music schools, public theaters, sports and tourist facilities as well as financial support to sports or cultural events and associations. Municipal federations are mostly in charge of economic development and they may cooperate on the provision of local public goods that are of the responsibility of municipalities, without any obligation. ${ }^{6}$

Importantly, almost all local public goods provided by municipalities are enjoyable by any household regardless of municipality of residence. This is clearly the case for urban planning, transport and environmental policies. However, it is also the case for sports or cultural facilities and events. In the case of swimming pools and public libraries for instance, there are two kinds of preferential access rules: a special fee for residents, or a special fee for residents and residents of close-by jurisdictions. While fees might differ depending on jurisdiction of residence, access can never be denied to anyone. Access to primary schools and kindergartens is subject to zoning which in principle prevents residents of a municipality to benefit from the school quality of a neighbor municipality. However, there are ways to circumvent school zoning in practice. Furthermore, small municipalities have been facing population decline for decades. In order to meet their legal obligation to provide primary and kindergarten schooling, municipalities in rural areas are allowed to form groups regarding schooling provision. ${ }^{7}$

To finance local public goods, municipalities have the autonomy to levy taxes. ${ }^{8}$ In 2015 , they raised around $€ 50$ billion or $2 \%$ of GDP in direct and indirect taxes of which $33 \%$ were from the tax on resident households, $28 \%$ from the tax on property owners, $20 \%$ from the local business tax, $2 \%$ from the land tax and the remaining 17\% from various small taxes (housing transaction taxes, waste management tax, etc.). ${ }^{9}$ As an alternative source of funding, municipalities receive $€ 17$ billion in operating subsidies to cover operating (i.e., non-investment) expenditure. These subsidies are formula-based - loosely speaking increasing with population and decreasing with mean income-and mostly coming from the central government. Finally, municipalities receive around $€ 13$ billion from other smaller sources such as various user fees. Together, these sources of funding cover $116 \%$ of municipalities' annual operating expenses (around $€ 69$ billion in 2015), the 16\% surplus being invested in infrastructure.

In 2015, French municipalities invested $€ 19$ billion in local infrastructure. Funding in the form of general endowments and investment subsidies accounted for $42 \%$ of total investment, the remaining

\footnotetext{
${ }^{6}$ They will all be in charge of water provision and waste management starting 2020.

${ }^{7}$ In any case, primary schools and kindergartens only account for $13 \%$ of municipalities' budget.

${ }^{8}$ This autonomy, however, is constrained by the presence of several rules limiting year-on-year variation in tax rates.

${ }^{9}$ Source: Ministry of Finance.
} 
$58 \%$ being financed by operating surpluses and additional debt. General endowments can take the form of in-kind gifts from the central government or non-targeted and automatic transfers such as VAT refunds on infrastructure expenditure. Investment-targeted subsidies however are more specific and aimed at financing well-defined investment projects. These are awarded by the boards of counties and provinces as well as by the central government to municipalities that were successful in their grant application. While we do not observe jurisdictions' applications to investment grants, we argue in Section 5 that these subsidies are plausibly exogenous shocks to local public good supply.

There is substantial cross-sectional variation in investment subsidies received each year. For the purpose of our paper, we define a jurisdiction's investment subsidy stock in year $t$ as the sum of subsidies ever received by the jurisdiction up to $t$. This investment subsidy stock concept captures how much of a jurisdiction's public assets are being financed by public funds coming from a higher layer of government. ${ }^{10}$ To make yearly subsidies more comparable between municipalities, we operate some normalization. We divide the total subsidy amount received in year $t$ by the subsidy stock in year $t-1$. The normalized yearly subsidy can then be interpreted as the growth in the municipal subsidy stock. We then subtract to each municipal-level observation the national or own MF average. In Figure 1 we report the resulting distributions pooling subsidy stocks' yearly growth in 2007, 2009 and 2010.11 Panel

Figure 1: Distribution of Subsidy Stock Yearly Growth

A. Relative to Mean National Change

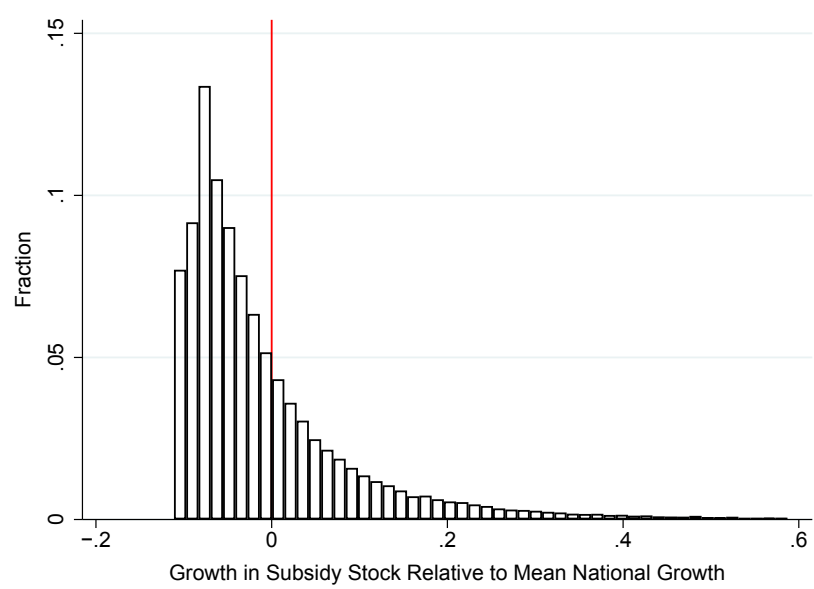

B. Relative to Mean MF Change

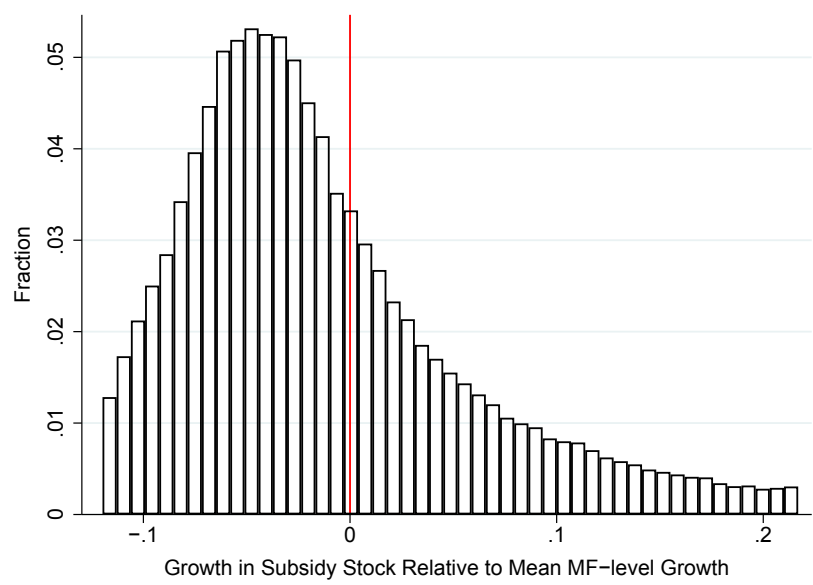

Note: These histograms plot the distribution of the yearly growth in normalized subsidy stocks pooling years 2007, 2009 and 2010. Panel A normalizes each municipality-level observation by the national geometric mean. Panel B normalizes each municipality-level observation by the geometric mean of all municipalities belonging to the municipality's MF. In each Panel, top and bottom $1 \%$ observations are censored for exposition purposes.

\footnotetext{
${ }^{10}$ Subsidies financing durable investments are recorded as a liability stock in the municipal accounts. They are depreciated at the same speed as the investment they help financing to keep reflecting their current contribution to local assets.

${ }^{11}$ Our data are from the French municipal financial accounts (Balance Comptable des Communes) that we present in more details in Section 4.
} 
A shows the pooled distribution of this percentage change in excess of the national percentage change. It exhibits substantial variation with the $1^{\text {st }}$ percentile being at $-11 \%$ and the $99^{\text {th }}$ percentile at $+59 \%$. Panel B shows a slightly modified distribution, where each jurisdiction's subsidy percentage change is considered relatively to the mean change in the jurisdiction's MF. Again, it exhibits substantial dispersion with the $1^{\text {st }}$ percentile being at $-19 \%$ and the $99^{\text {th }}$ percentile at $+51 \%$.

\section{Theoretical Model}

This section develops our spatial equilibrium model. It extends the seminal framework of Rosen (1974) and Roback (1982) to account for heterogeneous preferences for jurisdictions in the spirit of the recent urban economics literature. Most importantly, we allow for endogenous rents, wages, local public goods and taxes. A distinguishing feature of our model is its focus on local public goods. Endogenous fiscal amenities - taxes and public spending — are central in households' location decisions and are determined through an elementary voting mechanism.

The model shares some methodological features with the urban or economic geography frameworks of Busso et al. (2013), Ahlfeldt et al. (2015), Suárez Serrato and Zidar (2016), Diamond (2016) and Fajgelbaum and Gaubert (2018). There is a finite collection of $J$ jurisdictions indexed by $j$ with fixed boundaries, as well as a finite collection of $A$ mutually exclusive geographic areas indexed by $a$ in which the $J$ jurisdictions are nested. Because these nesting areas can be made arbitrarily large, our framework is flexible enough to accommodate many institutional settings. We note $a_{j}$ the area $j$ belongs to.

There is a continuum of imperfectly mobile households of measure $1, N_{j}$ being the share of households living in jurisdiction $j$. Households inelastically supply one unit of labor in their jurisdiction of residence. Jurisdiction $j$ is characterized by a vector of endogenous observables - wage $w_{j}$, rental price

$r_{j}$, aggregate public good measure $\mathcal{G}_{j}$, ad-valorem local housing tax $\tau_{j}^{h}$ and local business tax $\tau_{j}^{k}$ - as well as unobserved residential amenities. Local public goods are financed by local housing and business taxes as well as subsidies coming from the central government. A national proportional income $\operatorname{tax} \tau^{w}$ finances government subsidies to the $J$ jurisdictions. The sections below describe how demand for jurisdictions, housing supply, wages and local public goods are endogenously set in equilibrium.

\subsection{Preferences}

In order to easily connect theory and empirical analysis, we develop our conceptual framework in a Cobb-Douglas environment. Utility of household $i$ living in jurisdiction $j$ is

$$
U(\mathcal{C}, \mathcal{G}, i, j)=\mathcal{C}^{1-\phi} \mathcal{G}^{\phi} \mathcal{E}_{j}^{A} \exp \left(\mu_{i j}\right)
$$


where $\mathcal{G}$ is the aggregate local public good and $\mathcal{C}$ is a measure of aggregate private consumption, $\mu_{i j}$ represents the idiosyncratic taste of individual $i$ for jurisdiction $j$ and $\mathcal{E}_{j}^{A}$ captures jurisdiction $j^{\prime} \mathrm{s}$ exogenous residential amenities. Parameter $\phi \in[0,1]$ is the taste for public goods relative to private consumption, that we assume homogeneous across households.

Consumption Agents enjoy aggregate private consumption $\mathcal{C}$ defined by

$$
\mathcal{C}=c^{1-\alpha} h^{\alpha}
$$

where $c$ is consumption of the nationally traded good taken as the numéraire and $h$ is $m^{2}$ housing consumption. Parameter $\alpha \in[0,1]$ is the housing consumption share which we assume to be constant across households. Given post-tax rental prices $r\left(1+\tau^{h}\right)$ and net income $\left(1-\tau^{w}\right) w$, consumption of the numéraire good is

$$
c=\left(1-\tau^{w}\right) w-r\left(1+\tau^{h}\right) h
$$

Public good The aggregate public good measure $\mathcal{G}_{j}$ depends on the congested local public good of the jurisdiction households live in and on that of all other jurisdictions belonging to the same area $a_{j}$ due to the presence of cross-boundary spillovers. For a jurisdiction $j$, we assume that congested public goods of other jurisdictions belonging to area $a_{j}$ enter $\mathcal{G}_{j}$ with equal spillover weights while spillovers coming from jurisdictions outside of $a_{j}$ are zero. This binary structure for spillovers' spatial decay is simplistic yet allows to flexibly test for their presence in different settings. We define $\mathcal{G}_{j}$ as the geometric average of $j$ 's own congested public good and that of other jurisdictions of $a_{j}$ :

$$
\mathcal{G}_{j}=\mathbb{G}_{j}^{\delta} \prod_{j^{\prime} \in a_{j}} \mathbb{G}_{j^{\prime}}^{(1-\delta) /\left|a_{j}\right|}
$$

where $\mathbb{G}_{j}$ represents the congested public good in $j$ and $\left|a_{j}\right|$ is the cardinal of $a_{j}$, i.e., the number of jurisdictions in the geographic area $j$ belongs to. Parameter $\delta \in[0,1]$ controls the intensity of spillovers, that is, the extent to which households benefit from local public goods of adjacent jurisdictions. When $\delta=1$ there are no spillovers and residents only enjoy the public goods provided in their jurisdiction. When $\delta=0$ there are full spillovers within any area $a$ so that conditional on living in $a$, jurisdiction of residence does not matter for the enjoyment of public goods present in jurisdictions of $a$. We adopt a symmetric approach for modeling congestion. We model $G_{j}$, the congested public good of jurisdiction $j$ as

$$
\mathbb{G}_{j}=\frac{G_{j}}{\left(N_{j}^{\delta} \prod_{j^{\prime} \in a_{j}} N_{j^{\prime}}^{(1-\delta) /\left|a_{j}\right|}\right)^{\kappa}}
$$

where $G_{j}$ is the quantity of local public goods provided by jurisdiction $j$, which are endogenously determined along with local taxes. Parameter $\kappa \in[0,1]$ controls the intensity of congestion. When 
$\kappa=1$, public good is fully rival and public good benefits are appropriately measured by per capita spending. When $\kappa=0$, public good is fully non-rival and public good benefits are appropriately measured by absolute public spending. As such, $\kappa$ is a parameter central to agglomeration economies. The spillover parameter $\delta$ is also involved in determining the amount of congestion deteriorating the benefits from $G_{j}$. It controls how much of public service congestion is coming from adjacent jurisdictions as a direct consequence of symmetric benefit spillovers. Absent spillovers, $\delta=1$ and public good in $j$ is only congested by residents of $j$. When $\delta=0$, public good in $j$ is equally enjoyed and congested by all residents of $a_{j}$.

Residential amenities Jurisdiction $j$ is further characterized by the unobserved residential amenities $\mathcal{E}_{j}^{A}$. They capture the mean appeal of the jurisdiction's fixed characteristics across individuals and include traditional amenities such as the weather, geographic location, etc. They also capture timevarying amenities other than those explicitly modeled. These amenities are equally valued by all residents of $j$.

Idiosyncratic tastes Each individual $i$ is characterized by a vector $\left\{\mu_{i 1}, \ldots, \mu_{i J}\right\}$ of idiosyncratic tastes. These $\mu_{i j}$ 's are assumed to be i.i.d. across and among individuals and distributed Extreme Value TypeI with parameters $(0, \sigma)$. They represent individual-jurisdiction specific utility premiums and notably capture heterogeneity in mobility costs and in the valuation of jurisdictions' fixed amenities. ${ }^{12}$ Parameter $\sigma$ controls the dispersion of these idiosyncratic tastes and is inversely related to household mobility. When $\sigma$ is higher, density around the indifference threshold between any two jurisdictions is thinner as more households are infra-marginal. As a consequence, the migration response to a marginal change in the appeal of one jurisdiction relative to the other gets smaller.

Model parameters to be estimated so far are $\{\sigma, \phi, \kappa, \delta\}$ capturing inverse household mobility, taste for the public good, public good congestion and cross-boundary spillovers. The housing consumption share $\alpha$ will be calibrated from the literature.

\subsection{Conditional Housing Demand}

Conditional on living in $j$, agent $i$ decides how much housing to consume while being net wage, housing price and tax taker. Given the constant share assumption, conditional individual housing

\footnotetext{
${ }^{12} \mathrm{An}$ interpretation of a higher value for $\mu_{i j}$ relative to any other $\mu_{i j^{\prime}}$ is $j$ being the jurisdiction in which $i$ was born, educated and socialized. Another interpretation is heterogeneity in preferences for local exogenous amenities (e.g., weather, natural amenities, etc.).
} 
demand and numéraire consumption equal

$$
\begin{aligned}
& h_{j}^{D}=\alpha \frac{\left(1-\tau^{w}\right) w_{j}}{r_{j}\left(1+\tau_{j}^{h}\right)} \\
& c_{j}=(1-\alpha)\left(1-\tau^{w}\right) w_{j}
\end{aligned}
$$

and do not depend on $i$. Per capita housing and numéraire consumption may hence be treated as endogenous jurisdiction amenities.

\subsection{Demand for Jurisdictions}

Agent $i$ chooses to live in the jurisdiction that maximizes $U(\mathcal{C}, \mathcal{G}, i, j)$. We can write:

$$
\ln U(\mathcal{C}, \mathcal{G}, i, j)=v_{j}+\mu_{i j}
$$

where

$$
v_{j}=(1-\phi) \ln \left(\mathcal{C}_{j}\right)+\phi \ln \left(\mathcal{G}_{j}\right)+\ln \left(\mathcal{E}_{j}^{A}\right)
$$

Households first solve for optimal housing and numéraire good consumption conditional on jurisdiction of residence according to (6). Based on their idiosyncratic tastes $\mu_{i j}$, they make the extensive margin choice of where to live upon observing local aggregate private consumption $\left\{\mathcal{C}_{j}\right\}$, aggregate local public goods $\left\{\mathcal{G}_{j}\right\}$ as well as exogenous amenities $\left\{\mathcal{E}_{j}^{A}\right\}$. When comparing different jurisdictions, households are thus $v_{j}$ takers. This conditional logit setup was first introduced by McFadden (1973) in a broader context of discrete choices. Demand for jurisdiction $j$ then equals the expected set of households for which $j$ yields the highest utility, i.e., $N_{j}=\mathbb{E}\left[\mathbb{1}_{\left\{u_{i j}>u_{i q} \forall q \neq j\right\}}\right]$. Because idiosyncratic tastes are distributed Extreme Value Type-I and enter utility separately from other components, population in jurisdiction $j$ is equal to

$$
N_{j}=\frac{\exp \left(v_{j} / \sigma\right)}{\sum_{j^{\prime}} \exp \left(v_{j^{\prime}} / \sigma\right)}
$$

Loosely speaking, demand for jurisdiction $j$ is the ratio between how attractive the jurisdiction is and the mean jurisdiction appeal in the country. Equation (9) notably implies that no jurisdiction is empty and that the market for jurisdictions clears:

$$
\sum_{j} N_{j}=1
$$

Total housing demand in jurisdiction $j$ is then the result of intensive margin consumption and extensive margin in-migration:

$$
H_{j}^{D}=h_{j}^{D} N_{j}
$$




\subsection{Housing Supply}

We assume that a representative absentee landlord has the opportunity to put existing homes on the market or to develop new ones, rented at a price $r$ per $m^{2}$ of housing. The marginal opportunity or development cost is increasing in the quantity of housing already on the market and decreasing in the jurisdiction area $T$. Formally, the cost of providing housing is $\left(\frac{H}{T_{j}}\right)^{1+\frac{1}{\eta_{j}}} \mathcal{E}_{j}^{C}$ where $\eta_{j}$ is the housing supply elasticity. Further differences in local housing supply determinants are captured by the cost shifter $\mathcal{E}_{j}^{C}$. Since it enters the housing supply cost function in a multiplicative way, it is isomorphic to a reduction in available land. Profit maximization yields the inverse housing supply equation

$$
\ln \left(r_{j}\right)=\frac{1}{\eta_{j}} \ln \left(\frac{H_{j}^{S}}{T_{j}}\right)+\ln \left(\mathcal{E}_{j}^{C}\right)
$$

\subsection{Labor Demand}

Local labor markets are not the focus of this paper. However, our analysis needs to account for endogenous wages as they are potentially affected by endogenous business taxation and productivity, e.g, through public investments. We make two standard assumptions. First, each jurisdiction produces a quantity $Y_{j}$ of the traded good with a constant return to scale technology using local labor and capital. Second, absentee capital owners supply capital in all jurisdictions at a fixed interest rate $R$. We further assume that local business taxation is proportional to the outflow of local interest payments accruing to capital owners. With these assumptions, one easily shows that the inverse labor demand equation has the following form:

$$
w_{j}=\theta_{j}^{Y}\left(\{G\}_{j^{\prime}}\right) f\left(\left(1-\tau_{j}^{k}\right) R\right)
$$

with $w_{j}$ the local wage, $\tau_{j}^{k}$ the local business tax, $f$ any function and $\theta_{j}^{\gamma}\left(\{G\}_{j^{\prime}}\right)$ the local labor productivity that may be endogenous to the quantity of public goods $G_{j^{\prime}}$ of any jurisdiction $j^{\prime}$ in $a_{j}$. With this formulation, local wages are negatively affected by an increase in the local business tax and are positively affected by productivity shocks. Our empirical analysis would be unchanged if we allowed for tax competition and a more general production function with decreasing returns to scale (e.g., because of land use), productivity agglomeration gains or productivity spillovers as long as we econometricians observe the equilibrium wage. We would simply replace our inverse labor demand equation by a reduced-form expression such as

$$
w_{j}=f_{j}\left(R,\left\{N, \tau^{k}, \theta^{Y}\right\}_{j^{\prime}}\right)
$$




\subsection{Public Good Supply}

As mentioned in Section 3.1, $G_{j}$ is the quantity of public goods provided by jurisdiction $j .{ }^{13}$ Local taxes - ad-valorem housing tax $\tau_{j}^{h}$ and business tax $\tau_{j}^{k}$ - and subsidies $F_{j}$ from higher layers of government fund the production of $G_{j}$. In our setup, $F_{j}$ is exogenous. Residents of jurisdiction $j$ choose the triplet $\left\{G_{j}, \tau_{j}^{h}, \tau_{j}^{k}\right\}$ that maximizes their utility subject to the jurisdiction budget constraint. Because we assume homogeneous preferences for private consumption, the voting mechanism is akin to a maximization problem by a local social planner.

Residents' preferred policy is found by maximizing

$$
(1-\alpha) \ln \left(\left(1-\tau^{w}\right) w-r\left(1+\tau^{h}\right) h\right)+\alpha \ln h+\frac{\phi}{1-\phi} \delta \ln G
$$

over $\left\{G, \tau^{h}, \tau^{k}\right\}$ subject to jurisdiction budget constraint

$$
\Gamma_{j}(G)=\tau^{h} r H+\tau^{k} R K+F
$$

where $\Gamma_{j}$ maps public good quantities into the required public funds. Subsidies are financed by a national income tax $\tau^{w}$ that endogenously adjusts so that national budget is balanced:

$$
\tau^{w}=\frac{\sum_{j} F_{j}}{\sum_{j} N_{j} w_{j}}
$$

Although we dot not solve for local policies in the comprehensive case, this framework is useful for our welfare application in Section 7.

\subsection{Equilibrium}

We close the model by imposing market clearing conditions for the traded good and housing:

$$
\begin{aligned}
& \sum_{j} Y_{j}=\sum_{j} N_{j} c_{j} \\
& H_{j}^{S}=H_{j}^{D} \text { for all } j
\end{aligned}
$$

Definition 1. Given the model's parameters $\{\sigma, \phi, \kappa, \delta, \alpha\}$ and $\left\{\eta_{j}, T_{j}\right\}$, local fundamentals $\left\{\mathcal{E}_{j}^{A}, \mathcal{E}_{j}^{C}\right\}$, functional forms $\left\{f, \Gamma_{j}, \theta_{j}^{Y}\right\}$ and national subsidies $\left\{F_{j}\right\}$, an equilibrium is defined by jurisdiction population $\left\{N_{j}\right\}$, individual consumption $\left\{\mathcal{C}_{j}, c_{j}, h_{j}\right\}$, housing supply $\left\{H_{j}\right\}$, local prices $\left\{w_{j}, r_{j}\right\}$, public goods $\left\{G_{j}, \mathbb{G}_{j}, \mathcal{G}_{j}\right\}$, local taxes $\left\{\tau_{j}^{h}, \tau_{j}^{k}\right\}$ and the income tax $\tau^{w}$, which are determined by the following system of equations: aggregate and congested local public good definitions (4) and (5); local planner's optimization problem (14) and (15); jurisdiction utility (8); demand for jurisdictions (9); conditional housing demand (6); housing supply (12); labor demand (13); market clearing conditions (17) and national budget constraint (16).

Because of agglomeration forces in the model, Definition 1 may not characterize a unique equilibrium. We argue in Section 6 that structural parameters can be uniquely identified nonetheless.

\footnotetext{
${ }^{13}$ Section B details how we construct $G$ from available data. In our empirical application, $G$ includes both the flow of public services stemming from the use of public infrastructure and the flow of local public services that are typically staff expenditure, maintenance costs, subsidies to associations, etc.
} 


\subsection{Residential Amenities}

We use the equilibrium equations to express changes in unobserved residential amenities as a function of structural parameters and changes in observable endogenous variables. This step provides theoretical support to our difference-in-differences strategy in Section 5 and is the foundation of our GMM structural estimation in Section 6.

We first take the log of the demand for jurisdictions equation (9) and plug in jurisdiction utility equation (8), consumption equations (2) and (6), and public good definitions (4) and (5). We find an expression for residential amenities $\ln \left(\mathcal{E}_{j}^{A}\right)$ :

$$
\begin{aligned}
\ln \left(\mathcal{E}_{j}^{A}\right) & =-(1-\phi)(1-\alpha) \ln \left(1-\tau^{w}\right)-(1-\phi)(1-\alpha) \ln \left(w_{j}\right) \\
& -(1-\phi) \alpha \ln \left(h_{j}\right)-\phi \delta \ln \left(G_{j}\right)-\phi(1-\delta) \frac{1}{\left|a_{j}\right|} \sum_{j^{\prime} \in a_{j}} \ln \left(G_{j^{\prime}}\right) \\
& +\left(\sigma+\kappa \phi \delta^{2}\right) \ln \left(N_{j}\right)+\phi\left(1-\delta^{2}\right) \kappa \frac{1}{\left|a_{j}\right|} \sum_{j^{\prime} \in a_{j}} \ln \left(N_{j^{\prime}}\right) \\
& +\sigma \ln \sum_{j^{\prime}} \exp \left(v_{j^{\prime}} / \sigma\right)+\text { constant }
\end{aligned}
$$

While our model is set up in a static framework, we introduce time here as our empirical strategy in the following sections relies on time variation. In this new setup, residential amenities $\mathcal{E}_{j t}^{A}$ may contain time fixed effects in addition to jurisdiction fixed effects. Using (18) we derive two expressions describing how residential amenities change over time. First, take a jurisdiction $j$ nested in the larger geographic area $a_{j}$. We find an expression for how jurisdiction $j^{\prime}$ s residential amenities change over time relatively to residential amenities of all jurisdictions belonging to $a_{j}$ (what we call within-a amenity changes). Then, consider any geographic area $a$. We find an expression for how the average residential amenity in $a$ changes relatively to the average amenity in all geographic areas in the country (what we call between-a amenity changes).

Looking at within- $a$ and between- $a$ relative changes bears two advantages. First, it provides a theoretical framework for our DiD and GMM estimations that does not require to fix the utility of one jurisdiction or the denominator of (9). ${ }^{14}$ Second and given the assumption on the structure of spillovers, it allows us to isolate the spillover parameter $\delta$.

Within- $a$ amenity changes We subtract to equation (18) its within- $a_{j}$ average. This differences out all terms that are common across jurisdictions of $a_{j}$, including any $a_{j}$-specific time fixed effect. We then first-difference the resulting equation which absorbs any jurisdiction fixed effect. The final expression

\footnotetext{
${ }^{14}$ See for instance the seminal work of McFadden (1973) and more recently Diamond (2016) or Fajgelbaum et al. (2015) for examples of how this technical point is dealt with. We instead absorb the unobserved denominator of equation (9) by expressing residuals in relative terms.
} 
for amenity changes is

$$
\begin{aligned}
\Delta \ln \overline{\mathcal{E}_{j t}^{A}} & =\left(\sigma+\kappa \phi \delta^{2}\right) \Delta \ln \bar{N}_{j t}-(1-\alpha)(1-\phi) \Delta \ln \bar{w}_{j t} \\
& -\alpha(1-\phi) \Delta \ln \bar{h}_{j t}-\delta \phi \Delta \ln \bar{G}_{j t}
\end{aligned}
$$

where

$$
\bar{X}_{j}=\frac{X_{j}}{\prod_{j^{\prime} \in a_{j}} X_{j^{\prime}}^{\frac{1}{\left|a_{j}\right|}}}
$$

for any variable $X$ and $\Delta$ is the first-difference operator between any two arbitrary periods. Note that with full spillovers $(\delta=0)$, within- $a$ relative public good changes have no effect on within- $a$ relative migration responses as location does not matter for the enjoyment of public goods conditional on living in $a .^{15}$

Between- $a$ amenity changes Going back to equation (18), we take its average across all jurisdictions of any geographic area $a$. Treating $a$ as the new level of observation, we then subtract the average across all $a$ 's in the country. This step absorbs all fixed effects common across $a^{\prime}$, including common time fixed effect. Alternatively, one may subtract the average across all $a^{\prime}$ s within smaller geographic units in which the $a^{\prime}$ s are nested to better account for spatial variation in the time fixed effects. We then first-difference the resulting equation which absorbs any $a$ fixed effect. The final expression is

$$
\begin{aligned}
\Delta \ln \widehat{\mathcal{E}_{a t}^{A}} & =(\sigma+\kappa \phi) \Delta \ln \widehat{N}_{a t}-(1-\alpha)(1-\phi) \Delta \ln \widehat{w}_{a t} \\
& -\alpha(1-\phi) \Delta \ln \widehat{h}_{a t}-\phi \Delta \ln \widehat{G}_{a t}
\end{aligned}
$$

where

$$
\widehat{X}_{a}=\frac{\prod_{j \in a} X_{j}^{\frac{1}{|a|}}}{\prod_{a^{\prime}}\left(\prod_{j \in a^{\prime}} X_{j}^{\frac{1}{\left|a^{\prime}\right|}}\right)^{\frac{1}{A}}}
$$

for any variable $X$ and $A$ is the number of areas $a$. Importantly, these between- $a$ amenity changes do not feature parameter $\delta$. Indeed, public good spillovers are contained within each $a$ while equation (20) is at the $a$ level. ${ }^{16}$

\footnotetext{
${ }^{15}$ Alternatively, one can plug in the housing consumption expression from equation (6):

$$
\begin{aligned}
\Delta \ln \overline{\mathcal{E}_{j t}^{A}} & =\left(\sigma+\kappa \phi \delta^{2}\right) \Delta \ln \bar{N}_{j t}-(1-\phi) \Delta \ln \bar{w}_{j t} \\
& +\alpha(1-\phi) \Delta \ln \bar{r}_{j t}+\alpha(1-\phi) \Delta \ln \overline{\mathcal{T}}_{j t}-\delta \phi \Delta \ln \bar{G}_{j t}
\end{aligned}
$$
}

where $\mathcal{T}=1+\tau^{h}$.

${ }^{16}$ Alternatively, one can plug in the housing consumption expression from equation (6):

$$
\begin{aligned}
\Delta \ln \widehat{\mathcal{E}_{a t}^{A}} & =(\sigma+\kappa \phi) \Delta \ln \widehat{N}_{a t}-(1-\phi) \Delta \ln \widehat{w}_{a t} \\
& +\alpha(1-\phi) \Delta \ln \widehat{r}_{a t}+\alpha(1-\phi) \Delta \ln \widehat{\mathcal{T}}_{a t}-\phi \Delta \ln \widehat{G}_{a t}
\end{aligned}
$$




\section{Data}

We take advantage of a unique combination of panel administrative datasets that we obtained from the French Ministry of Finance and Ministry for the Environment as well as publicly available datasets at the jurisdiction level, overall covering the period 2000-2016. In this section we introduce the data and describe how we construct the variables present in the model.

Sample Our sample is the universe of mainland French municipalities that experience no boundary changes between 1999 and 2016. Not dropping municipalities experiencing boundary changes — such as municipalities merging or acquiring land from others - may lead to artificial variation in their supply of local public goods, population and economic outcomes. Fortunately, very few jurisdictions experience such changes and this manipulation leaves us with 34,835 jurisdictions, i.e., $96 \%$ of them, and an almost-complete partition of the French mainland territory.

Municipal financial accounts We use detailed municipal financial accounts (Balance Comptable des Communes) obtained from the French Ministry of Finance for every year between 2002 and 2016. Financial accounts contain information on municipalities' detailed asset and liability position as well as the composition of their yearly budget. Although it would be of great interest to disentangle the various components of local public goods, we are unable to classify the various items by their nature as the existing categories follow accounting definitions. This is of little consequence, however, as this paper is more general and seeks to address the broad inefficiencies in the provision of local public goods and not the effect of a particular type of public good.

We construct the public good quantity $G$ from municipal accounts by assuming that $G$ is a CobbDouglas public good index capturing both durable facilities and operating expenditure that benefit residents (see Appendix B for detailed methodology). We construct durable facilities as the sum of all public assets minus the raw value of the land and financial assets such as cash. ${ }^{17}$ As mentioned in Section 2, investments notably include schools, transportation infrastructure, parks improvements, sports facilities, museums, art collections, etc. They also include investment subsidies to other parties such as local clubs and associations. Importantly, they do not contain social housing units. ${ }^{18}$ We construct operating expenditure as the sum of staff expenditure, maintenance spending, payments for external services and operating subsidies to third parties. ${ }^{19}$

\footnotetext{
${ }^{17}$ Taking out the raw value of the land seems natural as residents are unlikely to value it. Given that land is mostly a gift from the central government, erasing this asset as well as the corresponding liability from the balance sheet is neutral in our analysis. Cash and other liquid assets can be considered negative debt and are accounted for in our theoretical framework in the form of future taxes. Assets are recorded at book value and account for investment depreciation.

${ }^{18}$ Social housing units, when publicly owned, are held by ad hoc entities and not by jurisdictions.

${ }^{19}$ We exclude interests payments as they do not correspond to consumable services.
} 
In our model, local public budgets are partly financed by public subsidies $F_{j}$ coming from the central government and higher layers of local government. In our empirical application, we instrument local public goods using a subset of these subsidies, namely investment-targeted subsidies, that we call $S_{j}$. We define $S_{j}$ as the sum of all investment subsidies ever received by municipality $j$ from counties, provinces and the central government minus all associated depreciation. In 2016, investment subsidies represent $23 \%$ of the financing of public capital. Endowments account for $28 \%$ while the remaining $41 \%$ are from local contributions - past (reserves) or future (debt). As mentioned in Section $2, S_{j}$ depreciates together with the public capital it helps financing. We will see that $S_{j}$ proves a good basis for instrumenting public goods $G_{j}$.

Population and housing We use FILOCOM (Fichier des Logements à la Commune) which is an exhaustive database on household housing stock. It provides information on each non-commercial dwelling every two years between 1994 and 2014 such as its location, surface, vacancy status, whether it is a main or a secondary home, rented or owner-occupied, and its number of residents. We use FILOCOM to construct our municipality-level population and housing database which contains the stock of rented or owner-occupied main homes per jurisdiction and the total and per capita housing $m^{2}$ surface. Population $N_{j}$ from the model is all inhabitants of housing units for which the head of household is aged 20-65 in jurisdiction $j$. Total housing consumption $H_{j}$ is how much $m^{2}$ are consumed by the $N_{j}$ residents, and per capita housing consumption is $h_{j}=H_{j} / N_{j}$.

Housing prices We use data on housing prices instead of rents as there is no exhaustive database on rents at the jurisdiction level prior to 2015. We combine housing transactions database from the notary offices (named BIEN for the Parisian region and PERVAL for the rest of France). We construct a database on housing prices per $\mathrm{m}^{2}$ for every two years between 2000 and 2014 at the municipality level. We assume that housing transaction prices from the notary data are the net present value of unobserved rents $r$. Proportional changes in $r$ thus equal proportional changes in housing prices. This method bears two caveats, one methodological and the other regarding the quality of the price data. First, although tenants pay rent every year - explicitly or implicitly — not all jurisdictions record housing transactions every year. As such, we can infer the rent growth of a jurisdiction only when it experiences a transaction in two consecutive periods. Second, the coverage of housing transactions in the notary data is not exhaustive.

Local tax data We use detailed local tax data (Recensement des Eléments d'Imposition à la Fiscalité Directe Locale-REI) for every year from 2002 to 2016. REI features all tax bases and rates at the jurisdiction level. We compute the ad-valorem local residence tax of the model from observed residence tax revenues $\operatorname{Rev}_{h}$, total housing stock $H$ and housing prices $p$ at the jurisdiction level: $\tau^{h}=\frac{\operatorname{Rev} h}{H r}$ where housing 
prices are the net present value of rents $r=\frac{R}{1+R} \times p$.

Wages We use labor income data from the IRCOM (Impôt sur le Revenu par Commune) dataset. IRCOM summarizes labor and social security total income at the municipal level from 2002 to 2016. We construct our jurisdiction wage measure $w$ as total labor income divided by the number of tax units reporting positive labor income.

Socio-demographics and geographic data We use census data to get jurisdiction-level information on total population and socio-demographic characteristics for years 1990, 1999, 2008 and 2013. We also use publicly provided data from the National Statistical Institute (INSEE) on jurisdictions' geography (municipal federation they belong to, distance to center of urban area center, area, etc.). Although our analysis does not study the public goods provided by municipal federations, we use these geographic groupings for the definition of the $a^{\prime}$ s. From 2000 to 2016, municipalities gradually joined MFs. In 2016, all municipalities belonged to municipal federations. We assign each municipality to its $2016 \mathrm{MF}$ for the whole duration of our panel so that these geographic groupings are constant over time.

Table 1 gives elementary descriptive statistics on jurisdictions summarizing some of the above constructed variables.

Table 1: Descriptive Statistics on Jurisdictions

\begin{tabular}{l|r|r}
\hline Variable & Mean & St. Dev. \\
\hline Current spending $^{\mathrm{a}}$ & $1,517,088$ & $23,022,598$ \\
Current spending per adult $^{\mathrm{b}}$ & 1,111 & 1,786 \\
Investment stock $^{\mathrm{a}}$ & $9,383,611$ & $98,714,400$ \\
Investment stock per adult $^{\mathrm{b}}$ & 13,481 & 24,130 \\
Population $^{\mathrm{c}}$ & 1,746 & 14,614 \\
${\text { Population } 20-65^{\mathrm{d}}}^{\text {Housing price per square meter }}$ & 994 & 4,573 \\
Net income per adult $^{\mathrm{d}}$ & 1,570 & 978 \\
Housing service per jurisdiction $^{\mathrm{d}}$ & 10,848 & 3,614 \\
Housing surface per adult $^{\mathrm{d}}$ & 16,247 & 83,086 \\
\hline
\end{tabular}

Note: This table gives the averages and standard deviations across jurisdictions for some of Section 5 constructed variables in 2009 or the closest available year.

${ }^{a} 2009$ municipal accounts, author's calculations

${ }^{b} 2009$ municipal accounts, 2008 Census data, author's calculations

$b_{2009}$ municipal accounts, 2009 FILOCOM, author's calculations

$d_{2009}$ FILOCOM, author's calculations

'2008 Census data, author's calculations

'2008 Notaries databases, author's calculations 


\section{Reduced-Form Evidence}

This section builds on the theoretical framework set out in Section 3 and presents the results of DiD models looking at the impact of changes in local public goods on changes in a range of economic outcomes - population, housing consumption, housing prices and wages.

In our empirical application, the $a^{\prime}$ s are the municipal federations in their 2016 form introduced in Section 2. Investigating whether these geographic areas are relevant for further fiscal integration makes economic and historical sense. Indeed, as argued in Section 2, jurisdictions historically grouped into MFs to partly internalize public good externalities and rationalize costs. We expect a relatively higher public good supply shock to increase relative migration towards targeted jurisdictions, increase total housing consumption, bid up rents in the housing market and consequently lower per capita housing $\mathrm{m}^{2}$ consumption. Because of public good spillovers within MFs, we expect within-MF changes in public good supply to have a smaller impact than between-MF changes. Although labor markets are not the focus of this paper, we can conjecture that potential productivity increases would increase wages. ${ }^{20}$

\subsection{DiD Framework}

Changes in public goods are likely endogenous to changes in the other variables of our model. We instrument changes in local public goods using the large variation in investment-targeted subsidies for which we give descriptive evidence in Sections 2 and 4. This identification strategy would be undermined if investment subsidies were correlated with changes in jurisdictions' characteristics. Such correlation would arise, for instance, if investment subsidy were systematically granted based on jurisdictions' population, housing or labor market outcomes. We follow Suárez Serrato and Zidar (2016) and Fuest et al. (2018) and use DiD models to look at cumulative changes in a range of economic outcomes around investment subsidy shocks while relying on the absence of pre-trends to make the case for the validity of our instrument.

In line with our theoretical framework, we look at both within-MF and between-MF variations in public goods and other endogenous variables. We instrument within-MF changes in public goods with within-MF yearly changes in jurisdictions' subsidy stock $\Delta \ln \bar{S}_{j}$. Similarly, we instrument between-MF changes in public goods with between-MF yearly changes in jurisdictions' subsidy stock $\Delta \ln \widehat{S}_{a}$.

We pool shocks happening in 2007, 2009 and 2010 and keep a [-6,4] distance windows around shock years. We limit ourselves to these shocks for two reasons. First, it allows us to have a balanced panel in terms of distance to the shocks and sufficient temporal depth - i.e., 6 years pre-shock — to inspect the pre-trends. This mechanically reduces the scope to shocks happening around the middle of our sample. Second, we do not include the 2008 subsidies since 2008 is a municipal election year

\footnotetext{
${ }^{20}$ Note that although it is not modeled here, a public good supply shock may come with a public labor demand shock that would increase wages.
} 
and we suspect (and empirically confirm) that subsidies that year were much more endogenous to jurisdiction conditions.

For both within-MF and between-MF regressions, we investigate responses from population, housing per capita, total housing, wage, rents and the public good index.

Within-MF regressions We first run the following regressions:

$$
\Delta \ln \bar{X}_{j, d,-6}=\beta_{d}^{W} \Delta \ln \bar{S}_{j, 0,-1}+\sum_{k=-5}^{-1} \beta_{k}^{W} \Delta \ln \bar{S}_{j, k, k-1}+\mathcal{I}_{j} \cdot \gamma_{d}^{W}+u_{j, d}^{W}
$$

where $X$ is any of the model's endogenous variables. We run a separate regression for each $d \in$ $\{-4,-2,0,2,4\}$ where $d=0$ is any shock year, i.e., 2007, 2009 or 2010. The main explanatory variable is the one-year relative subsidy change $\Delta \ln \bar{S}_{j, 0,-1}$. $\mathcal{I}_{j}$ is a vector of flexible dummies for 1999 baseline characteristics included to control for those changes in unobserved amenities, housing supply or productivity determinants that are correlated with these observed characteristics. ${ }^{21}$ To deal with potential serial correlation of the instrument we also control for $\Delta \ln \bar{S}_{j, k, k-1}$ with $k \leq-1$, that is, all subsidy shocks happening before the shock year. We cluster standard errors at the MF level to account for spatial correlation of the error term as well as auto-correlation since our regressions pool shocks happening in different years.

While the instrument is the one-year log difference in our subsidy stock measure, we look at long differences in post-shock outcomes to account for construction delays, frictions in year-on-year responses by individuals and more generally for dynamic adjustments to the shock. Regression coefficients we obtain are interpreted as cumulative elasticities.

Between-MF regressions Similarly, we run the following regressions:

$$
\Delta \ln \widehat{X}_{a, d,-6}=\beta_{d}^{B} \Delta \ln \widehat{S}_{a, 0,-1}+\sum_{k=-5}^{-1} \beta_{k}^{B} \Delta \ln \widehat{S}_{a, k, k-1}+\mathcal{I}_{a} \cdot \gamma_{d}^{B}+u_{a, d}^{B}
$$

The reduced-form elasticities $\beta_{d}$ 's represent how the subsidy shock in period 0 affects cumulative outcome growth between -6 and $d \in[-4,4]$. The absence of pre-trends, i.e., $\beta_{d}=0$ for $d<0$ for all outcomes of our within-MF and between-MF regressions would strongly support the validity of our instrument.

\subsection{Results}

We present graphical evidence on the evolution of our different outcomes around subsidy shocks based on our within-MF and between-MF DiD models. These graphs have no immediate "treatment effect"

\footnotetext{
${ }^{21}$ Controls include normalized baseline 1999 jurisdiction population and density.
} 
Figure 2: Within-MF Public Good Changes

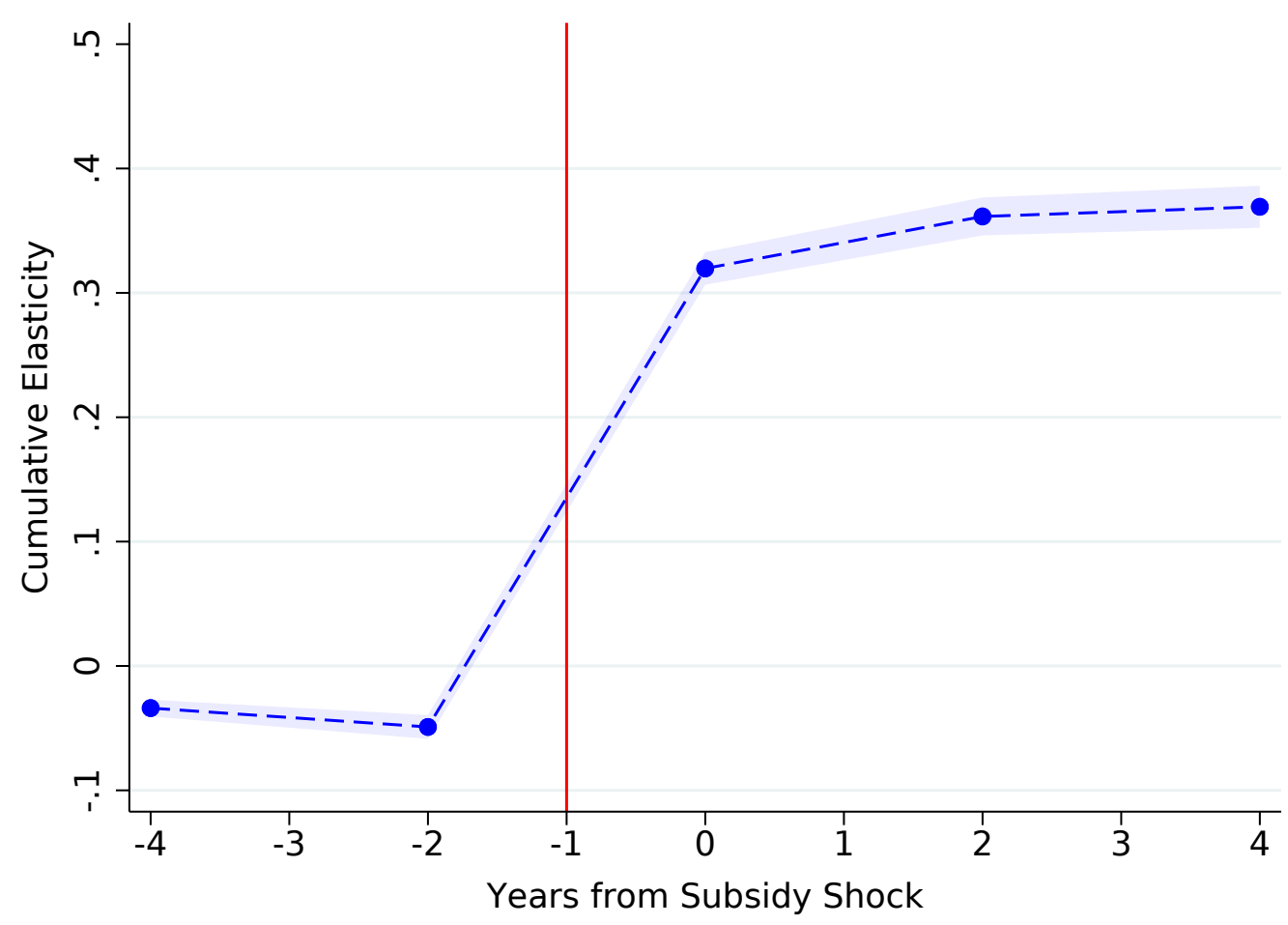

Note: This graph plots the coefficients $\beta_{d}^{W}$ of Section 5 regressions. It shows the effect of changes in a municipality's subsidy stock in year 0 on cumulative changes in local public goods starting 6 years prior to the shock year. All changes are relative to mean changes in the MF. Standard errors are clustered at the MF level. We report the $5 \%$ confidence bands.

interpretation but show how the gradient of different outcomes is affected by presumably exogenous changes in subsidy stocks. Their contribution, however, is twofold. They provide convincing evidence of absence of selection into treatment, as well as of significant behavioral responses to changes in local public goods. They also give support to our theoretical framework as we find stronger behavioral responses - in terms of migration, housing consumption and housing prices - in the between-MF setup than in the within-MF setup, which we interpret as evidence of stronger public good spillovers within municipal federations than between.

Within-MF behavioural responses Figure 2 shows the first stage result, i.e., how the cumulative growth of our public good index evolves around a sudden investment subsidy shock. For each municipality, changes are relative to the mean change in the MF it belongs to. The graph reports our DiD coefficients $\beta_{d}^{W}$, that is, the effect of the shock in $d=0$ on public good's cumulative growth starting in $d=-6$. Visual inspection of the pre-trends confirms the exclusion restriction. Before $d=0$, cumulative growth is flat and while it is significantly different from zero, it is not economically significant compared to the subsequent hike. After $d=0$, growth in $G$ becomes strongly positively correlated 
Figure 3: Within-MF Migration Response

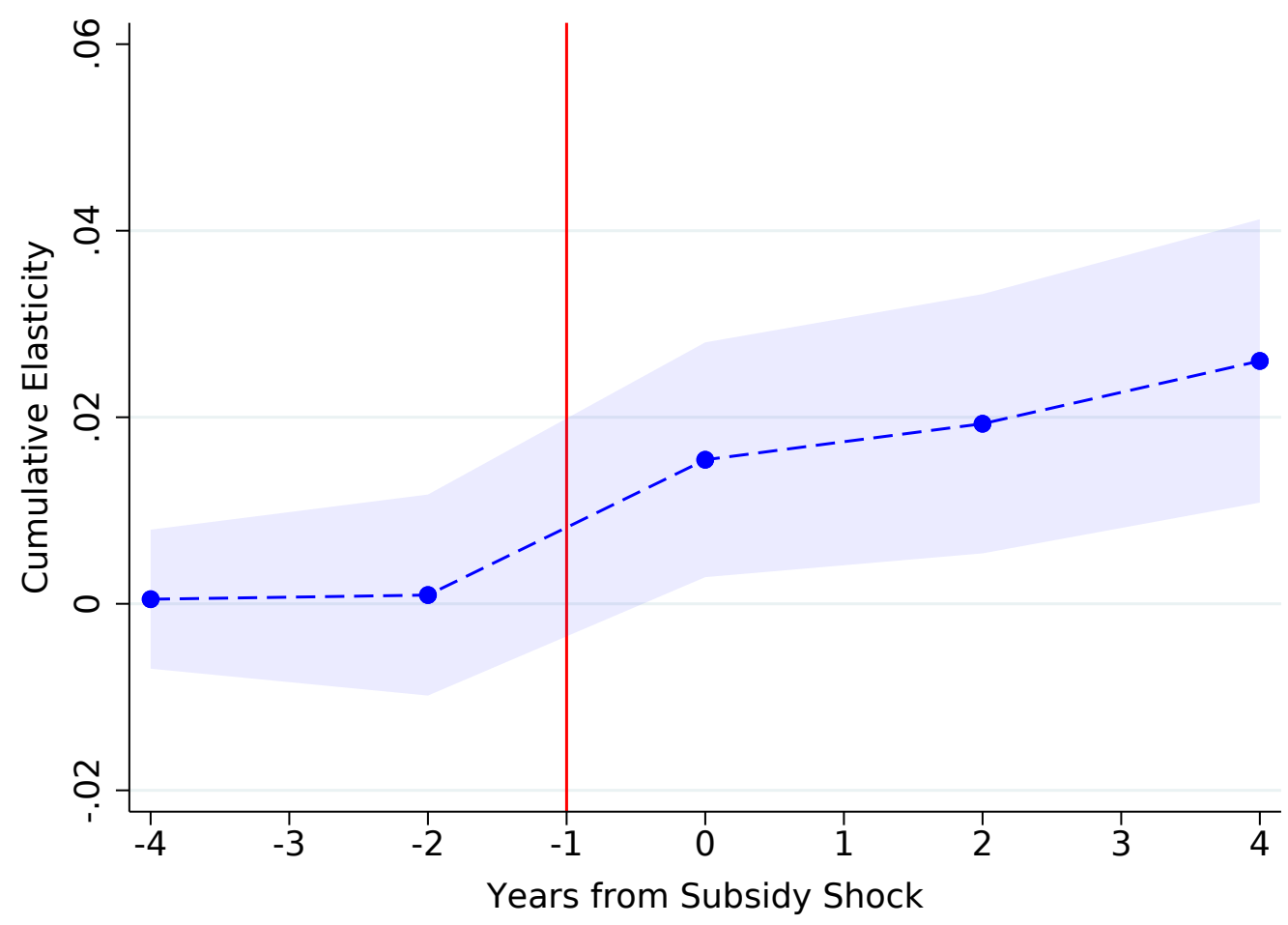

Note: This graph plots the coefficients $\beta_{d}^{W}$ of Section 5 regressions. It shows the effect of changes in a municipality's subsidy stock in year 0 on cumulative changes in the number of residents aged 20-65 starting 6 years prior to the shock year. All changes are relative to mean changes in the MF. Standard errors are clustered at the MF level. We report the 5\% confidence bands.

with the shock. A $1 \%$ change in the stock of investment-targeted subsidies leads to a $0.37 \%$ change in the public good index after five years. This effect is significant at the $1 \%$ level.

We now turn to the reduced-form effect of subsidy shocks on population. Figure 3 shows that treatment intensity is not correlated with municipality migration dynamics prior to $d=0$. However, municipalities which received a relatively higher subsidy shock subsequently experienced relatively higher in-migration. A 1\% relative increase in investment-targeted subsidies leads to a $0.03 \%$ relative increase in population after five years. This effect is significant at the $1 \%$ level. Put together with the first stage result, the reduced-form elasticity of population to public spending within a municipal federation is approximately 0.07. In other words, when municipality public spending grows 10 percentage points more than (geometric) mean public spending in the MF, municipality population grows 0.7 percentage points more than (geometric) mean population in the MF.

It is useful to give a concrete example illustrating the intensity of migration responses within municipal federations. Consider a municipal federation $a$ in its final 2016 form with mean number of member municipalities (27 municipality members) all having 2009 mean population (1,000 residents), mean investment level $(€ 9,400,000)$ and mean operating expenditure $(€ 1,540,000)$. Let us abstract from 
Figure 4: Within-MF Per Capita Housing and Wage Responses

A. Per Capita Housing Consumption (in $m^{2}$ )

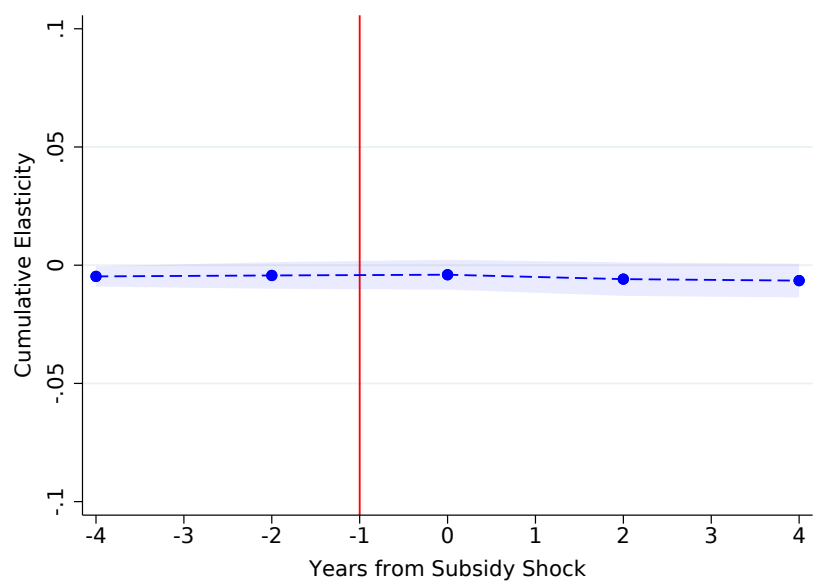

B. Wage

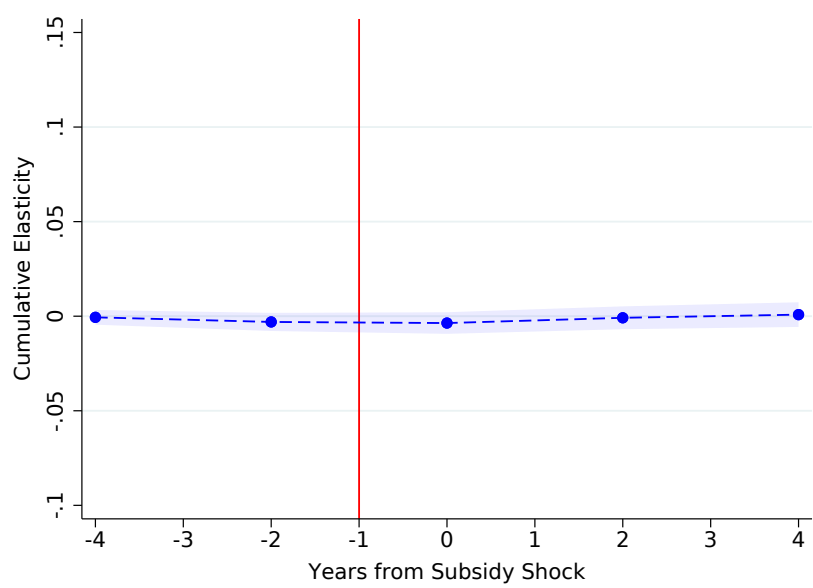

Note: These graphs plot the coefficients $\beta_{d}^{W}$ of Section 5 regressions. They show the effect of changes in a municipality's subsidy stock in year 0 on cumulative changes in per capita housing consumption and wages starting 6 years prior to the shock year. All changes are relative to mean changes in the MF. Standard errors are clustered at the MF level. We report the $5 \%$ confidence bands.

public good depreciation for simplicity. Assume that municipality $j$ of $a$ raises its investment level and yearly expenditure by $10 \%$, that is, invests $€ 940,000$ in durable infrastructure and commits to increase yearly operating expenditure by $€ 154,000$. All other member municipalities of $a$ decrease them by $10 \% / 26=0.38 \% \approx 0 \%$. Other municipalities in other MFs do not change their policies. Mean public good growth in $a$ is zero so that $a$ will experience no in-migration according to the model's equations. Municipality $j$ experiences a 10 percentage points growth in public services in excess of the zero mean MF growth, and will experience a 0.7 percentage points population growth. This represents in-migration of 7 additional residents coming from out-migration from other municipalities of $a$ for an initial investment of $€ 940,000$ and an increase of $€ 154,000$ in yearly expenditure.

Figure 4 shows how housing consumption per capita and wages evolve around the subsidy shock. Pre-trends are flat and not significantly different from zero in all Panels. They make an even stronger case for investment subsidies as exogenous shocks to local public good supply. None of the endogenous outcomes - public goods, population, housing consumption and wages - exhibit pre-shock dynamics correlated with shock intensity. Panel A offers evidence that subsidy shocks are not correlated with increasing or decreasing pressure in local housing markets. Furthermore, we find that per capita housing consumption, which subsumes housing prices and residence tax responses, is not affected by the subsidy shocks. Panel B gives comfort that public investment shocks are not driven by favourable or unfavourable trends in local productivity. Wages seem to be unaffected by subsidy shocks. The 
Table 2: Within-MF Sensitivity Analysis

\begin{tabular}{lccc}
\hline & $(1)$ & $(2)$ & $(3)$ \\
\hline & $\Delta \ln \bar{G}_{j}$ & $\Delta \ln \bar{G}_{j}$ & $\Delta \ln \bar{G}_{j}$ \\
\hline \multirow{2}{*}{$\Delta \ln \bar{S}_{j}$} & $0.363^{* * *}$ & $0.372^{* * *}$ & $0.369^{* * *}$ \\
& $(0.009)$ & $(0.009)$ & $(0.009)$ \\
\hline & $\Delta \ln \bar{N}_{j}$ & $\Delta \ln \bar{N}_{j}$ & $\Delta \ln \bar{N}_{j}$ \\
\hline \multirow{2}{*}{$\Delta \ln \bar{S}_{j}$} & $0.033^{* * *}$ & $0.032^{* * *}$ & $0.026^{* * *}$ \\
& $(0.007)$ & $(0.008)$ & $(0.008)$ \\
\hline & $\Delta \ln \bar{w}_{j}$ & $\Delta \ln \bar{w}_{j}$ & $\Delta \ln \bar{w}_{j}$ \\
\hline \multirow{2}{*}{$\Delta \ln \bar{S}_{j}$} & 0.002 & 0.003 & 0.001 \\
& $(0.003)$ & $(0.003)$ & $(0.003)$ \\
\hline \multirow{2}{*}{$\Delta \ln \bar{S}_{j}$} & $\Delta \ln \bar{h}_{j}$ & $\Delta \ln \bar{h}_{j}$ & $\Delta \ln \bar{h}_{j}$ \\
\hline & -0.006 & -0.006 & -0.007 \\
& $(0.003)$ & $(0.004)$ & $(0.004)$ \\
\hline \multirow{2}{*}{$\Delta \ln \bar{S}_{j}$} & $\Delta \ln \overline{\mathcal{T}}_{j}$ & $\Delta \ln \overline{\mathcal{T}}_{j}$ & $\Delta \ln \overline{\mathcal{T}}_{j}$ \\
\hline Lag $\Delta \ln \bar{S}_{j}$ & 0.002 & 0.002 & 0.001 \\
Baseline Controls & $(0.003)$ & $(0.003)$ & $(0.003)$ \\
\hline \hline Observations & & Yes & Yes \\
\hline
\end{tabular}

Note: This Table reports estimates for $\beta_{d=4}^{W}$, i.e., the effect of the shock happening in $d=0$ on cumulative outcome growth between $d=-6$ and $d=4$. Lag shocks include all past shocks up to $d=-1$. We flexibly control for baseline 1999 jurisdiction population and density. Standard errors are clustered at the MF level. ${ }^{*}$ significant at $10 \%$; ${ }^{* *}$ significant at $5 \%$; ${ }^{* * *}$ significant at $1 \%$.

distance window we consider might be too small to dissipate frictions in wage adjustments, however. ${ }^{22}$ Within-MF subsidy shocks hence seem to induce migration responses through changes in local public goods that do not capture significant changes in other endogenous municipality characteristics.

Table 2 reports alternative estimates without the different control variables. Our preferred estimates in column (3) correspond to the endpoints of Figures 2, 3 and 4. They are largely unaffected when we experiment with different specifications.

Between-MF behavioural responses We now investigate how MF-level changes in investment subsidies affect changes in MF-level economic outcomes. Figure 5 is the symmetric of Figure 2 and shows the first stage of our between-MF regressions. All changes are relative to mean regional changes, taking the geometric average across each municipal federation as the new level of observation. Public good cumulative growth is not significantly different from zero before the shock but it adjusts sharply after the shock. A $1 \%$ increase in the subsidy stock leads to a $0.42 \%$ increase in the public good index after five years. This effect is significant at the $1 \%$ level.

\footnotetext{
${ }^{22}$ We also abstract from the possibility that agents commute to neighbor municipalities to work, which would dilute effects on wages even further.
} 
Figure 5: Between-MF Public Good Changes

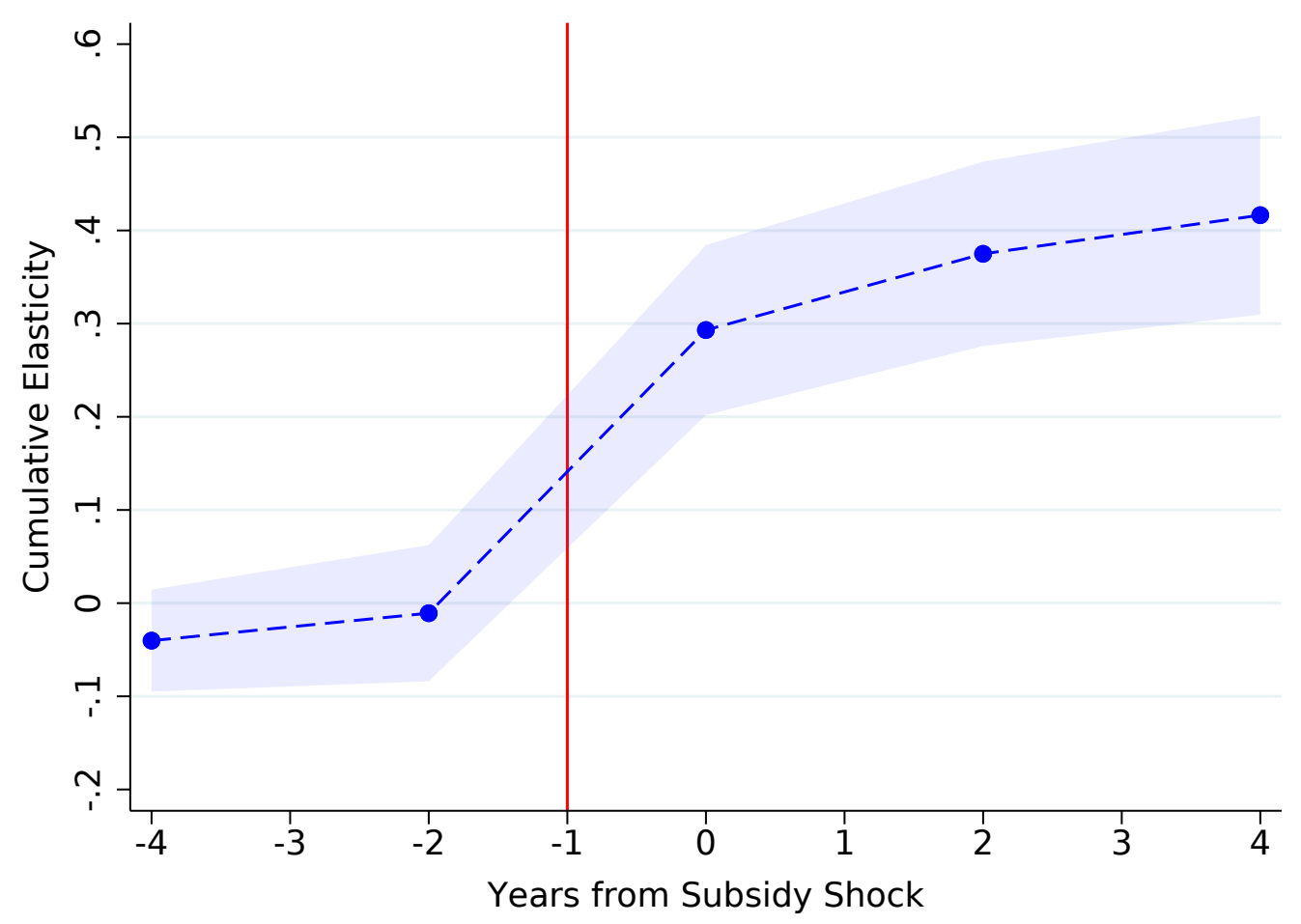

Note: This graph plots the coefficients $\beta_{d}^{B}$ of Section 5 regressions. It shows the effect of changes in a MF subsidy stock in year 0 on cumulative changes in local public goods starting 6 years prior to the shock year. All changes are relative to regional mean changes. Standard errors are clustered at the MF level. We report the 5\% confidence bands.

Figure 6 shows that MFs which received higher subsidy shocks also experienced relatively higher in-migration. A $1 \%$ relative shock leads to a $0.15 \%$ relative population increase after five years. This effect is significant at the $1 \%$ level. It represents a population elasticity with respect to public goods of approximately 0.37 , that is, a 10 percentage points increase in public spending in excess of regional public spending growth is met with a subsequent 3.7 percentage points excess population growth. This estimate is roughly five times higher than the point estimate of within-MF regressions. As outlined in our theoretical framework, a candidate mechanism to explain this discrepancy is the presence of cross-boundary spillovers. Indeed, in the polar case of full spillovers, changes in municipality local public goods relative to mean changes in the MF should not affect within-MF migration. However, changes between MFs would still affect migration decisions as we assume spillovers abruptly die out at the MF frontier.

Again it is useful to illustrate the intensity of migration responses between municipal federations. Consider the same setting as the above example, but this time assume that all municipalities of $a$ increase their investment and yearly expenditure by $10 \%$, that is, invest $€ 940,000$ in durable infrastructure and commit to increase yearly expenditure by $€ 154,000$. All other municipalities in all other 
Figure 6: Between-MF Migration Response

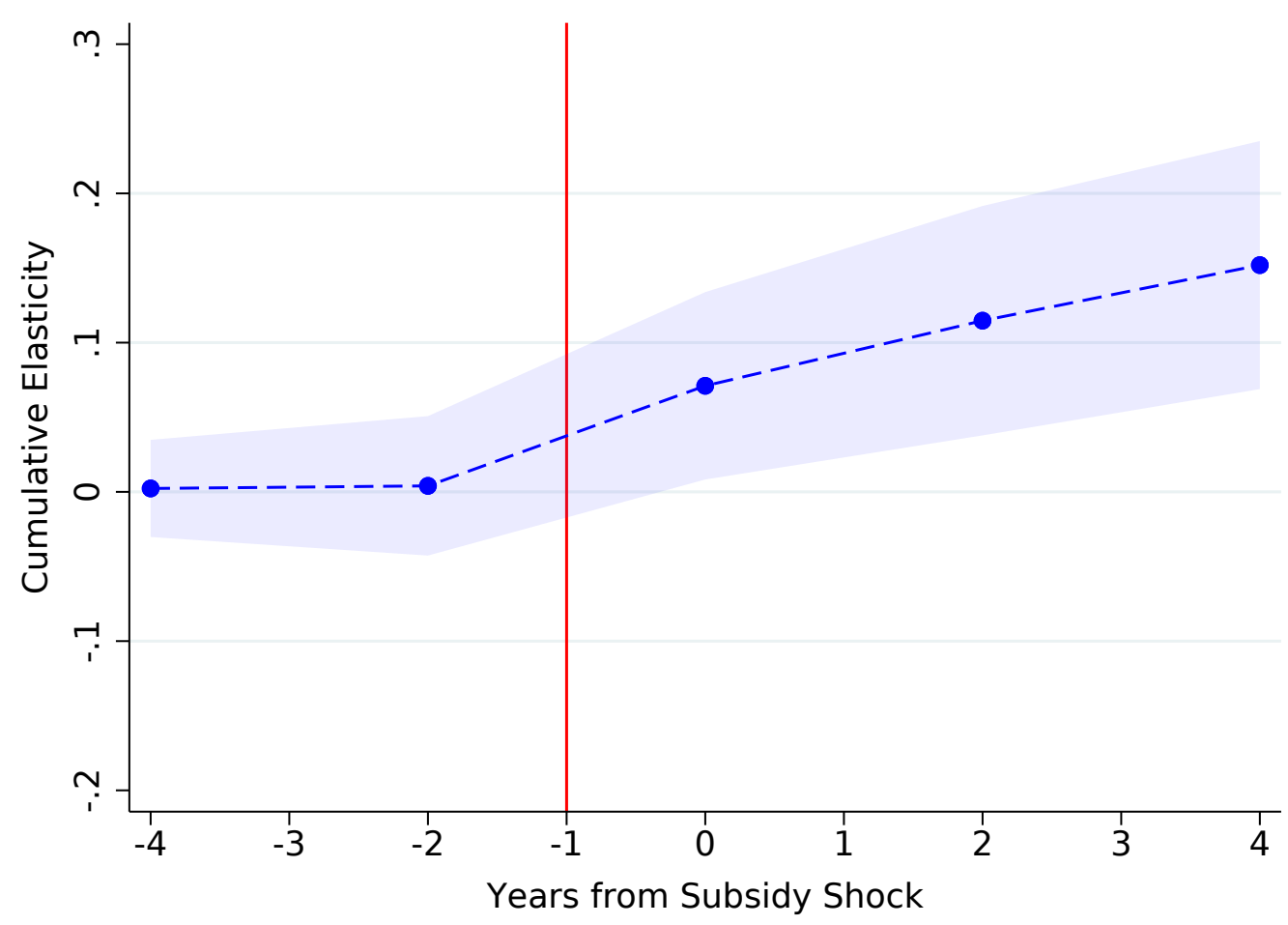

Note: This graph plots the coefficients $\beta_{d}^{B}$ of Section 5 regressions. It shows the effect of changes in a MF subsidy stock in year 0 on cumulative changes in the number of residents aged 20-65 starting 6 years prior to the shock year. All changes are relative to regional mean changes. Standard errors are clustered at the MF level. We report the 5\% confidence bands.

municipal federations decrease them by $10 \% / 1,266 \approx 0 \%$. Municipalities of $a$ experience a mean 10 percentage points growth in public services in excess of the zero mean growth, and will experience a mean 3.7 percentage points population growth. This represents in-migration of 37 additional residents coming to each municipality of $a$ from out-migration from other federations for an initial investment of $€ 940,000$ and an increase of $€ 154,000$ in yearly services.

Figure 7 suggests that this reduced-form elasticity differs from the micro (i.e., absent general equilibrium adjustments) migration responses to public good changes since it does not hold constant adjustments in other local amenities. Panel A shows again that subsidies were not awarded according to local trends in housing supply determinants. However, consumable housing per capita decreases in equilibrium in response to migration pressure and increasing marginal housing supply costs with a reduced-form elasticity of housing per capita with respect to public goods of -0.07 . This also contrasts with our within-MF analysis. Panel B shows again that local productivity dynamics are not correlated with subsidy shocks. However, we find this time that wages are affected by local public goods. This result suggests that local public investment is also shifting the labor demand curve upwards by boosting local productivity. This is further evidenced by Panel $C$ where we report the cumulative elasticities 
Figure 7: Between-MF Per Capita Housing and Wage Responses

A. Per Capita Housing Consumption (in $\mathrm{m}^{2}$ )

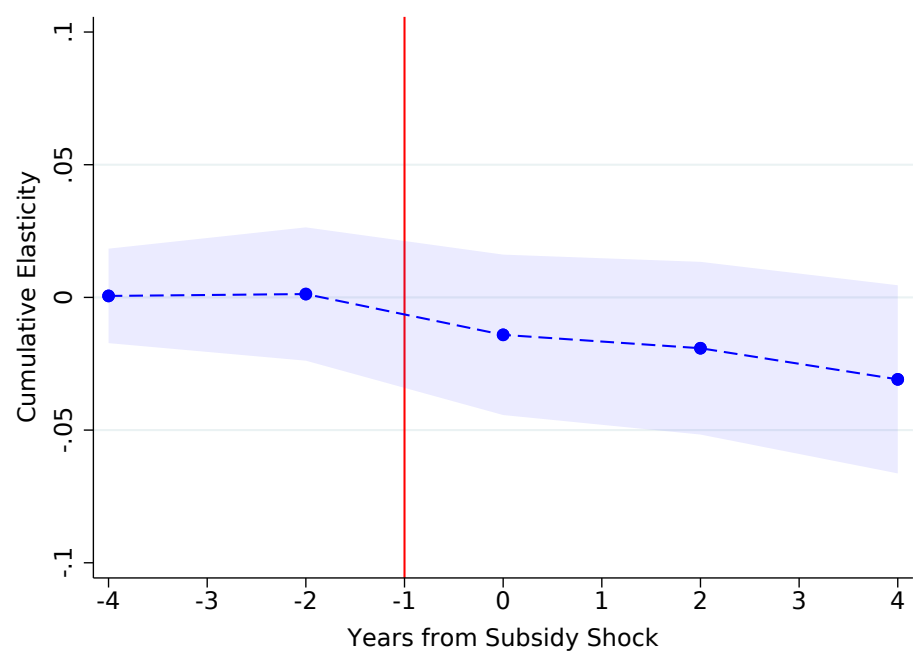

B. Wage

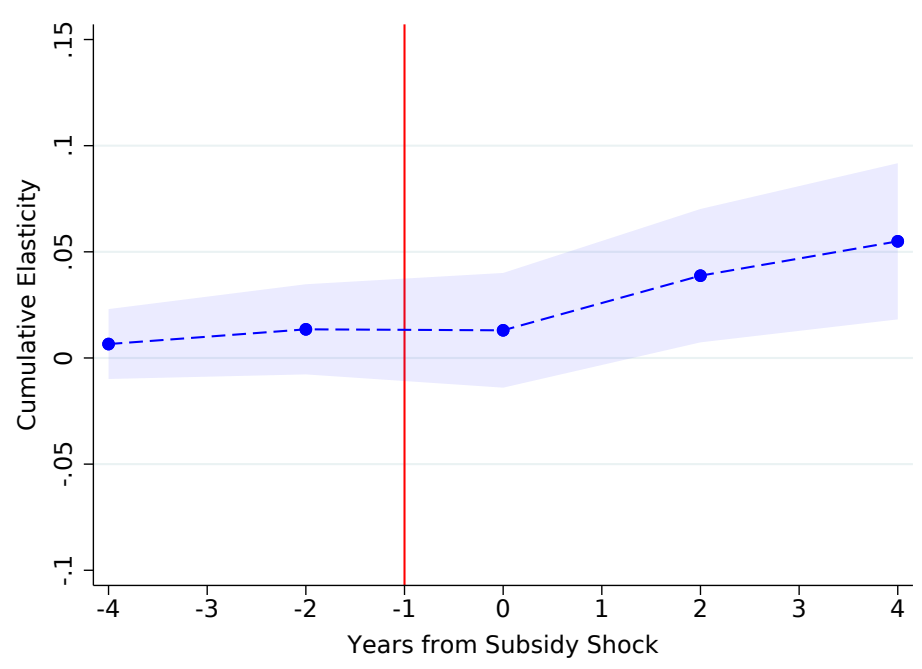

C. Recorded Businesses

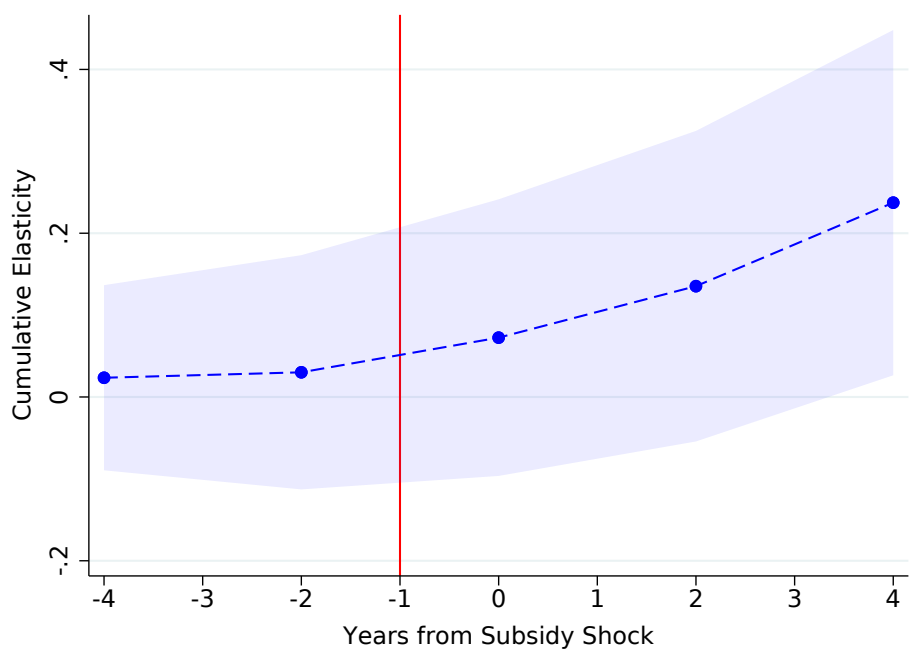

27

Note: These graphs plot the coefficients $\beta_{d}^{B}$ of Section 5 regressions. They show the effect of changes in a MF subsidy stock in year 0 on cumulative changes in per capita housing consumption, wages and number of businesses starting 6 years prior 
of the (geometric) average number of businesses with respect to the subsidy stock. Contrasting this result with the absence of within-MF wage variation hints at the presence of production spillovers or commuting within municipal federations. In any case, these effects are fully captured by the residential wage variation and do not bias our spillover estimates as long as we separately instrument wage changes in the GMM estimation.

Table 3: Between-MF Sensitivity Analysis

\begin{tabular}{lccc}
\hline & $(1)$ & $(2)$ & $(3)$ \\
\hline & $\Delta \ln \widehat{G}_{a}$ & $\Delta \ln \widehat{G}_{a}$ & $\Delta \ln \widehat{G}_{a}$ \\
\hline$\Delta \ln \widehat{S}_{a}$ & $0.258^{* * *}$ & $0.416^{* * *}$ & $0.466^{* * *}$ \\
& $(0.048)$ & $(0.055)$ & $(0.055)$ \\
\hline & $\Delta \ln \widehat{N}_{a}$ & $\Delta \ln \widehat{N}_{a}$ & $\Delta \ln \widehat{N}_{a}$ \\
\hline$\Delta \ln \widehat{S}_{a}$ & $0.094^{* *}$ & $0.152^{* * *}$ & $0.148^{* * *}$ \\
& $(0.038)$ & $(0.042)$ & $(0.045)$ \\
\hline & $\Delta \ln \widehat{w}_{a}$ & $\Delta \ln \widehat{w}_{a}$ & $\Delta \ln \widehat{w}_{a}$ \\
\hline$\Delta \ln \widehat{S}_{a}$ & 0.008 & $0.055^{* * *}$ & $0.050^{* *}$ \\
& $(0.017)$ & $(0.019)$ & $(0.020)$ \\
\hline \multirow{2}{*}{$\Delta \ln \widehat{S}_{a}$} & $\Delta \ln \widehat{h}_{a}$ & $\Delta \ln \widehat{h}_{a}$ & $\Delta \ln \widehat{h}_{a}$ \\
\hline & $-0.036^{* *}$ & -0.031 & -0.030 \\
& $(0.016)$ & $(0.018)$ & $(0.019)$ \\
\hline \multirow{2}{*}{$\Delta \ln \widehat{S}_{a}$} & $\Delta \ln \widehat{\mathcal{T}}_{a}$ & $\Delta \ln \widehat{\mathcal{T}}_{a}$ & $\Delta \ln \widehat{\mathcal{T}}_{a}$ \\
\hline Lag $\Delta \ln \widehat{S}_{a}$ & -0.017 & -0.019 & -0.023 \\
Baseline Controls & $(0.015)$ & $(0.016)$ & $(0.016)$ \\
Time FE X & Yes & Yes & Yes \\
\hline \hline Observations & Younty & Region & Yation \\
\hline
\end{tabular}

Note: This Table reports estimates for $\beta_{d=4}^{B}$, i.e., the effect of the shock happening in $d=0$ on cumulative outcome growth between $d=-6$ and $d=4$. Lag shocks include all past shocks up to $d=-1$. We flexibly control for baseline 1999 jurisdiction population and density. In the model, time fixed effects in the residuals are assumed to be uniform at the national level and we divide endogenous variables by their national geometric mean. Here, we allow for division by either national, regional of county geometric mean to account for year, year $\mathrm{X}$ region or year $\mathrm{X}$ county fixed effects in the structural residuals. Standard errors are clustered at the MF level. * significant at $10 \%$; ${ }^{* *}$ significant at $5 \%$; ${ }^{* * *}$ significant at $1 \%$.

Overall these results are consistent with weaker public good spillovers between municipal federations than within. Table 3 reports alternative estimates where we let the fixed effect in the residential amenities be at the national or county level, i.e., where we divide each MF-level observation by the national or county geometric mean instead of the regional mean. They are largely unaffected when we experiment with different specifications. While the migration response seems to be smaller when absorbing county fixed effects instead of national or regional ones, it mirrors a weaker first stage intensity so that the reduced-form elasticities are comparable. Our preferred estimates in column (2) correspond to the endpoints of Figures 5, 6 and 7. 
Figure 8: Within-MF Housing Supply and Housing Price Responses

A. Total Housing Consumption (in $m^{2}$ )

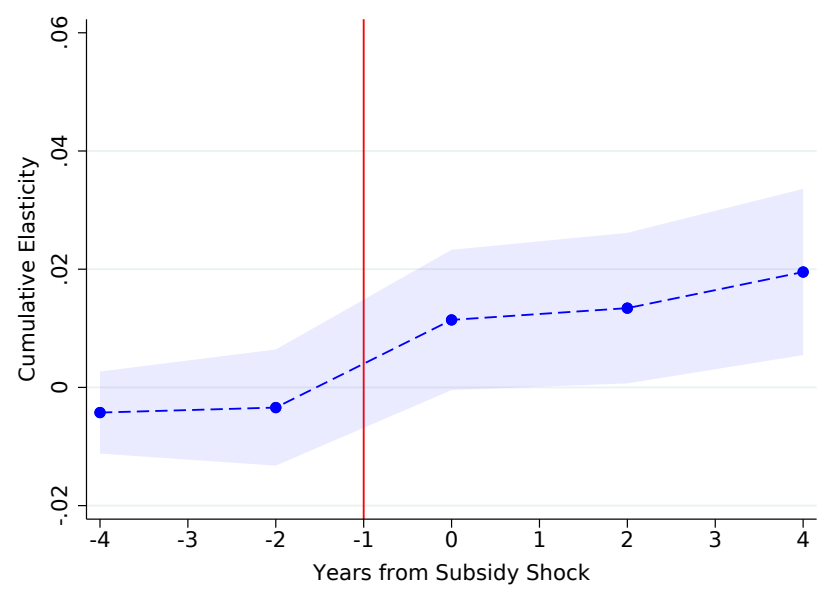

B. Housing Prices

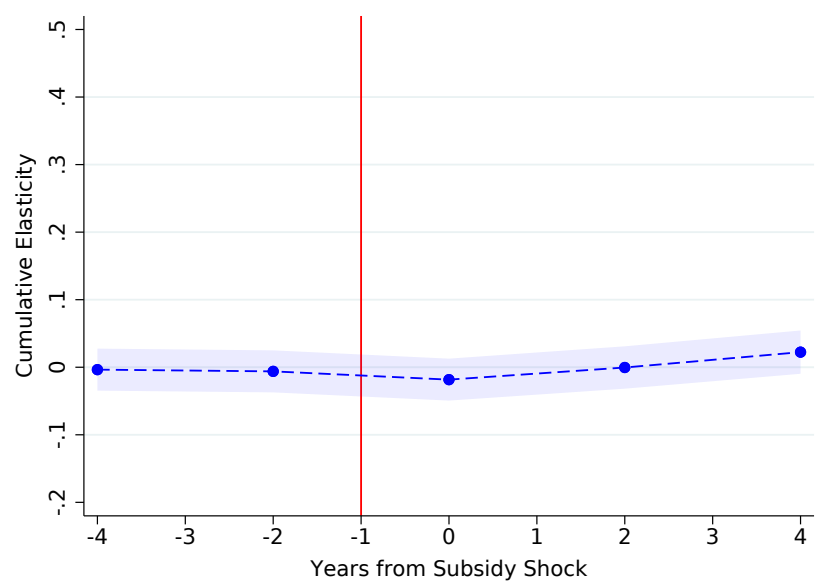

Note: These graphs plot the coefficients $\beta_{d}^{W}$ of Section 5 regressions. They show the effect of changes in a municipality's subsidy stock in year 0 on cumulative changes in total $m^{2}$ of housing consumed and housing prices starting 6 years prior to the shock year. All changes are relative to MF mean changes. Standard errors are clustered at the MF level. We report the $5 \%$ confidence bands.

Figure 9: Between-MF Housing Supply and Housing Price Responses

A. Total Housing Consumption (in $m^{2}$ )

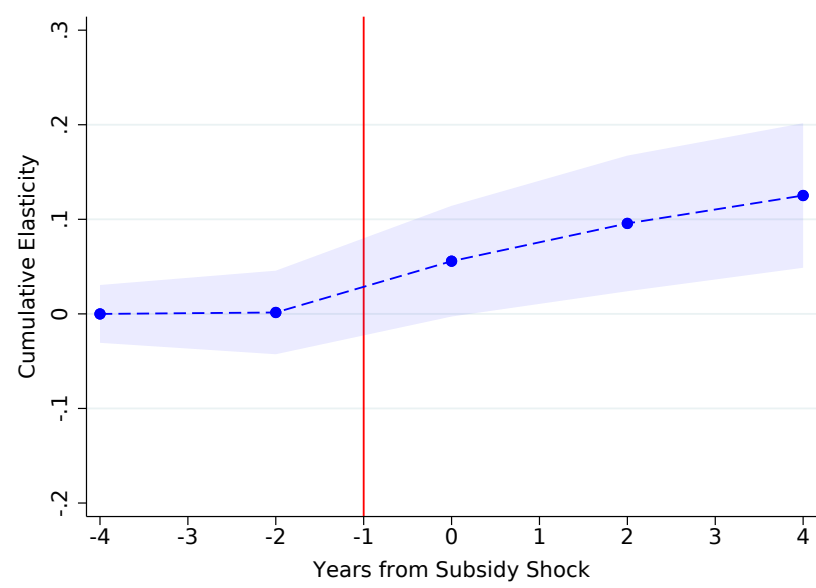

B. Housing Prices

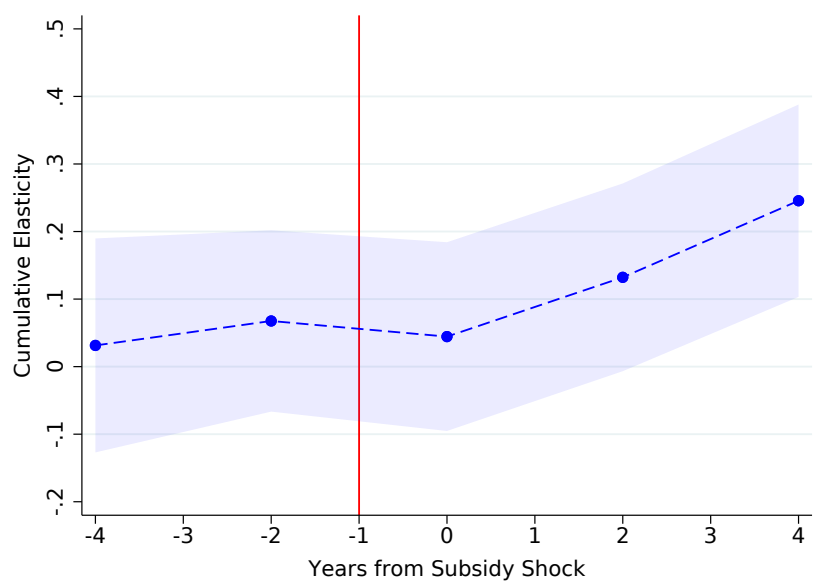

Note: These graphs plot the coefficients $\beta_{d}^{B}$ of Section 5 regressions. They show the effect of changes in a MF's subsidy stock in year 0 on cumulative changes in total $\mathrm{m}^{2}$ of housing consumed and housing prices starting 6 years prior to the shock year. All changes are relative to regional mean changes. Standard errors are clustered at the MF level. We report the $5 \%$ confidence bands. 
Housing supply and price capitalization Figures 8 and 9 report the results of our housing supply regressions and show how total $\mathrm{m}^{2}$ housing consumption and housing prices (in $€ / \mathrm{m}^{2}$ ) are affected by investment subsidies changes. Panel A of Figure 8 reports estimates for housing consumption changes conditional on municipal federation. A $1 \%$ increase in the subsidy stock relative to the MF average increase is met with a $0.02 \%$ relative increase in total consumed $m^{2}$ by $20-65$ residents after five years. This estimate is significant at the 1\% level. Panel B shows housing price capitalization results: a 1\% increase in the subsidy stock is met with an insignificant $0.02 \%$ increase in housing prices after five years.

Panel A of Figure 9 reports estimates for MF-level mean housing consumption changes conditional on region. A $1 \%$ increase in the subsidy stock relative to the regional average increase is met with a $0.13 \%$ relative increase in total consumed $m^{2}$ by 20-65 residents after five years. This estimate is significant at the 1\% level. Panel B again shows housing price capitalization estimate. This time, a $1 \%$ increase in the subsidy stock is met with an $0.24 \%$ increase in housing prices after five years significant a 1\%. Panel B hence comforts our interpretation of subsidy shocks as additional public good amenities

Table 4: Housing Supply Sensitivity Analysis

\begin{tabular}{lccc}
\hline & $(1)$ & $(2)$ & $(3)$ \\
\hline & $\Delta \ln \bar{H}_{j}$ & $\Delta \ln \bar{H}_{j}$ & $\Delta \ln \bar{H}_{j}$ \\
\hline \multirow{2}{*}{$\ln \bar{S}_{j}$} & $0.027^{* * *}$ & $0.026^{* * *}$ & $0.020^{* * *}$ \\
& $(0.007)$ & $(0.007)$ & $(0.007)$ \\
\hline & $\Delta \ln \bar{r}_{j}$ & $\Delta \ln \bar{r}_{j}$ & $\Delta \ln \bar{r}_{j}$ \\
\hline \multirow{2}{*}{$\Delta \ln \bar{S}_{j}$} & -0.026 & 0.015 & 0.016 \\
& $(0.025)$ & $(0.017)$ & $(0.017)$ \\
\hline Lag $\Delta \ln \bar{S}_{j}$ & & Yes & Yes \\
Baseline Controls & & & Yes \\
\hline \hline Observations & 99,593 & 99,593 & 99,593 \\
\hline \hline & $\Delta \ln \widehat{H}_{a}$ & $\Delta \ln \widehat{H}_{a}$ & $\Delta \ln \widehat{H}_{a}$ \\
\hline \multirow{2}{*}{$\Delta \ln \widehat{S}_{a}$} & $0.073^{* *}$ & $0.125^{* * *}$ & $0.132^{* * *}$ \\
& $(0.035)$ & $(0.039)$ & $(0.041)$ \\
\hline & $\Delta \ln \widehat{r}_{a}$ & $\Delta \ln \widehat{r}_{a}$ & $\Delta \ln \widehat{r}_{a}$ \\
\hline \multirow{2}{*}{$\Delta \ln \widehat{S}_{a}$} & $0.173^{* *}$ & $0.246^{* * *}$ & $0.239^{* * *}$ \\
& $(0.072)$ & $(0.073)$ & $(0.075)$ \\
\hline Lag $\Delta \ln \widehat{S}_{a}$ & Yes & Yes & Yes \\
Baseline Controls & Yes & Yes & Yes \\
Time FE X & County & $\operatorname{Region}$ & Nation \\
\hline \hline Observations & 5,428 & 5,428 & 5,428 \\
\hline
\end{tabular}

Note: This Table reports estimates for $\beta_{d=4}$, i.e., the effect of the shock happening in $d=0$ on cumulative outcome growth between $d=-6$ and $d=4$. Lag shocks include all past shocks up to $d=-1$. Controls include baseline 1999 jurisdiction population and density. Standard errors are clustered at the MF level. ${ }^{*}$ significant at $10 \%$; ${ }^{* *}$ significant at $5 \%$; ${ }^{* * *}$ significant at $1 \%$. 
that are positively valued by residents. Most importantly, significant housing price capitalization in the between-MF setup and not in the within-MF setup is consistent with the presence of strong within-MF spillovers. It is worth noting that housing price response is an order of magnitude larger than the per capita housing drop in the between-MF case. We argue that housing price responses are more representative of the longer-term adjustment in rental prices facing newcomers as short- to mediumterm per capita housing responses might be dampened by adjustment frictions. We use housing prices in our GMM to estimate the model's parameters.

Table 4 reports alternative estimates. Our preferred estimates in column (3) correspond to the endpoints of Figures 8 and 9. They are robust to different specifications.

Overall, these reduced-form results show that households value local public goods as evidenced by migration responses and capitalization in housing prices. They also highlight, in line with our theoretical framework, that the intensity of cross-boundary spillovers influences the magnitude of migration responses to local public good supply shocks.

\subsection{Robustness Checks}

We run a series of robustness checks investigating whether the observed migration patterns could be driven by mechanisms other than responses to changes in positively valued public goods.

A first concern is that changes in local public spending may not be valued by residents in themselves, but may be correlated with changes in housing supply determinants through $\mathcal{E}^{C}$. This would be the case if public good shocks were land improvements - new roads, pathways, etc. — of no intrinsic value but destined to welcome social housing units or private housing developments following changes in land use regulation. Residents would migrate towards municipalities experiencing positive housing supply shocks because of lower rents. More generally, if our subsidy shocks are correlated with shocks in the determinants of housing supply it may bias the interpretation of our estimates. As a test to alleviate this concern, we can look back at the rents results of Figure 9. A positive housing supply shock would have a negative effect on rents. Our results show the exact opposite suggesting that people indeed value local public goods beyond any correlated shift in the housing supply curve.

A second concern is that migration responses may entirely be driven by the inflow of public employees necessary to operate the new facilities or services financed by the subsidy shocks. Indeed, our model does not account for public employment. Public goods may be of little value in themselves, but workers may react to public labor demand shocks that would increase wages. It is not conceptually a problem as we could have modelled public good provision as taking public employment as input. The identification of the partial effect of public good supply would still be achieved in the GMM procedure provided that we separately instrument changes in local wages. We nevertheless assess the importance 
of this channel and show evidence that the public employment effect is marginal. We look at how the share of public employees in the population - crudely measured as public staff payroll divided by total local payroll - evolves around subsidy shocks. Combining this estimate with total population responses and the pre-shock shares of public employees, we conclude that observed behavioral responses coming from public employment only explain approximately 12\% of total 20-65 population response (see derivations in appendix $\mathrm{C}$ ).

\section{Structural Estimation}

This section carries out a GMM estimation of the model's parameters. We derive moments conditions using expressions for changes in residential amenities introduced in Section 3. Section 5 makes the case for subsidy shocks as a valid instrument in this framework. We provide additional evidence that residential amenity changes are likely mean-independent of subsidy shocks and ground our GMM estimation strategy on these more stringent conditions.

\subsection{Generalized Method of Moments}

As mentioned, we structurally estimate the models' parameters using a non-linear generalized method of moments. We ground our GMM estimation on moment conditions of the form

$$
\mathbb{E}\left[\Delta \ln \mathcal{E}^{A} \times Z\right]=0
$$

where $Z$ is an instrument uncorrelated with changes in unobserved residential amenities $\Delta \ln \mathcal{E}^{A}$. Section 5 gives support to the following two moment conditions:

$$
\begin{aligned}
& \mathbb{E}\left[\Delta \ln \overline{\mathcal{E}_{j}^{A}} \times \bar{Z}_{j}\right]=0 \\
& \mathbb{E}\left[\Delta \ln \widehat{\mathcal{E}_{a}^{A}} \times \widehat{Z}_{a}\right]=0
\end{aligned}
$$

where $\bar{Z}_{j}$ (resp. $\widehat{Z}_{a}$ ) is a variable of residuals obtained from regressing 2007, 2009 and 2010 subsidy shocks $\Delta \ln \bar{S}_{j}$ (resp. $\Delta \ln \widehat{S}_{a}$ ) on a vector of flexible dummies for 1999 baseline characteristics and lagged shocks as in regression (21) (resp. (22)).

Section 5 provides evidence of the absence of pre-trends in the model's endogenous variables, which implies that the empirical counterparts of conditions (24) hold in pre-shock periods. To see why, notice that equations (19) and (20) express changes in residential amenities as a sum of linear functions of observables. Sufficient conditions for (24) to hold for pre-shock periods are then $\mathbb{E}\left[\Delta \ln \bar{Y}_{j} \times \bar{Z}_{j}\right]=0$ and $\mathbb{E}\left[\Delta \ln \widehat{Y}_{a} \times \widehat{Z}_{a}\right]=0$ in pre-shock periods for all observables $Y$ of (19) and (20), which is precisely what Section 5 shows. As is typically done in DiD frameworks, we make the assumption that this absence of correlation between subsidy shocks and amenity changes also holds for post-shock periods, which allows us to estimate model parameters with GMM. 
In practice, the GMM procedure looks for the set of parameters that minimizes the empirical counterparts of our moment conditions, keeping the endogenous variables of the model at their observed values in the data. As such, the two moment conditions in (24) are not enough on their own to identify all the parameters of our model. Our GMM estimation relies on more moments conditions. In particular, we investigate whether more restrictive conditions of the form $\mathbb{E}\left[\Delta \ln \mathcal{E}^{A} \mid Z\right]=0$ hold. It would similarly be supported by evidence that the empirical counterpart of $\mathbb{E}[\Delta \ln Y \mid Z]=0$ holds for all outcomes $Y$ in pre-shock periods. The next section provides non-parametric evidence of such relationship between subsidy shock intensity and cumulative outcome changes.

\subsection{Non-Parametric Evidence}

We provide further evidence on the absence of pre-trends by looking at the non-parametric relationship between subsidy shocks on the one hand, and pre- or post-shock cumulative outcome changes on the other hand. We run kernel regressions where the dependent variable is alternatively $\Delta \ln \bar{G}_{j,-6,-2}$, $\Delta \ln \bar{G}_{j,-2,4}, \Delta \ln \bar{N}_{j,-6,-2}$ and $\Delta \ln \bar{N}_{j,-2,4}$. The explanatory variable is $\bar{Z}_{j,-1,0}$, i.e., the variable of residuals obtained from regressing 2007, 2009 and 2010 shocks $\Delta \ln \bar{S}_{j,-1,0}$ on the set of baseline controls and lagged shocks. ${ }^{23}$ Figure 10 presents the results.

The dependent variable in Panel A (resp. in Panel C) is $\Delta \ln \bar{G}_{j,-6,-2}$ (resp. $\Delta \ln \bar{N}_{j,-6,-2}$ ). Panels A and $C$ show again that the average relationship between subsidy shock and pre-shock outcome growth is close to zero. In addition, they offer evidence that municipality expected outcomes grow at the same rate as their MF geometric average conditional on shock intensity. In mathematical terms, this translates into $\mathbb{E}\left[\Delta \ln \bar{Y}_{j,-6,-2} \mid \bar{Z}_{j,-1,0}\right]=0$ for $Y \in\{G, N\}$. This mean-independence property will be central to our GMM analysis.

In Panels B and D, the dependent variables are $\Delta \ln \bar{G}_{j,-2,4}$ and $\Delta \ln \bar{N}_{j,-2,4}$. They offer reassurance that the average effects reported in the Figures of Section 5 are not driven by outliers. Public good and migration responses are visible across the full distribution of subsidy shocks.

Figure 11 provides similar evidence on how $\Delta \ln \widehat{G}_{a}$ and $\Delta \ln \widehat{N}_{a}$ change with $\widehat{Z}_{a,-1,0}$. Panels $\mathrm{A}$ and $\mathrm{C}$ show the absence of correlation between subsidy shock and pre-shock normalized outcome growth which similarly translates into $\mathbb{E}\left[\Delta \ln \widehat{Y}_{a,-6,-2} \mid \widehat{Z}_{a,-1,0}\right]=0$ for $Y \in\{G, N\}$. Panels B and D offer additional evidence that responses to subsidy shocks are observed all along the distribution of shock intensity. Finally, Figure 12 similarly shows that housing prices $\Delta \ln \widehat{r}_{a}$ evolve in a similar fashion in

\footnotetext{
${ }^{23}$ The fitted values and confidence bands are computed from running kernel regressions of the dependent variable on these initial residuals and on 1000 additional samples of residuals. We generate synthetic residuals using the wild cluster bootstrap procedure proposed in Cameron et al. (2008). We assume that errors are correlated within clusters which we take to be counties. Each cluster randomly draws a $+1 /-1$ coefficient with probability 0.5 and all residuals of a same cluster are multiplied by the same coefficient. These synthetic residuals are then added back to the original fitted values. We run the first-step regression again on this pseudo-sample and store the coefficient estimates. We do this 1000 times. We then generate 1000 pseudo-samples of residuals by fitting each saved model on the original data and saving the residuals. The graphs report the pivotal bootstrap confidence band and the bias-corrected fitted values.
} 
different cells of shock intensity in pre-shock periods and that the price response is coming from the full range of shock values.

These graphs also show that changes in jurisdictions' populations and rents are not necessarily proportional to changes in local public goods. Our model supports these non-proportional responses. For example, jurisdictions' proportional responses to changes in local public goods may differ because of heterogeneity in housing supply elasticity or production technology for the traded good. In addition, jurisdictions' budget constraints introduce non-linearity in endogenous variables' responses to subsidy shocks. Importantly, these non-proportional responses are precisely what enables us to add more

Figure 10: Kernel Regressions: Within-MF Changes

A. G 4-year Relative Growth Pre-Shock

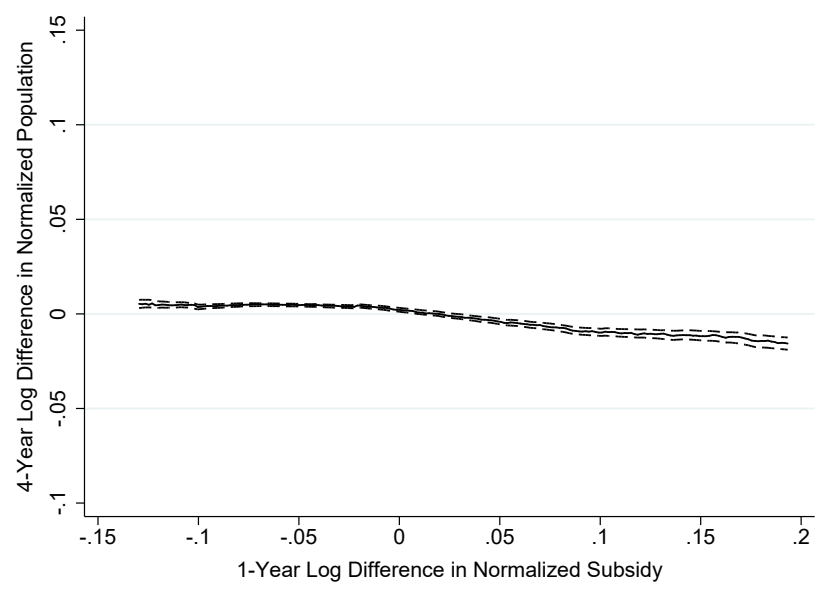

C. N 4-year Relative Growth Pre-Shock

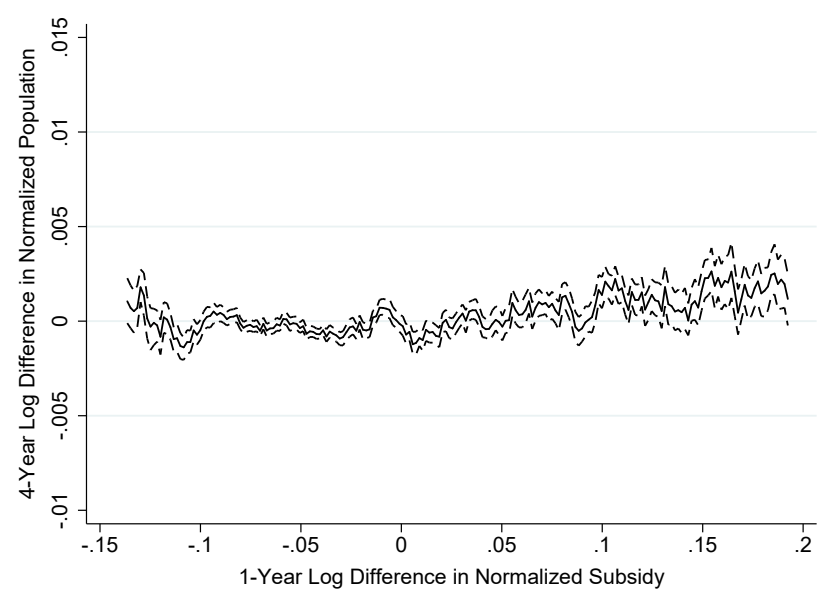

B. G 6-year Relative Growth Post-shock

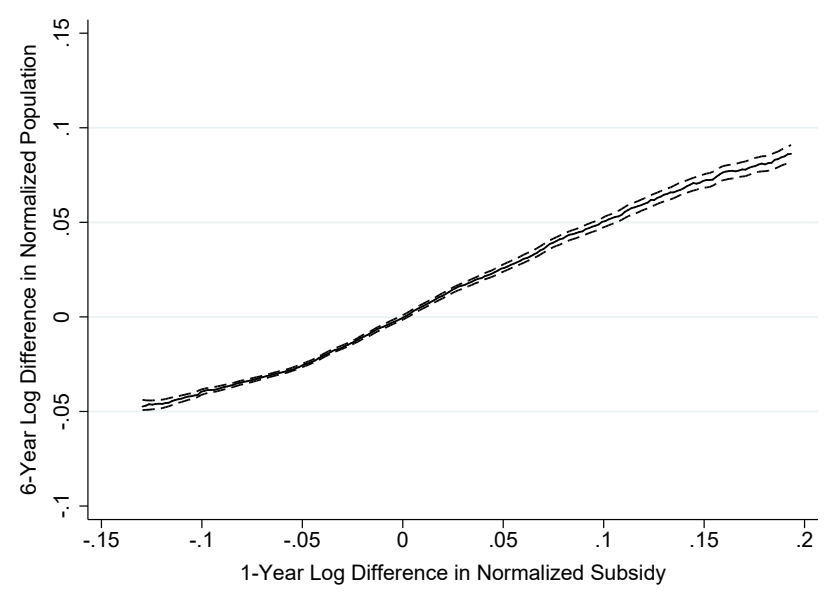

D. N 6-year Relative Growth Post-Shock

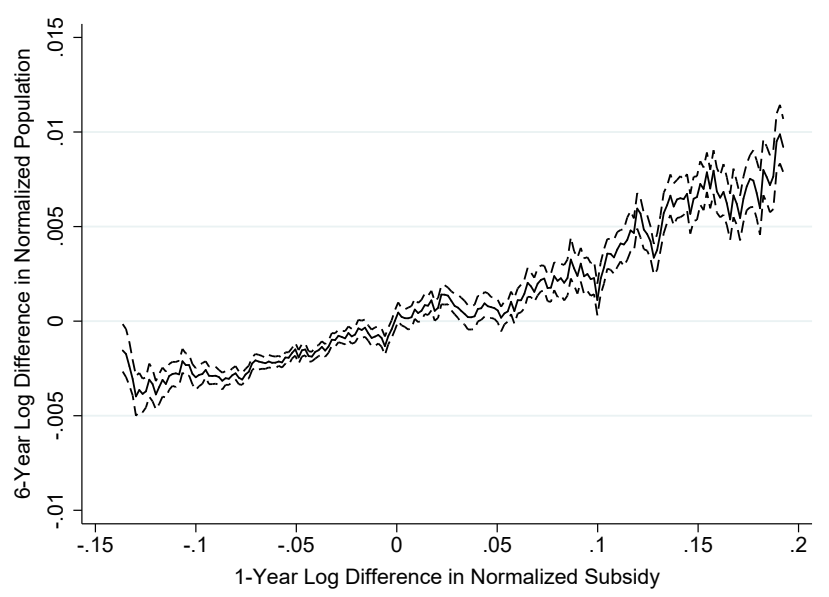

Note: This Figure shows the outcomes of non-parametric regressions where the explanatory variable is the within-MF relative subsidy shock. Dependent and explanatory variables are first residualized with respect to bins of fixed 1999 characteristics and lagged shocks. Bias-corrected fitted values and 1\% confidence band are computed based on 1,000 bootstrap replications. 
moment conditions to (24).

\subsection{Moment Conditions}

The non-parametric evidence in Section 6.2 showed that subsidy shocks likely satisfy mean-independence conditions of the form $\mathbb{E}[\Delta \ln \mathcal{E} \mid Z]=0$. These are more restrictive than the usual conditions of zero correlation between instrument and unobserved fundamentals $\mathbb{E}[\Delta \ln \mathcal{E} \times Z]=0$. Indeed, with meanindependence of the unobserved fundamentals with respect to our original instrument $Z$, any function

Figure 11: Kernel Regressions: Between-MF Changes (1/2)

A. G 4-year Relative Growth Pre-Shock

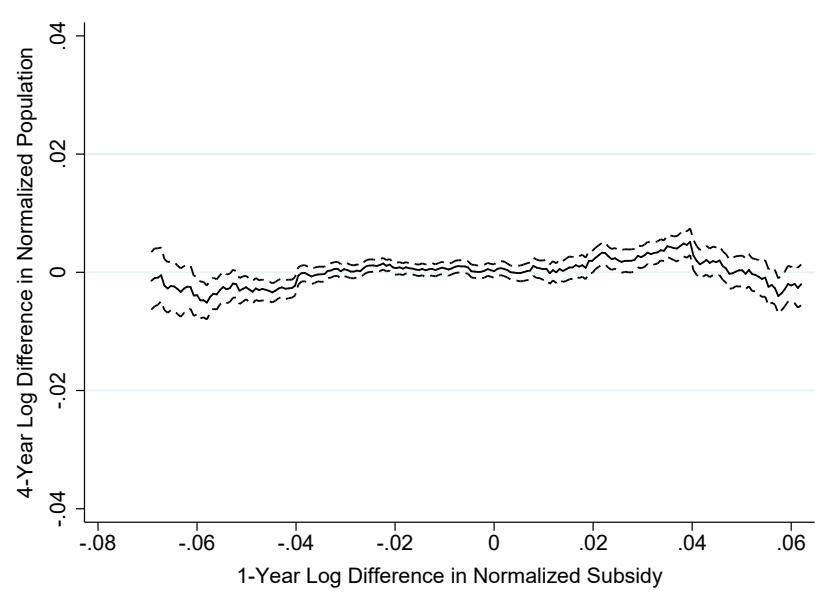

C. N 4-year Relative Growth Pre-Shock

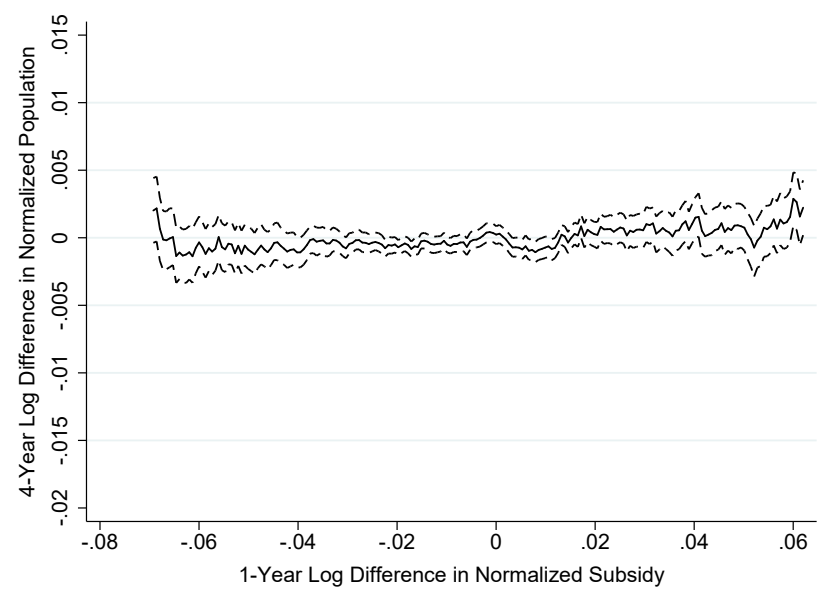

B. G 6-year Relative Growth Post-shock

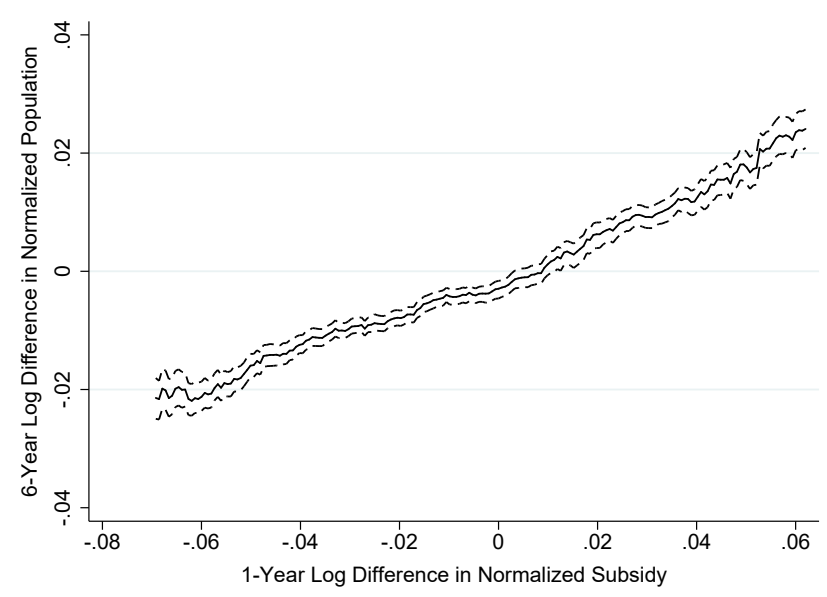

D. N 6-year Relative Growth Post-Shock

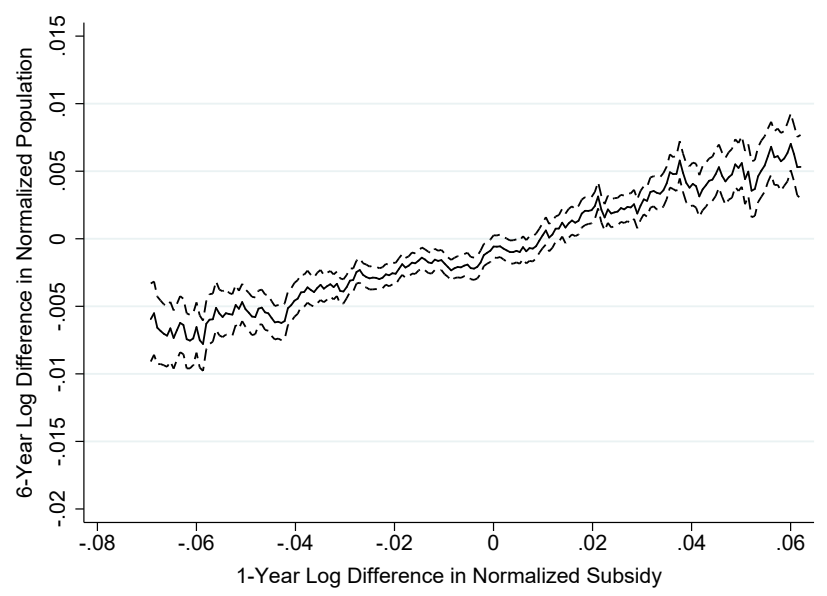

Note: This Figure shows the outcomes of non-parametric regressions where the explanatory variable is the between-MF relative subsidy shock. All changes are relative to mean regional changes. Dependent and explanatory variables are first residualized with respect to bins of fixed 1999 characteristics and lagged shocks. Bias-corrected fitted values and $1 \%$ confidence band are computed based on 1,000 bootstrap replications. 
Figure 12: Kernel Regressions: Between-MF Changes (2/2)

A. $r$ 4-year Relative Growth Pre-Shock

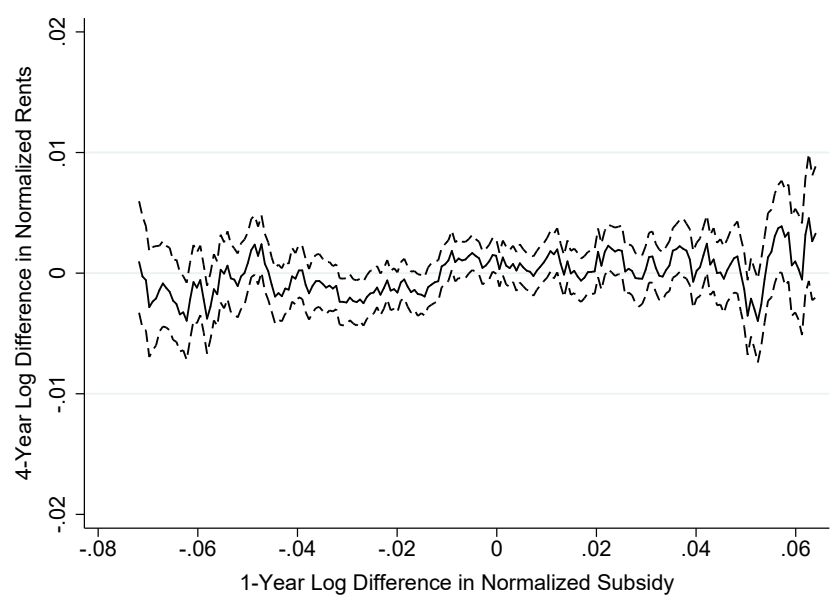

B. $r$ 6-year Relative Growth Post-Shock

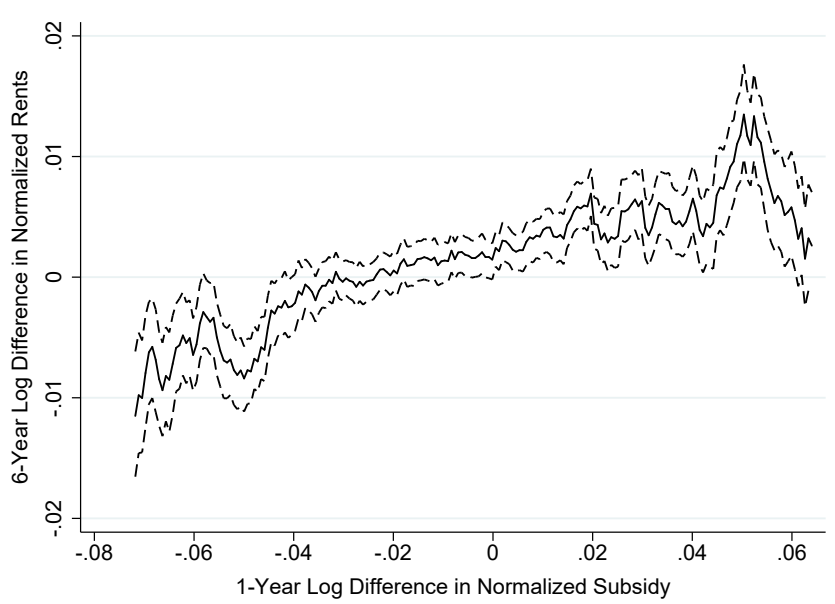

Note: This Figure shows the outcomes of non-parametric regressions where the explanatory variable is the between-MF relative subsidy shock. All changes are relative to mean regional changes. Dependent and explanatory variables are first residualized with respect to bins of fixed 1999 characteristics and lagged shocks. Bias-corrected fitted values and 1\% confidence band are computed based on 1,000 bootstrap replications.

of $Z$ may be used as an additional instrument (see Wooldridge 2010). We apply this property to a discrete number of indicator functions as in Ahlfeldt et al. (2015): we partition the empirical distribution of $\bar{Z}$ (or $\widehat{Z}$ ) into subintervals of equal range. We define $\mathbb{I}_{m}^{W}$ (resp. $\mathbb{I}_{m}^{B}$ ) the indicator function equal to one if $\bar{Z}$ (resp. $\widehat{Z}$ ) belongs to the subinterval $m$ of the partition of $\bar{Z}$ (resp. of $\widehat{Z}$ ).

We can now state all our moment conditions:

$$
\begin{aligned}
& \mathbb{E}\left[\Delta \ln \overline{\mathcal{E}_{j}^{A}} \times \mathbb{I}_{m}^{W}\right]=0 \quad \text { for all } m \in\{1, \ldots, M\} \\
& \mathbb{E}\left[\Delta \ln \overline{\mathcal{E}_{j}^{A}} \times \bar{Z}_{j}\right]=0
\end{aligned}
$$

using the within-MF expression (19) for residential amenities and

$$
\begin{aligned}
& \mathbb{E}\left[\Delta \ln \widehat{\mathcal{E}_{a}^{A}} \times \mathbb{I}_{m}^{B}\right]=0 \quad \text { for all } m \in\{1, \ldots, M\} \\
& \mathbb{E}\left[\Delta \ln \widehat{\mathcal{E}_{a}^{A}} \times \widehat{Z}_{a}\right]=0
\end{aligned}
$$

using the between-MF expression (20) for residential amenities. These additional moments conditions provided by indicator variables $\left\{\mathbb{I}_{m}^{W}, \mathbb{I}_{m}^{B}\right\}$ bring additional information for the GMM estimation only if they are not collinear. Section 6.2 provides such evidence and discusses the sources of non-linearity driving the endogenous variables' non-proportional responses.

All outcome changes plugged in (25) and (26) are the eight-year relative cumulative growths between year -4 and year 4 around the 2007, 2009 and 2010 subsidy shocks. The identifying assumption is that subsidy shocks and indicator variables $\left\{\mathbb{I}_{m}^{W}, \mathbb{I}_{m}^{B}\right\}$ are uncorrelated with jurisdiction or 
MF changes in unobserved residential amenities. As mentioned, DiD results of Section 5.2 and their decomposition in Section 6.2 suggest that this is indeed the case.

We simultaneously estimate the model's parameters using a two-step non-linear GMM procedure. The GMM estimation looks for the set of parameters that minimizes the empirical counterpart of moment conditions (25) and (26), keeping the endogenous variables of the model at their observed values in the data. As in Ahlfeldt et al. (2015), our moment conditions may not uniquely identify the model's parameters as the objective function might not be globally concave. In practice, the GMM objective function is well behaved and we find a global minimum.

To make sure that the arbitrarily chosen number of subintervals for the partition of $\bar{Z}$ and $\widehat{Z}$ does not affect our results, we try alternative specifications with different numbers of moments. However, the estimation requires a sufficient number of subintervals to pick up enough variation in jurisdiction responses to subsidy shocks. We report parameter estimates for specifications varying between 40 and 60 subintervals for each calibrated value of the housing consumption share.

\subsection{Estimation Results}

We report estimates of our structural parameters for different calibrated values of the housing consumption share $\alpha$. Calibrating the consumption share allows us to improve the robustness of our estimates given the multiplicative fashion in which it interacts with other parameters. Tables 5, 6, 7 and 8 report estimates of the model's parameters for $\alpha \in\{0.25,0.30,0.35,0.40\}$.

We estimate a taste parameter for public goods $\phi$ that varies between 0.11 and 0.25 according to the calibrated housing share. For a given value of $\alpha$, our estimate is robust for different number of moments. Given the Cobb-Douglas specification of preferences, the interpretation is that municipalities spend between $11 \%$ and $25 \%$ of their total resources on public goods. This estimate is typically increasing with the calibrated $\alpha$. Indeed, a higher taste for public goods is needed to compensate for given housing price changes when the taste for housing is higher, holding constant migration and public good changes. Parameter $\phi$ is the only parameter which is directly comparable with estimates from the existing literature, which we report in Table 9. Our estimates fall in the range of existing estimates.

Estimates for inverse household mobility $\sigma$ lie between 0.03 and 0.14 . These estimates are much lower than those found for instance in Serrato and Wingender (2011) or Diamond (2016). First, notice that the size of the considered French jurisdictions is much smaller than the geographic unit of these studies, typically the MSA. Mobility between locations is then expected to be different. Second, it is interesting to note that given modeling assumptions, parameter $\sigma$ is isomorphic to any combination of parameters $\sigma-\tilde{\kappa}$ where $\tilde{\kappa}$ would capture positive agglomeration externalities from increased density beyond those transiting through increased public goods and potential changes in wages. Hence, our 
estimated $\sigma$ is actually capturing mobility frictions net of all non-public and non-productive agglomeration effects, e.g., endogenous residential amenities such as in Diamond (2016).

We find substantial public good spillovers between jurisdictions of a same municipal federation. Estimates for $\delta$ all lie between 0 and 0.08 . While they are typically decreasing with the calibrated $\alpha$, the relationship is not trivial. When taste for housing increases, lower benefit spillovers are needed to explain observed housing price increases, i.e., location must matter for the enjoyment of public goods. However, higher congestion spillovers can also explain observed price changes, because additional congestion brought by new residents matters less than congestion caused by residents of neighbor jurisdictions. Our estimates show that the second effect prevails.

Recall that $\delta=0$ means full spillovers within a municipal federation, while $\delta=1$ means no spillovers. In line with our previous empirical evidence, our estimates suggest that spillovers are very strong in the examined French setting. A back-of-the-envelope calculation for the average municipal federation size -27 member municipalities - implies that local public spending in a municipality accounts for $4-11 \%$ of the bundle of local public goods enjoyed by its residents, and that local public spending in its average neighbor municipality — belonging to the same municipal federation - accounts for $3.2-3.5 \%$ of this bundle. ${ }^{24}$ These large estimates are unsurprising given the large of number of French jurisdictions and the fact that the only restriction to benefiting from local public goods in other municipalities is travel distance - there is almost no legal restriction such as zoning.

Our estimates for public good congestion are the least robust across specifications. However, we find significant estimates for $\kappa \phi$ that are typically below estimates for $\phi$. This points to local public services being not fully rival and subject to economies of scale, and to the existence of other sources of local inefficiencies due to fiscal agglomeration effects. Indeed, these estimates suggest that the cost of providing public services increases less than one for one with population, making denser jurisdictions more attractive from a public amenity perspective.

\section{Welfare Implications}

Our empirical analysis in Sections 5 and 6 documents strong public good spillovers across jurisdiction borders. Decentralized public good provision is likely to be sub-optimally low, i.e., there may be welfare gains from coordination. While current subsidies from counties, regions and the central government may carry some Pigovian flavour, it is unlikely that they fully tackle spillover inefficiency. In this section, we focus on a simplified version of our model and simulate the welfare impact of an administrative reform merging together all municipalities belonging to a same municipal federation. As mentioned in Section 2, these groupings were historically introduced precisely to deal with spillovers

\footnotetext{
${ }^{24}$ The weight put on own public goods is $\delta+\frac{1}{|a|}(1-\delta)$ where $|a|$ is the number of member jurisdictions in the MF. We take the mean number of member jurisdictions, i.e., 27 for this computation.
} 
Table 5: Structural Parameters for $\alpha=0.25$

\begin{tabular}{llllllllllll}
\hline \# Subintervals & 40 & 42 & 44 & 46 & 48 & 50 & 52 & 54 & 56 & 58 & 60 \\
\hline Spillovers $(\delta)$ & 0.077 & 0.051 & 0.071 & 0.024 & 0.029 & 0.034 & 0.063 & 0.056 & 0.031 & 0.063 & 0.042 \\
& 0.011 & 0.005 & 0.008 & 0.009 & 0.012 & 0.014 & 0.007 & 0.007 & 0.017 & 0.007 & 0.009 \\
PG Taste $(\phi)$ & 0.114 & 0.150 & 0.139 & 0.142 & 0.147 & 0.138 & 0.155 & 0.175 & 0.153 & 0.163 & 0.148 \\
& 0.007 & 0.005 & 0.005 & 0.004 & 0.009 & 0.012 & 0.006 & 0.007 & 0.009 & 0.012 & 0.007 \\
Mobility $(\sigma)$ & 0.113 & 0.103 & 0.142 & 0.069 & 0.065 & 0.079 & 0.125 & 0.124 & 0.080 & 0.118 & 0.099 \\
& 0.009 & 0.011 & 0.006 & 0.008 & 0.014 & 0.012 & 0.007 & 0.005 & 0.013 & 0.006 & 0.004 \\
PG Congestion $(\kappa \phi)$ & 0.056 & 0.113 & 0.065 & 0.134 & 0.166 & 0.118 & 0.094 & 0.131 & 0.174 & 0.144 & 0.061 \\
& 0.013 & 0.021 & 0.012 & 0.012 & 0.022 & 0.027 & 0.017 & 0.010 & 0.024 & 0.016 & 0.038 \\
\hline
\end{tabular}

Note: This Table reports our structural parameters estimation for $\alpha=0.25$. Standard errors are computed using a wild cluster bootstrap procedure based on 1,000 replications.

Table 6: Structural Parameters for $\alpha=0.30$

\begin{tabular}{llllllllllll}
\hline \# Subintervals & 40 & 42 & 44 & 46 & 48 & 50 & 52 & 54 & 56 & 58 & 60 \\
\hline Spillovers $(\delta)$ & 0.073 & 0.037 & 0.053 & 0.016 & 0.028 & 0.031 & 0.056 & 0.041 & 0.015 & 0.052 & 0.035 \\
& 0.009 & 0.005 & 0.004 & 0.007 & 0.013 & 0.009 & 0.008 & 0.004 & 0.014 & 0.008 & 0.006 \\
PG Taste $(\phi)$ & 0.132 & 0.178 & 0.162 & 0.165 & 0.165 & 0.154 & 0.173 & 0.194 & 0.183 & 0.190 & 0.168 \\
& 0.004 & 0.009 & 0.009 & 0.005 & 0.007 & 0.011 & 0.009 & 0.007 & 0.012 & 0.012 & 0.007 \\
Mobility $(\sigma)$ & 0.104 & 0.083 & 0.112 & 0.048 & 0.046 & 0.069 & 0.104 & 0.098 & 0.067 & 0.105 & 0.080 \\
& 0.007 & 0.013 & 0.006 & 0.008 & 0.013 & 0.009 & 0.009 & 0.007 & 0.016 & 0.010 & 0.006 \\
PG Congestion $(\kappa \phi)$ & 0.063 & 0.152 & 0.100 & 0.160 & 0.168 & 0.138 & 0.109 & 0.166 & 0.197 & 0.161 & 0.064 \\
& 0.010 & 0.023 & 0.013 & 0.018 & 0.023 & 0.025 & 0.013 & 0.011 & 0.021 & 0.024 & 0.024 \\
\hline
\end{tabular}

Note: This Table reports our structural parameters estimation for $\alpha=0.30$. Standard errors are computed using a wild cluster bootstrap procedure based on 1,000 replications.

Table 7: Structural Parameters for $\alpha=0.35$

\begin{tabular}{llllllllllll}
\hline \# Subintervals & 40 & 42 & 44 & 46 & 48 & 50 & 52 & 54 & 56 & 58 & 60 \\
\hline Spillovers $(\delta)$ & 0.047 & 0.027 & 0.043 & 0.000 & 0.000 & 0.025 & 0.037 & 0.040 & 0.012 & 0.025 & 0.015 \\
& 0.008 & 0.005 & 0.005 & 0.008 & 0.007 & 0.006 & 0.006 & 0.010 & 0.007 & 0.006 & 0.010 \\
PG Taste $(\phi)$ & 0.155 & 0.188 & 0.179 & 0.200 & 0.196 & 0.177 & 0.194 & 0.211 & 0.193 & 0.219 & 0.188 \\
& 0.009 & 0.010 & 0.005 & 0.007 & 0.005 & 0.015 & 0.006 & 0.013 & 0.010 & 0.008 & 0.007 \\
Mobility $(\sigma)$ & 0.092 & 0.071 & 0.088 & 0.031 & 0.014 & 0.063 & 0.092 & 0.086 & 0.045 & 0.071 & 0.065 \\
& 0.010 & 0.010 & 0.006 & 0.011 & 0.013 & 0.007 & 0.006 & 0.011 & 0.008 & 0.008 & 0.005 \\
PG Congestion $(\kappa \phi)$ & 0.092 & 0.156 & 0.123 & 0.200 & 0.225 & 0.176 & 0.154 & 0.179 & 0.229 & 0.187 & 0.142 \\
& 0.023 & 0.020 & 0.017 & 0.013 & 0.009 & 0.043 & 0.019 & 0.019 & 0.015 & 0.012 & 0.033 \\
\hline
\end{tabular}

Note: This Table reports our structural parameters estimation for $\alpha=0.35$. Standard errors are computed using a wild cluster bootstrap procedure based on 1,000 replications. 
Table 8: Structural Parameters for $\alpha=0.40$

\begin{tabular}{llllllllllll}
\hline \# Subintervals & 40 & 42 & 44 & 46 & 48 & 50 & 52 & 54 & 56 & 58 & 60 \\
\hline Spillovers $(\delta)$ & 0.035 & 0.019 & 0.037 & 0.007 & -0.001 & 0.014 & 0.025 & 0.027 & 0.017 & 0.023 & 0.017 \\
& 0.005 & 0.005 & 0.007 & 0.004 & 0.004 & 0.008 & 0.003 & 0.009 & 0.008 & 0.007 & 0.004 \\
PG Taste $(\phi)$ & 0.181 & 0.221 & 0.183 & 0.214 & 0.221 & 0.205 & 0.230 & 0.254 & 0.232 & 0.252 & 0.228 \\
& 0.009 & 0.008 & 0.009 & 0.006 & 0.006 & 0.021 & 0.009 & 0.010 & 0.012 & 0.012 & 0.007 \\
Mobility $(\sigma)$ & 0.070 & 0.050 & 0.074 & 0.033 & -0.003 & 0.046 & 0.078 & 0.063 & 0.042 & 0.063 & 0.051 \\
& 0.007 & 0.014 & 0.005 & 0.007 & 0.012 & 0.015 & 0.005 & 0.008 & 0.015 & 0.011 & 0.010 \\
PG Congestion $(\kappa \phi)$ & 0.126 & 0.217 & 0.140 & 0.230 & 0.252 & 0.156 & 0.193 & 0.226 & 0.262 & 0.171 & 0.163 \\
& 0.017 & 0.030 & 0.022 & 0.011 & 0.027 & 0.041 & 0.016 & 0.013 & 0.017 & 0.027 & 0.033 \\
\hline
\end{tabular}

Note: This Table reports our structural parameters estimation for $\alpha=0.40$. Standard errors are computed using a wild cluster bootstrap procedure based on 1,000 replications.

Table 9: Structural Parameters Calibration and Estimation

\begin{tabular}{|c|c|c|}
\hline Parameter & Values from literature & Treatment in this paper \\
\hline$\alpha$ & 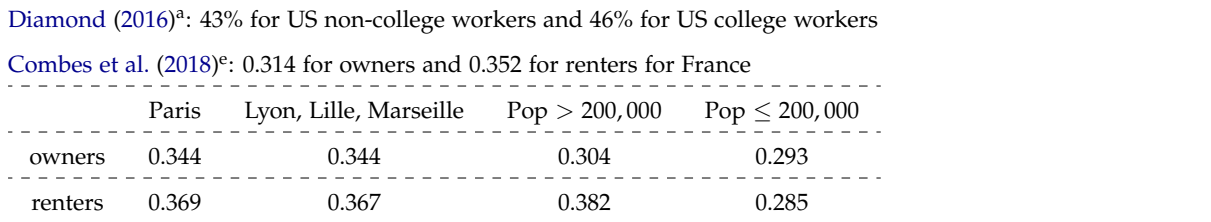 & Calibration from literature \\
\hline$\phi$ & $\begin{array}{l}\text { Serrato and Wingender }(2011)^{\mathrm{b}}:[0.391,0.502] \text { for US non-college workers and }[0.228,0.267] \text { for US college workers } \\
\text { Fajgelbaum et al. (2015): }[0.11,0.23] \text { for the US } \\
\text { Serrato and Wingender }(2016)^{\mathrm{d}}: 0.26 \text { for the US } \\
\text { Diamond }(2016)^{\mathrm{a}}: 0.03 \text { for US non-college workers and } 0.32 \text { for US college workers }\end{array}$ & Estimation with GMM \\
\hline 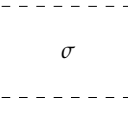 & $\begin{array}{l}\text { Serrato and Wingender }(2011)^{\mathrm{b}}:[0.342,0.399] \text { for US non-college workers and }[0.350,0.376] \text { for US college workers } \\
\text { Diamond }(2016)^{\mathrm{a}}: 0.24 \text { for US non-college workers and } 0.47 \text { for US college workers } \\
\text { Diamond }(2016)^{\mathrm{a}} \text { : } 0.21 \text { with a standard deviation of } 0.22 \text { for the US }\end{array}$ & Estimation with GMM \\
\hline$\eta$ & $\begin{array}{l}\text { Serrato and Wingender }(2011)^{\mathrm{b}}:[0.407,0.813] \text { for the US } \\
\text { Combes et al. }(2018)^{\mathrm{e}}: 0.208 \text { with most alternative estimates being between } 0.15 \text { and } 0.30 \text { for France }\end{array}$ & Calibration from literature \\
\hline 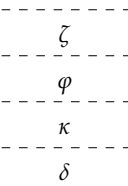 & 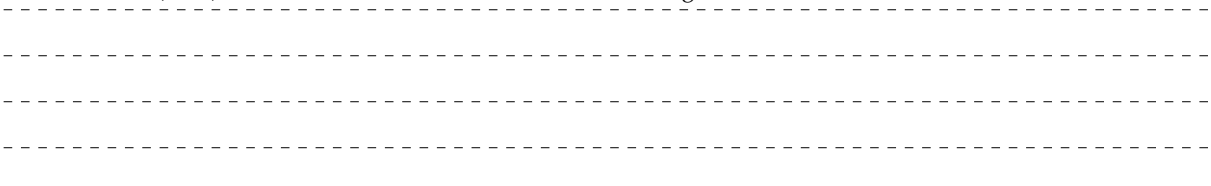 & $\begin{array}{l}\text { Calibration with our data } \\
\text { Calibration with our data } \\
\text { Estimation with GMM } \\
\text { Estimation with GMM }\end{array}$ \\
\hline
\end{tabular}

${ }^{a} \alpha$ : the author uses US CEX survey data. $\phi: 1.012 / 2.116=\frac{\phi}{1-\phi}$ for unskilled workers and $0.274 / 4.026=\frac{\phi}{1-\phi}$ for skilled workers. $\phi$ is a structural parameter capturing workers' valuation of all amenities compared to the traded good and is not public good specific. $\sigma$ : we take $\sigma$ to be the inverse of the structural wage coefficient in the author's favourite specification (3) which gives $1 / 0.4026=0.24$ for US non-college workers and $1 / 2.116=0.47$ for US college workers. $\eta$ : inverse housing supply elasticity of 0.21 with standard deviation of 0.22 .

${ }^{b} \eta=0.813$ when using housing prices and 0.407 when using rents. Author's preferred specification is non-linear.

${ }^{d}$ From Fajgelbaum et al. (2015) literature review on structural parameters. See their Table A.17.

${ }^{e}$ Use family expenditure survey for $\alpha$ values. 
and economies of scale. However, member jurisdictions still maintained a high degree of independence and it is a natural check to investigate whether this residual autonomy is at the root of significant deadweight loss.

We first back out the fundamentals of the model $\left\{\mathcal{E}_{j}^{A}, \mathcal{E}_{j}^{C}\right\}$ from the model's equilibrium variables that we observe as econometricians in the year 2014, and from parameters that we have estimated or calibrated from the literature. We then make several assumptions to ensure that the equilibrium in our simplified setup is tractable. Motivated by the suppression of the French local business tax in 2011, we first assume that local public revenues only come from the residence tax. In this simplified version, we also assume away public subsidies from the central government. We make a series of other assumptions: (i) residents are myopic and do not anticipate migration responses when they vote for public goods and taxes; (ii) the public good production function is the identity, i.e., $\Gamma(x)=x$; (iii) housing supply elasticities $\eta_{j}$ are constant across jurisdictions; (iv) local productivity $\theta_{j}^{Y}$ does not depend on local public goods and (v) the geographic fundamentals that we back out from the observed 2014 allocation still define the geographic landscape in this simplified model. This version of the model has a unique and tractable equilibrium given parameters $\{\alpha, \kappa, \sigma, \phi, \delta, \eta\}$ and geographic fundamentals $\left\{\mathcal{E}_{j}^{A}, \mathcal{E}_{j}^{C}\right\}$. While this setting does not allow us to evaluate a reform that applies to the observed situation, it helps illustrate the magnitude of potential welfare gains.

Prior to the reform, residents vote for public goods as in Section 3.6 absent subsidies and business taxation. They choose the housing tax rate $\tau_{j}^{h}$ and the level of public good $G_{j}$ that maximize $v_{j}$ under the budget constraint $r_{j} N_{j} h_{j} \tau_{j}^{h}=G_{j}$. Following the merger, residents vote for a new level of public spending pooling tax bases of all former member jurisdictions. To ensure that welfare remains comparable between pre- and post-reform situations, we assume that pre-reform jurisdictions are still relevant for labor and housing markets. The only change is the degree of cooperation in the provision of local public goods, now chosen at the MF level. Residents of $j \in a$ hence choose the housing tax $\tau_{a}^{h}$ and the level of public good $G_{a}$ that maximize $v_{j}$ under the budget constraint $G_{a}=\sum_{j^{\prime} \in a} r_{j^{\prime}} N_{j^{\prime}} h_{j^{\prime}} \tau_{a}^{h}{ }^{25}$ We assume that the total amount of local public goods is then allocated to all jurisdictions of $a$ in proportion to their pre-reform share of the total quantity of public good in the municipal federation. This allocation rule allows us to center our welfare analysis on efficiency gains and neutralizes the redistributive channel that would be present with, say, an egalitarian allocation. Our analysis would also work with alternative allocation rules but the welfare channels would be more intricate.

We note $X^{o}$ the variables observed in 2014, which we assume are the equilibrium variables of the full model. In the simplified model, we call $X^{n}$ the pre-reform equilibrium variables and $X^{m}$ the

\footnotetext{
${ }^{25}$ The result of this optimization problem is the same for any jurisdiction $j$ in $a$, see Appendix D.
} 
post-reform equilibrium variables. Local public good supply before the reform is characterized by

$$
\begin{aligned}
& 1+\tau_{j}^{n}=1+\frac{\phi\left(\delta+\frac{1-\delta}{\left|a_{j}\right|}\right)}{(1-\phi) \alpha} \\
& G_{j}^{n}\left[1+\tau_{j}^{n}\right]=\Phi \tau_{j}^{n} N_{j}^{n} w_{j}^{n} \alpha
\end{aligned}
$$

where $\Phi$ is a constant defined in Appendix D. After the merger, local public good supply is characterized by

$$
\begin{aligned}
& 1+\tau_{a}^{m}=1+\frac{\phi}{(1-\phi) \alpha} \\
& G_{j}^{m}=\Phi \frac{G_{j}^{n}}{\sum_{j^{\prime} \in a_{j}} G_{j^{\prime}}^{n}} \sum_{j^{\prime} \in a_{j}} \frac{\tau_{j^{\prime}}^{m}}{1+\tau_{j^{\prime}}^{m}} N_{j^{\prime}}^{m} w_{j^{\prime}} \alpha
\end{aligned}
$$

Using backed out fundamentals, we can express all endogenous variables in these two simulated cases as functions of 2014 observables. We assume that social welfare is ${ }^{26}$

$$
\mathrm{W}=\mathbb{E}\left[\max _{j} \ln U(\mathcal{C}, \mathcal{G}, i, j)\right]
$$

Because idiosyncratic preferences are distributed Extreme Value Type-I, the welfare change associated with the reform is

$$
\begin{aligned}
\Delta \mathrm{W} & =\mathrm{W}^{m}-\mathrm{W}^{n} \\
& =\sigma \ln \left(\frac{\sum_{j} \exp \left(v_{j}^{m} / \sigma\right)}{\sum_{j} \exp \left(v_{j}^{n} / \sigma\right)}\right)
\end{aligned}
$$

In the model, utility is homogeneous to euros so we interpret these welfare changes as percentage changes of a money metric. All detailed equations are given in Appendix D.

In our baseline scenario, we simulate the welfare change taking $\alpha=0.3$ for the housing consumption share and $\eta=0.2$ for the housing supply elasticity. These two values correspond to the literature's central estimates for France (see Table 9). For each parameter of $\{\kappa, \sigma, \phi, \delta\}$, we use its average estimation across specifications of Section 6. Because this simulation is based on estimated parameters and fundamentals, we report the associated Monte Carlo standard errors that we compute using the parameters' estimated variance-covariance structure.

In our central specification, we estimate that a reform that would fully merge jurisdictions at the existing federation level would increase welfare by around $60 \%$. This welfare gain is significant at the $1 \%$ level. Tables $10 \mathrm{a}$ and $10 \mathrm{~b}$ report welfare change estimates for alternative values of $\eta$ and $\alpha$. They are largely robust across values of $\eta$. However they vary between $40 \%$ and $137 \%$ when we plug alternative housing consumption shares holding $\eta=0.20$. This is expected as our GMM estimates for

\footnotetext{
${ }^{26}$ The choice of a utilitarian welfare criterion is akin to considering that policy choices are made behind the "veil of ignorance". Increasing welfare is then equivalent to increasing the expected utility of ex-ante homogeneous agents. Evaluating the proposed reform through the lens of an ex-post Pareto criterion will likely change its desirability.
} 
Table 10: Welfare Change Estimates

(a) Welfare Change for $\alpha=0.30$

\begin{tabular}{lll}
\hline$\eta$ & $\Delta \mathrm{W}$ mean & $\Delta \mathrm{W}$ sd \\
\hline 0.15 & $60 \%$ & $19 \%$ \\
0.20 & $63 \%$ & $21 \%$ \\
0.25 & $66 \%$ & $23 \%$ \\
\hline
\end{tabular}

(b) Welfare Change for $\eta=0.20$

\begin{tabular}{lll}
\hline$\alpha$ & $\Delta \mathrm{W}$ mean & $\Delta \mathrm{W}$ sd \\
\hline 0.25 & $40 \%$ & $13 \%$ \\
0.30 & $63 \%$ & $21 \%$ \\
0.35 & $100 \%$ & $29 \%$ \\
0.40 & $137 \%$ & $35 \%$ \\
\hline
\end{tabular}

Note: These Tables report the welfare impact of a merger of all French jurisdictions at the municipal federation level in our simplified model, holding constant either $\alpha$ or $\eta$. Standard errors are computed based on 1,000 Monte Carlo simulations.

spillovers and taste for public goods are increasing with the calibrated $\alpha$, which makes welfare gains from a coordination reform increasing with $\alpha$.

This strong result is unsurprising given our spillover estimates, but should be interpreted as an upper bound. First, it is obtained in a hypothetical context without public subsidies. Because current subsidies may already be partly correcting spillover externalities, we expect that the welfare gains from a reform that would apply to the observed situation holding constant observed subsidies would be smaller. We also emphasize that by abstracting from the political deadweight loss that may arise under a more centralized regime, our analysis only investigates one side of the centralization efficiency trade-off. More work is needed to finely assess how much the inability to tailor policies to local needs as well as other potential political frictions would decrease overall welfare gains.

\section{Conclusion}

This paper develops a simple yet flexible framework to test for potential welfare gains from centralization of public goods provision. We first build a spatial equilibrium model with endogenous public goods causing consumption spillovers across jurisdictions' borders. The binary structure for spillover spatial decay makes it easily amenable to empirical analysis. Our model shows how one can exploit differential behavioral responses to shocks in local public goods at different geographic levels to uncover the intensity of public good spillovers.

We then bring new insights on spillovers in the fragmented French institutional context by providing reduced-form evidence of migration and housing price responses to changes in local public goods. We estimate our model with GMM and find substantial public good spillovers, corroborating our reduced-form evidence. A jurisdiction's public goods account for approximately $4-11 \%$ of the local public good bundle enjoyed by its residents, and public spending in each neighbor municipality belonging to the same municipal federation - approximately accounts for an average $3.2-3.5 \%$ of this bundle.

In a final exercise, we simulate the effect of a reform redefining jurisdictions' administrative bound- 
aries in a simpler version of our model. Although we do not estimate the cost of centralization, our results suggest that increased coordination in the provision of public goods may substantially improve welfare. 


\section{References}

Ahlfeldt, G. M., S. J. Redding, D. M. Sturm, and N. Wolf (2015). The economics of density: Evidence from the berlin wall. Econometrica 83(6), 2127-2189.

Banzhaf, H. S. and R. P. Walsh (2008). Do people vote with their feet? an empirical test of tiebout. American Economic Review 98(3), 843-63.

Besley, T. and S. Coate (2003). Centralized versus decentralized provision of local public goods: a political economy approach. Journal of public economics 87(12), 2611-2637.

Bewley, T. F. (1981). A critique of tiebout's theory of local public expenditures. Econometrica: Journal of the Econometric Society, 713-740.

Bloch, F. and E. Ü. Zenginobuz (2006). Tiebout equilibria in local public good economies with spillovers. Journal of Public Economics 90(8-9), 1745-1763.

Bloch, F. and U. Zenginobuz (2007). The effect of spillovers on the provision of local public goods. Review of Economic Design 11(3), 199-216.

Bloch, F. and Ü. Zenginobuz (2015). Oates' decentralization theorem with imperfect household mobility. International Tax and Public Finance 22(3), 353-375.

Boadway, R. and J.-F. Tremblay (2012). Reassessment of the tiebout model. Journal of public

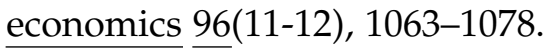

Brueckner, J. K. (2000). A tiebout/tax-competition model. Journal of Public Economics 77(2), 285-306.

Brueckner, J. K. (2003). Strategic interaction among governments: An overview of empirical studies. International regional science review 26(2), 175-188.

Busso, M., J. Gregory, and P. Kline (2013). Assessing the incidence and efficiency of a prominent place based policy. American Economic Review 103(2), 897-947.

Cameron, A. C., J. B. Gelbach, and D. L. Miller (2008). Bootstrap-based improvements for inference with clustered errors. The Review of Economics and Statistics 90(3), 414-427.

Carbonnier, C. et al. (2008). Fiscal competition between decentralized jurisdictions, theoretical and empirical evidence. Technical report, THEMA (THéorie Economique, Modélisation et Applications), Université de....

Case, A. C., H. S. Rosen, and J. R. Hines Jr (1993). Budget spillovers and fiscal policy interdependence: Evidence from the states. Journal of public economics 52(3), 285-307. 
Cheikbossian, G. (2008). Rent-seeking, spillovers and the benefits of decentralization. Journal of Urban Economics $63(1), 217-228$.

Combes, P.-P., G. Duranton, L. Gobillon, et al. (2018). The costs of agglomeration: House and land prices in french cities. CEPR Discussion Paper No. DP9240 (updated).

Conley, J. and M. Dix (1999). Optimal and equilibrium membership in clubs in the presence of spillovers. Journal of Urban Economics $\underline{46}(2), 215-229$.

Diamond, R. (2016). The determinants and welfare implications of us workers' diverging location choices by skill: 1980-2000. American Economic Review 106(3), 479-524.

Epple, D. and H. Sieg (1999). Estimating equilibrium models of local jurisdictions. Journal of political economy 107(4), 645-681.

Fajgelbaum, P. and C. Gaubert (2018). Optimal spatial policies, geography and sorting. Technical report, National Bureau of Economic Research.

Fajgelbaum, P. D., E. Morales, J. C. S. Serrato, and O. M. Zidar (2015). State taxes and spatial misallocation. Technical report, National Bureau of Economic Research.

Fuest, C., A. Peichl, and S. Siegloch (2018, February). Do higher corporate taxes reduce wages? micro evidence from germany. American Economic Review 108(2), 393-418.

Gordon, R. H. (1983). An optimal taxation approach to fiscal federalism. The Quarterly Journal of Economics 98(4), 567-586.

Konishi, H. (1996). Voting with ballots and feet: Existence of equilibrium in a local public good economy. Journal of Economic Theory 68(2), 480-509.

Leprince, M. and A. Guengant (2002). Interactions fiscales verticales et réaction des communes à la coopération intercommunale. Revue économique 53(3), 525-535.

Lockwood, B. (2002). Distributive politics and the costs of centralization. The Review of Economic Studies $\underline{69(2), 313-337 .}$

Lutz, B. (2015). Quasi-experimental evidence on the connection between property taxes and residential capital investment. American Economic Journal: Economic Policy 7(1), 300-330.

McFadden, D. (1973). Conditional logit analysis of qualitative choice behavior. Frontiers in Econometrics. 
Oates, W. E. (1969). The effects of property taxes and local public spending on property values: An empirical study of tax capitalization and the tiebout hypothesis. Journal of political economy $77(6)$, 957-971.

Oates, W. E. (1972). Fiscal Federalism. Number 14708 in Books. Edward Elgar Publishing.

Oates, W. E. (2005). Toward a second-generation theory of fiscal federalism. International tax and public finance $12(4), 349-373$.

Roback, J. (1982). Wages, rents, and the quality of life. Journal of political Economy 90(6), 1257-1278.

Rosen, S. (1974). Hedonic prices and implicit markets: product differentiation in pure competition. Journal of political economy $82(1), 34-55$.

Serrato, J. C. S. and P. Wingender (2011). Estimating the incidence of government spending. Technical report, Mimeo, 2011. 1.

Serrato, J. C. S. and P. Wingender (2016). Estimating local fiscal multipliers. Technical report, National Bureau of Economic Research.

Solé-Ollé, A. (2006). Expenditure spillovers and fiscal interactions: Empirical evidence from local governments in spain. Journal of Urban Economics 59(1), 32-53.

Suárez Serrato, J. C. and O. Zidar (2016). Who benefits from state corporate tax cuts? a local labor markets approach with heterogeneous firms. American Economic Review 106(9), 2582-2624.

Tiebout, C. M. (1956). A pure theory of local expenditures. Journal of political economy 64(5), 416-424.

Wellisch, D. (1994). Interregional spillovers in the presence of perfect and imperfect household mobility. Journal of Public Economics 55(2), 167-184.

Wooldridge, J. M. (2010). Econometric analysis of cross section and panel data. MIT press. 


\section{Appendices}

\section{A Jurisdiction Utility}

The full expression for utility in jurisdiction $j$ is

$$
\begin{aligned}
v_{j} & =(1-\phi)(1-\alpha) \ln (1-\alpha)+(1-\phi)(1-\alpha) \ln \left(1-\tau^{w}\right)+(1-\phi)(1-\alpha) \ln \left(w_{j}\right) \\
& +(1-\phi) \alpha \ln \left(h_{j}\right)+\phi \delta \ln \left(G_{j}\right)+\phi(1-\delta) \frac{1}{\left|a_{j}\right|} \sum_{j^{\prime} \in a_{j}} \ln \left(G_{j^{\prime}}\right)-\phi \delta^{2} \kappa \ln \left(N_{j}\right) \\
& -2 \phi \delta(1-\delta) \kappa \frac{1}{\left|a_{j}\right|} \sum_{j^{\prime} \in a_{j}} \ln \left(N_{j^{\prime}}\right)-\phi(1-\delta)^{2} \kappa \frac{1}{\left|a_{j}\right|} \sum_{j^{\prime} \in a_{j}} \ln \left(N_{j^{\prime}}\right)+\ln \left(\mathcal{E}_{j}^{A}\right)
\end{aligned}
$$

\section{B Local Public Goods}

Our baseline model features a simple representation of local public spending. In Appendix B.1, we develop a more realistic version that we use in our empirical applications in Sections 5 and 6. Appendix B.2 gives conditions under which our framework is time-consistent. We take our extended version to the data in Appendix B.3.

\section{B.1 Extension of the Model}

We assume that public good quantity $G$ produced by a jurisdiction has a Cobb-Douglas form:

$$
\ln G=\varphi \ln G^{s}+(1-\varphi) \ln G^{f}
$$

where $G^{s}$ is the stock of public capital and $G^{f}$ the flow of services annually consumed. Both are directly measured as spending in terms of the numéraire good and we abstract from differences in public good provision efficiency. Residents vote on the residence $\operatorname{tax} \tau^{h}$, the business $\operatorname{tax} \tau^{k}$ and the amount of $G^{s}$ and $G^{f}$. Because we assumed homogeneous preferences, the voting mechanism is akin to a maximization problem by a local social planner.

Residents commit to policy $\left\{G^{s}, G^{f}, \tau^{h}, \tau^{k}\right\}$ for current and all future periods. ${ }^{27}$ They pay for $G^{f}$ every year. Durable investments depreciate at the annual rate $\rho$. To maintain a constant level of infrastructure, residents hence have to pay $G^{s}$ the first year and $\rho G^{s}$ every following year.

Cities inherit zero net wealth from the past. ${ }^{28}$ They anticipate a flow of future subsidies $\left\{F_{t}\right\}_{0}^{\infty}$ and have access to international debt markets with fixed interest rate $R$. Residents' preferred policy is

${ }^{27}$ Appendix B.2 shows that policy choices are time-consistent if the environment stays constant. When there is a shock to the environment (e.g., in local amenities or public subsidies) jurisdictions change their equilibrium policy which is again time-consistent.

${ }^{28}$ Appendix B.2 shows that under no-Ponzi conditions, jurisdictions inherit exactly zero net wealth from past periods. Hence, there is no path-dependency in local public goods choices even in the presence of durable investments and a seemingly dynamic problem collapses into a static one. 
found by maximizing

$$
(1-\alpha) \ln \left(\left(1-\tau^{w}\right) w-r\left(1+\tau^{h}\right) h\right)+\alpha \ln h+\frac{\phi}{1-\phi} \delta\left(\varphi \ln G^{s}+(1-\varphi) \ln G^{f}\right)
$$

over $\left\{G^{s}, G^{f}, \tau^{h}, \tau^{k}\right\}$ subject to jurisdiction inter-temporal budget constraint

$$
\zeta G^{s}+G^{f}=\tau^{h} r H+\tau^{k} R K+\frac{R}{1+R}\left[\sum_{t=0}^{\infty}\left(\frac{1}{1+R}\right)^{t} F_{t}\right]
$$

where $\zeta=(\rho+R) /(1+R)$.

\section{B.2 Time Consistency and No Inherited Wealth}

We show that jurisdictions' decisions are time consistent. We prove it in the case without local business tax, but the argument remains valid in the presence of business taxes. We assume that jurisdictions actually inherit investment $G_{\text {init }}^{s}$ and debt $D_{\text {init }}$ from the past. Residents' preferred policy is given by

$$
\begin{aligned}
\max _{G^{s}, G^{f}, \tau} & (1-\alpha)(1-\phi) \ln \left(\left(1-\tau^{w}\right) w-r(1+\tau) h\right)+\alpha(1-\phi) \ln (h) \\
+ & \phi\left(\delta+\frac{1-\delta}{\left|a_{j}\right|}\right)\left(\varphi \ln \left(G^{s}\right)+(1-\varphi) \ln \left(G^{f}\right)\right)
\end{aligned}
$$

That is, after substituting in optimal housing and numéraire consumption:

$$
\max _{G^{s}, G^{f}, \tau}-\alpha(1-\phi) \ln (1+\tau)+\phi\left(\delta+\frac{1-\delta}{\left|a_{j}\right|}\right)\left(\varphi \ln \left(G^{s}\right)+(1-\varphi) \ln \left(G^{f}\right)\right)
$$

Optimal policy from $\mathbf{t}=\mathbf{0}$ (creation of the jurisdiction) In period $t=0$ (e.g., the creation of the jurisdiction), jurisdictions inherit zero investments $G_{\text {init }}^{s}=0$ and debt $D_{\text {init }}=0$. Residents choose and commit to a constant level of public good $G_{0}$ and a constant tax rate $\tau_{0}$ for current and all future periods $\{t=0, t=1, \ldots\}$. They furthermore assume that population will not change in future periods. When population changes because of, say, an amenity shock, the problem is reinitialized at period 0, but this time with a history and an a priori non-zero initial jurisdiction net wealth. Public goods are durable but depreciate at speed $\rho$. To commit to the initially chosen $G_{0}^{s}$ residents hence have to invest $\rho G_{0}^{s}$ every period from $t=1$. Residents receive a flow of subsidy equal to $F$ and constant over time (again, if $F$ changes the problem is reinitialized at period 0 with an a priori non-zero initial net wealth). jurisdictions can levy debt each year $\left\{D_{0}, D_{1}, D_{2}, \ldots\right\}$ that has to be repaid in full the next year, plus 
interests. Yearly budgets are given by

$$
\begin{array}{r}
G_{0}^{s}+G_{0}^{f}=D_{0}+\tau_{0} N h r+F \\
\rho G_{0}^{s}+G_{0}^{f}=-(1+R) D_{0}+D_{1}+\tau_{0} N h r+F \\
\rho G_{0}^{s}+G_{0}^{f}=-(1+R) D_{1}+D_{2}+\tau_{0} N h r+F \\
\vdots \\
\rho G_{0}^{s}+G_{0}^{f}=-(1+R) D_{t-1}+D_{t}+\tau_{0} N h r+F
\end{array}
$$

Let's multiply each budget line by

$$
p_{t} \equiv\left(\frac{1}{1+R}\right)^{t}
$$

and sum all lines up to $t=T$ :

$$
G_{0}^{s}+\rho G_{0}^{s} \sum_{t=1}^{T} p_{t}+G_{0}^{f} \sum_{t=0}^{T} p_{t}=\sum_{t=0}^{T} p_{t} D_{t}-(1+R) \sum_{t=1}^{T} p_{t} D_{t-1}+\tau_{0} N h r \sum_{t=0}^{T} p_{t}+F \sum_{t=0}^{T} p_{t}
$$

That is:

$$
G_{0}^{s}+G_{0}^{f}+\left(\rho G_{0}^{s}+G_{0}^{f}\right) \sum_{t=1}^{T} p_{t}=p_{T} D_{T}+\tau_{0} N h r \sum_{t=0}^{T} p_{t}+F \sum_{t=0}^{T} p_{t}
$$

We assume that the following no-Ponzi scheme condition holds:

$$
\lim _{T \rightarrow \infty} p_{T} D_{T}=0
$$

and take the limit of (38) when $T \rightarrow \infty$ to get the inter-temporal budget constraint:

$$
\zeta G_{0}^{s}+G_{0}^{f}=\tau_{0} N h r+F
$$

Note that we can express the debt stock at all $t$ by solving

$$
D_{t}=(1+R) D_{t-1}+\rho G_{0}^{s}+G_{0}^{f}-\tau_{0} N h r-F=(1+R) D_{t-1}+(\rho-1) G_{0}^{s}+D_{0}
$$

that is (noticing an arithmetico-geometric sequence):

$$
D_{t}=(1+R)^{t}\left(D_{0} \frac{1+R}{R}+(\rho-1) G_{0}^{s} \frac{1}{R}\right)-\frac{1}{R}\left((\rho-1) G_{0}^{s}+D_{0}\right)
$$

That is:

$$
p_{t} D_{t}=D_{0} \frac{1+R}{R}+(\rho-1) G_{0}^{s} \frac{1}{R}-p_{t} \frac{1}{R}\left((\rho-1) G_{0}^{s}+D_{0}\right)
$$

Taking the limit when $t \rightarrow \infty$ using the no-Ponzi condition yields

$$
0=D_{0} \frac{1+R}{R}+(\rho-1) G_{0}^{s} \frac{1}{R}
$$

Plugging (42) in (41), we find that debt is constant and that we are in a stationary setting (holding environment fixed):

$$
D_{t}=D_{0}=\frac{1-\rho}{1+R} G_{0}
$$


Optimal policy from $\mathbf{t}=\mathbf{1}$ (keeping environment fixed) At period 1, jurisdictions inherit debt (plus interests) and depreciated assets from period 0:

$$
(1-\rho) G_{0}^{s}-(1+R) D_{0}
$$

However, according to equation (42) this quantity is exactly zero. The optimization problem in period 1 is hence the same as in period 0 , and policy choices from period 1 onward are unchanged compared to those in period 0 . The proof by induction for any $t$ follows straightforwardly.

Optimal policy from $\mathbf{t}=\mathbf{1}$ (with a change in the environment) Initial net jurisdiction wealth is zero so the problem is reinitialized at period zero following a shock to the environment. The environment has changed however, so policy choices may be different in the new equilibrium.

\section{B.3 Taking the Extended Model to the Data}

We construct the public good index $G$ using our data on municipal accounts. First, we construct $G^{\mathrm{s}}$ and $G^{\text {f }}$, i.e., municipal durable facilities and annual public services. Then, we estimate parameter $\varphi$ of the Cobb-Douglas function.

Construction of $G^{s}$ We construct our public investment variable $G^{s}$ as the sum of all public assets minus the raw value of the land and financial assets such as cash. ${ }^{29}$ They are recorded at book value and account for investment depreciation. As mentioned in Section 2, investments notably include schools, transportation infrastructure, parks improvements, sports facilities, museums, art collections, etc. They also include investment subsidies to other parties such as local clubs and associations. Importantly, $G^{s}$ does not contain social housing units. ${ }^{30}$

Construction of $G^{f}$ We construct $G^{f}$, the flow of services annually consumed, as the sum of staff expenditure, maintenance spending, payments for external services and operating subsidies to third parties. We exclude interests payments as they do not correspond to consumable services.

Construction of $G$ To make sure that our constructed measures for $G^{\text {s }}$ and $G^{\text {f }}$ correctly reflect the amount of services chosen at the local level, we first check that they satisfy standard budget requirements. We then directly calibrate the ratio $\frac{G^{s}}{G^{f}}$ to recover parameter $\varphi$. We first estimate parameter $\rho$ by calibrating asset depreciation based on municipal financial accounts. Our central estimate is $\rho=0.010$.

\footnotetext{
${ }^{29}$ Taking out the raw value of the land seems natural as residents are unlikely to value it. Given that land is mostly a gift from the central government, erasing this asset as well as the corresponding liability from the balance sheet is neutral in our analysis. Cash and other liquid assets can be considered negative debt and are accounted for in our theoretical framework in the form of future taxes.

${ }^{30}$ Social housing units, when publicly owned, are held by ad hoc entities and not by jurisdictions.
} 
Figure 13: Model Fit: $G^{f}$ vs. $G^{s}$

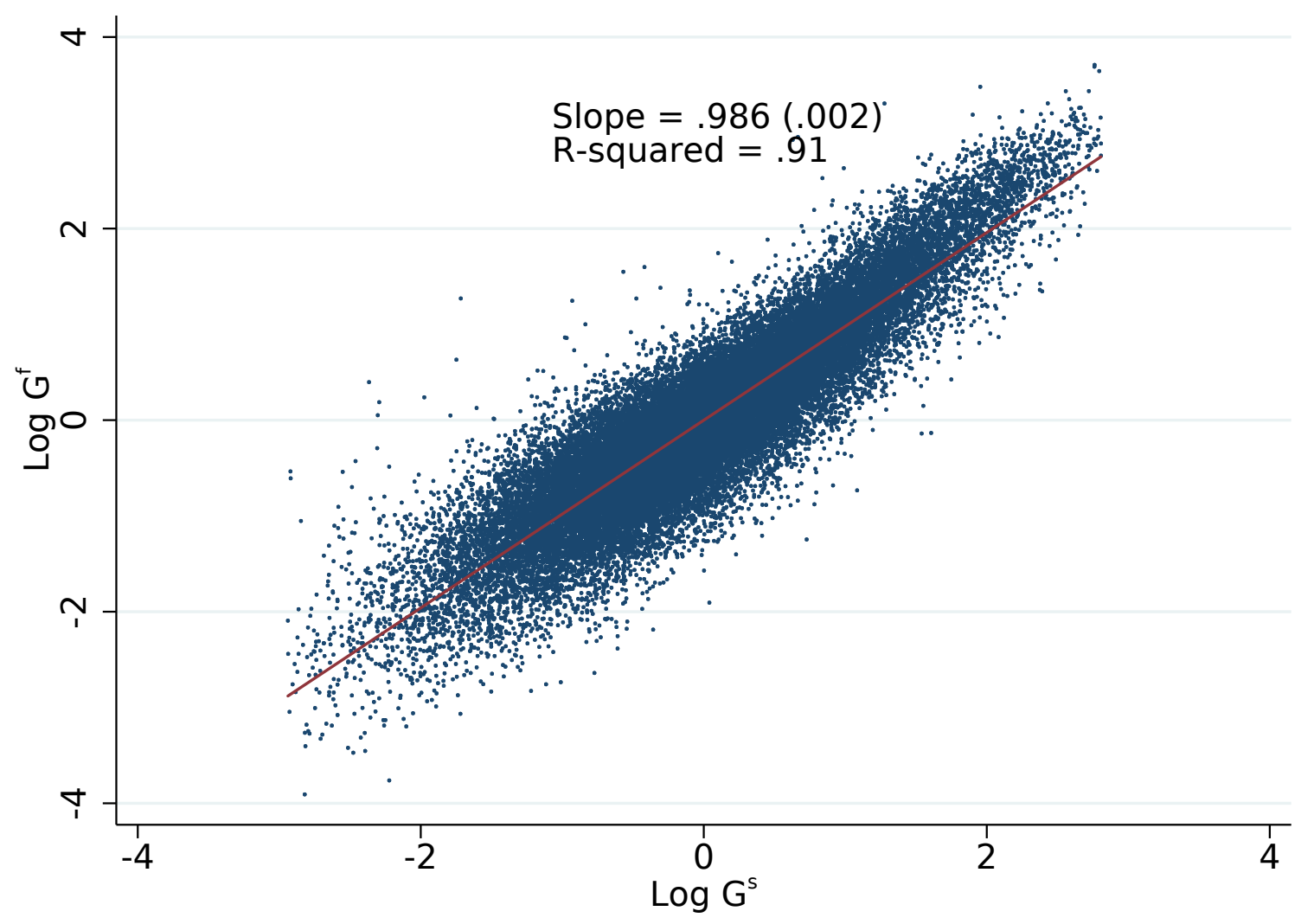

Note: This Figure shows the calibration exercise we carry out for our Cobb-Douglas modeling of how public goods enter utility.

Then we calibrate parameter $R$ from interests paid as a share of the debt stock. Our central estimate is $R=0.041$. Both estimates are robust across different calibration methods. We are then able to calibrate parameter $\zeta=\frac{\rho+R}{1+R}$ with a central estimate of $\zeta=0.049$. Finally, we estimate the ratio $\frac{G^{s}}{G^{f}}=\frac{\varphi}{(1-\varphi) \zeta}$ with a log-log regression reproduced in Figure 13. The Figure comforts our Cobb-Douglas specification as the slope is close to unity and residuals are quite small as indicated by the large $R^{2}$. Point estimate for the intercept is $1 / 0.074 \approx 13.5$, that is, capital investment approximately equals 13.5 years of operating expenditures. This leads to a central estimate $\varphi=0.378$. We can then rewrite our public good index $G$ as

$$
G=G^{\mathrm{s}}\left(\frac{1-\varphi}{\varphi} \zeta\right)^{1-\varphi} \approx 0.208 \times G^{\mathrm{s}}
$$

\section{DiD Robustness Checks}

Let jurisdiction total 20-65 population be

$$
N=N_{\bar{p}}+N_{p}
$$


where $N_{p}$ is the public sector population. Let $s_{p}=N_{p} / N$ be the pre-shock share of public employees in the population. Call $\widetilde{X}=\prod_{j^{\prime} \in a_{j}} X_{j^{\prime}}^{\frac{1}{\left|a_{j}\right|}}$. Within-MF changes in $N$ following a shock can be decomposed as follows:

$$
\begin{aligned}
d \ln (N / \widetilde{N}) & =\frac{d(N / \widetilde{N})}{N / \widetilde{N}} \\
& =\frac{d\left(N_{\bar{p}} / \widetilde{N}\right)}{N / \widetilde{N}}+\frac{d\left(N_{p} / \widetilde{N}\right)}{N / \widetilde{N}} \\
& =\frac{d\left(N_{\bar{p}} / \widetilde{N}\right)}{N / \widetilde{N}}+\frac{d\left(s_{p} N / \widetilde{N}\right)}{N / \widetilde{N}} \\
& =\frac{d\left(N_{\bar{p}} / \widetilde{N}\right)}{N / \widetilde{N}}+s_{p}\left[\frac{d(N / \widetilde{N})}{N / \widetilde{N}}+\frac{d s_{p}}{s_{p}}\right]
\end{aligned}
$$

The share of migration responses coming from public employment is then

$$
\frac{\frac{d\left(N_{p} / \widetilde{N}\right)}{N / \tilde{N}}}{\frac{d(N / \widetilde{N})}{N / N}}=s_{p}\left[1+\frac{d s_{p} / s_{p}}{\frac{d(N / \widetilde{N})}{N / \tilde{N}}}\right]
$$

Figure 14 shows an estimate for $\frac{d s_{p} / s_{p}}{\frac{d(S / \tilde{S})}{S / \tilde{S}}}$ of around 0.09. The estimate for $\frac{\frac{d(N / \tilde{N})}{N / \tilde{N}}}{\frac{d(S / \tilde{S})}{S / \widetilde{S}}}$ from Section 5.2 is around 0.03 . The average estimate for the pre-shock ratio of public staff to total 20-65 population is

Figure 14: Changes in (Public Employees) / (20-65 Population)

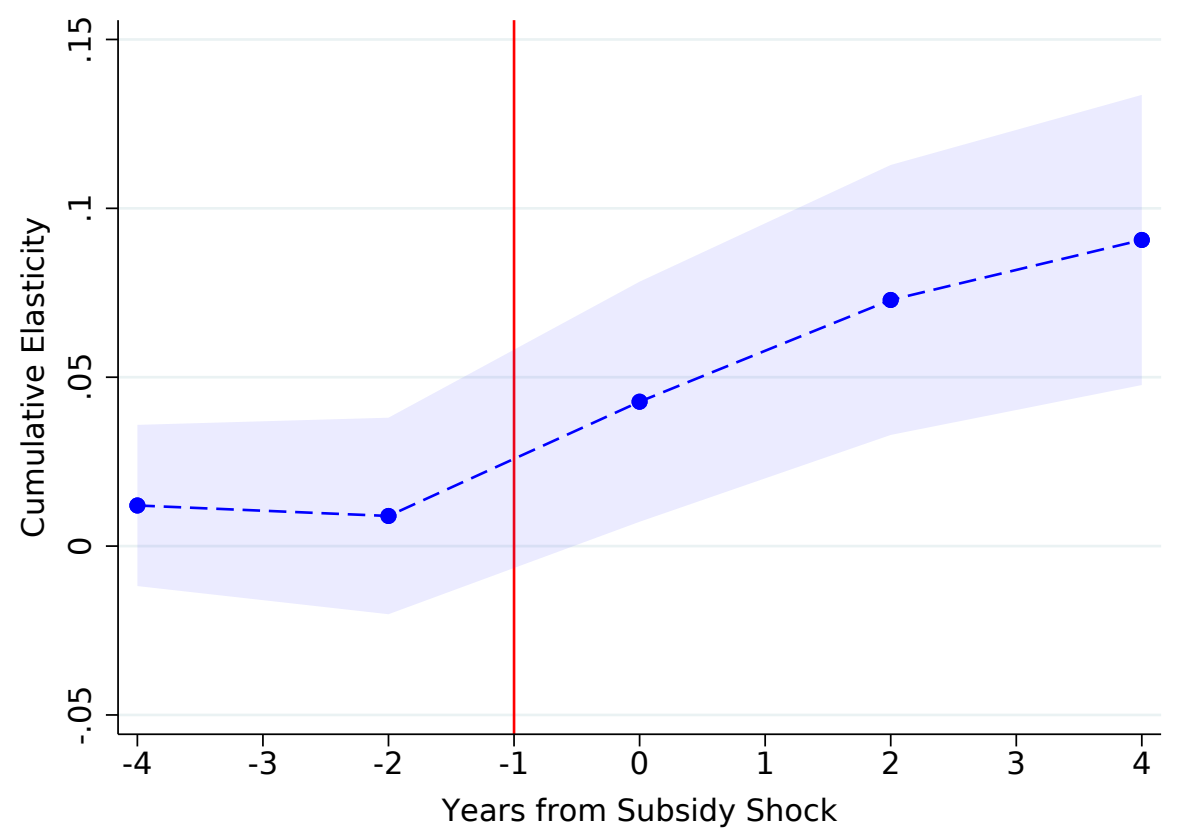

Note: This Figure plots the coefficient of regressions similar to Section 5 regressions. The dependent variable is the proportional change in the absolute share of public employees in municipality population $\Delta \ln \left(s_{p}\right)$ and the explanatory variable is the within-MF subsidy shock $\Delta \ln (\bar{S})$. Standard errors are clustered at the MF level. We report the $5 \%$ confidence bands. 
$s_{p} \approx 3 \%$. Estimate for the share of migration responses coming from public employment is hence $\approx 3 \% \times(1+0.09 / 0.03)=12 \%$. We get similar estimates when when including paid subsidies to third parties in addition to public staff payroll.

\section{Welfare}

We detail here the calculations for the welfare analysis.

\section{D.1 Before the Merger}

We first back out the fundamentals of the model $\left\{\mathcal{E}_{j}^{A}, \mathcal{E}_{j}^{C}\right\}$ from (i) equilibrium endogenous variables of the model that we observe as econometricians in 2014, and (ii) parameters that we have estimated or calibrated from the literature. We then make several assumptions to ensure tractability of the equilibrium in our simplified setup. We assume away business taxes and subsidies form the central government and make five others assumptions: (i) residents are myopic and do not anticipate migration responses when they vote for public goods and taxes; (ii) the public good production function is the identity, i.e., $\Gamma(x)=x$; (iii) housing supply elasticities $\eta_{j}$ are constant across jurisdictions; (iv) local productivity $\theta_{j}^{Y}$ does not depend on local public goods and $(\mathrm{v})$ the geographic fundamentals that we back out from observed data are still defining geography in our simplified model. This version of the model has a unique and tractable equilibrium defined by the following equations:

$$
\begin{aligned}
& N_{j}=\frac{\exp \left(v_{j} / \sigma\right)}{\sum_{j^{\prime}} \exp \left(v_{j^{\prime}} / \sigma\right)} \\
& v_{j}=(1-\phi)(1-\alpha) \ln (1-\alpha)+(1-\phi)(1-\alpha) \ln \left(w_{j}\right) \\
& +(1-\phi) \alpha \ln \left(h_{j}\right)+\phi \delta \ln \left(G_{j}\right)+\phi(1-\delta) \frac{1}{\left|a_{j}\right|} \sum_{j^{\prime} \in a_{j}} \ln \left(G_{j^{\prime}}\right)-\phi \delta^{2} \kappa \ln \left(N_{j}\right) \\
& -2 \phi \delta(1-\delta) \kappa \frac{1}{\left|a_{j}\right|} \sum_{j^{\prime} \in a_{j}} \ln \left(N_{j^{\prime}}\right)-\phi(1-\delta)^{2} \kappa \frac{1}{\left|a_{j}\right|} \sum_{j^{\prime} \in a_{j}} \ln \left(N_{j^{\prime}}\right)+\ln \left(\mathcal{E}_{j}^{A}\right) \\
& \ln \left(r_{j}\right)=\frac{1}{\eta_{j}} \ln \left(\frac{H_{j}}{T_{j}}\right)+\ln \left(\mathcal{E}_{j}^{C}\right) \\
& 1+\tau_{j}^{h}=1+\frac{\phi\left(\delta+\frac{1-\delta}{\left|a_{j}\right|}\right)}{(1-\phi) \alpha} \\
& G_{j}\left[1+\tau_{j}^{h}\right]=\frac{\varphi^{\varphi}(1-\varphi)^{1-\varphi}}{\zeta^{\varphi}} \tau_{j}^{h} N_{j} w_{j} \alpha
\end{aligned}
$$

Equations (47) and (48) are the first order conditions for public good supply in this simplified version. ${ }^{31}$ Equations (44), (45) and (46) are identical in the simplified model and in our general model.

${ }^{31}$ The vote conditions derive from the following optimization problem: $\max _{\tau_{j}^{h}, G_{j^{\prime}}^{s}, G_{j}^{f}, G_{j}}\left(G_{j}^{\delta} \prod_{j^{\prime} \in a_{j}} G_{j^{\prime}}^{\frac{1-\delta}{\mid a_{j}}}\right)^{\phi} C_{j}^{1-\phi}$ under the 
We note $N^{o}, G^{o}, v^{o}, r^{o}$ and $\tau^{o}$ the equilibrium variables in the observed 2014 allocation and $N^{n}$, $G^{n}, v^{n}, r^{n}$ and $\tau^{n}$ the pre-reform equilibrium variables in the simplified model that wee show can be deduced from observed data.

We rewrite equilibrium conditions (44), (45) and (46):

$$
\begin{aligned}
& N_{j}=\frac{\exp \left(v_{j} / \sigma\right)}{\sum_{j^{\prime}} \exp \left(v_{j^{\prime}} / \sigma\right)} \\
& v_{j}=-\frac{\eta}{\eta+1}(1-\phi) \alpha \ln \left(1+\tau_{j}\right)+\phi \delta \ln \left(G_{j}\right)+\phi \frac{1-\delta}{\left|a_{j}\right|} \sum_{j \in a_{j}} \ln G_{j^{\prime}} \\
& -\left[(1-\phi) \alpha \frac{1}{\eta+1}+\phi \kappa \delta^{2}\right] \ln N_{j}-\phi \kappa \frac{1-\delta^{2}}{\left|a_{j}\right|} \sum_{j^{\prime} \in a_{j}} \ln N_{j^{\prime}}+\sigma \Theta_{j}^{A} \\
& \ln r_{j}=\frac{1}{\eta+1} \ln N_{j}-\frac{1}{\eta+1} \ln \left(1+\tau_{j}\right)+\Theta_{j}^{r}
\end{aligned}
$$

with the transformed residuals

$$
\begin{aligned}
& \Theta_{j}^{r}=\frac{\eta}{\eta+1} \ln \left(\mathcal{E}_{j}^{C}\right)+\frac{1}{\eta+1} \ln \frac{\alpha w_{j}}{T_{j}} \\
& \sigma \Theta_{j}^{A}=(1-\phi) \alpha \ln \alpha+(1-\phi)(1-\alpha) \ln (1-\alpha)+(1-\phi) \ln \left(w_{j}\right)-(1-\phi) \alpha \Theta_{j}^{r}+\phi \delta \Theta_{j}^{G} \\
& +\phi \frac{1-\delta}{\left|a_{j}\right|} \sum_{j \in a_{j}} \Theta_{j^{\prime}}^{G}+\ln \left(\mathcal{E}_{j}^{A}\right)
\end{aligned}
$$

Let's define the following operators:

- $\underline{X}_{j}=X_{j}-\sum_{j \in a} \frac{X_{j}}{\left|a_{j}\right|}$

- $\bar{X}_{j}=\exp \left(\underline{\ln }\left(X_{j}\right)\right)$

- $\underset{\sim}{X} a_{j}=\sum_{j^{\prime} \in a} \frac{X_{j^{\prime}}}{|a|}-\sum_{a^{\prime}} \sum_{j^{\prime} \in a^{\prime}} \frac{X_{j^{\prime}}}{J\left|a^{\prime}\right|}$

- $\widehat{X}_{j}=\exp \left(\ln _{\sim}\left(X_{j}\right)\right)$

- $\hat{X}_{j}=X_{j}-\sum_{j^{\prime}} \frac{X_{j^{\prime}}}{J}$

- $\check{X}_{j}=\exp \left(\hat{\ln }\left(X_{j}\right)\right)$

Applying the $\underline{L}$ operator to equations (47), (48), (49), and (50) gives:

$$
\begin{aligned}
{\left[\sigma+(1-\phi) \alpha \frac{1}{\eta+1}+\phi \kappa \delta^{2}-\phi \delta\right] \ln \frac{\overline{N_{j}^{n}}}{\overline{N_{j}^{o}}} } & =\phi \delta\left(\ln \overline{N_{j}^{o}}-\ln \overline{G_{j}^{o}}+\ln \overline{w_{j}}\right) \\
& +\frac{\eta}{\eta+1}(1-\phi) \alpha \ln \overline{1+\tau_{j}^{o}}
\end{aligned}
$$

constraints $\zeta G_{j}^{s}+G_{j}^{f}=N_{j} h_{j} r_{j} \tau_{j}^{h}, G_{j}=\left(G^{s}\right)^{\varphi}\left(G_{j}^{f}\right)^{1-\varphi}, C_{j}=c_{j}^{1-\alpha} h_{j}^{\alpha}, c_{j}=(1-\alpha) w_{j}$ and $h_{j}=\frac{\alpha w_{j}}{r_{j}\left(1+\tau_{j}^{h}\right)}$. In the main text, $\Phi=\frac{\varphi^{\varphi}(1-\varphi)^{1-\varphi}}{\zeta^{\varphi}}$. 
Applying the $\underset{\sim}{L}$ operator to equations (48), (49), and (50) we get:

$$
\begin{aligned}
{\left[\sigma+\frac{(1-\phi) \alpha}{(\eta+1)}+\phi \kappa-\phi\right] \ln \frac{\widehat{N_{a}^{n}}}{\widehat{N_{a}^{o}}} } & =\phi\left(\ln \widehat{N_{a}^{o}}-\ln \widehat{G_{a}^{o}}+\ln \widehat{w_{a}}+\ln \widehat{\tau_{a}^{n}}-\ln \widehat{1+\tau_{a}^{n}}\right) \\
& -\frac{\eta}{\eta+1}(1-\phi) \alpha \ln \frac{\widehat{1+\tau_{a}^{n}}}{\widehat{1+\tau_{a}^{o}}}
\end{aligned}
$$

Notice that we can write:

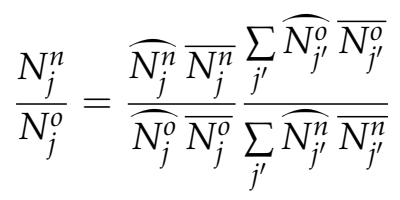

With equations (47), (53), (54), (55) and (48) — in this order — we get $\tau_{j}^{n}, N_{j}^{n}$ and $G_{j}^{n}$.

\section{D.2 After the merger}

We now assume that all jurisdictions within a municipal federation cooperate for the supply of public goods. Following the merger, residents vote for a new level of public goods pooling resources of all former member jurisdictions. To keep welfare comparable between pre- and post-reform situations, we assume that pre-reform jurisdictions still exist for the purpose of labor and housing markets. The only thing that changes is the level at which public good is supplied.

Housing tax rates are fixed by the MF council whose preferences exactly reflect those of all inhabitants in the MF. For a given MF $a$ the council chooses the housing tax rate and the level of local public good $G$ which maximize $v_{j}$ - with $j$ a jurisdiction belonging to the MF - the budget constraint $\sum_{j^{\prime} \in a} r_{j^{\prime}} N_{j^{\prime}} h_{j^{\prime}} \tau_{j^{\prime}}^{h}=G$. Importantly, the optimization problem gives the same $G$ and $\tau^{h}$ for all $j$ belonging to $a$. Once $G$ is chosen, a share is allocated to each jurisdiction. We assume that the allocation rule keeps public good shares unchanged, that is, jurisdiction $j$ gets a share $\frac{G_{j}^{n}}{\sum_{j^{\prime} \in a_{j}}^{n} G_{j^{\prime}}^{n}}$ of $G$.

We note $N^{m}, G^{m}, v^{m}, r^{m}$ and $\tau^{m}$ the equilibrium variable in the post-reform case. The new vote conditions are a $^{32}$

$$
\begin{aligned}
& 1+\tau_{a}^{m}=1+\frac{\phi}{(1-\phi) \alpha} \\
& G_{j}^{m}=\frac{\varphi^{\varphi}(1-\varphi)^{1-\varphi}}{\zeta^{\varphi}} \frac{G_{j}^{n}}{\sum_{j^{\prime} \in a_{j}} G_{j^{\prime}}^{n}} \sum_{j^{\prime} \in a_{j}} \frac{\tau_{j^{\prime}}^{m}}{1+\tau_{j^{\prime}}^{m}} N_{j^{\prime}}^{m} w_{j^{\prime}} \alpha
\end{aligned}
$$

where $\tau_{a}^{m}$ and $G_{a}^{m}$ are independant of the allocation rule chosen.

Equations (49), (50) and (51) still hold. We now rewrite $N^{m}, G^{m}, v^{m}, r^{m}$ and $\tau^{m}$ as function of $N^{n}$, $G^{n}, v^{n}, r^{n}$ and $\tau^{n}$.

\footnotetext{
${ }^{32}$ The vote conditions derive from the following optimization problem: $\max _{\tau_{a_{j},}^{H}, G_{a_{j}}, G_{a_{j}}, G_{a_{j}}^{f}}\left(\left[G_{a_{j}} w_{j}\right]^{\delta} \prod_{j^{\prime} \in a_{j}}\left[G_{a_{j}} w_{j^{\prime}}\right]^{\frac{1-\delta}{\left|a_{j}\right|}}\right)^{\phi} C_{j}^{1-\phi}$ under the constraints $\zeta G_{a_{j}}^{s}+G_{a_{j}}^{f}=\sum_{j^{\prime} \in a_{j}} N_{j} h_{j} r_{j} \tau_{a_{j}}^{H}, G_{a_{j}}=\left(G_{a_{j}}^{s}\right)^{\varphi}\left(G_{a_{j}}^{f}\right)^{1-\varphi}, C_{j}=c_{j}^{1-\alpha} h_{j}^{\alpha}, c_{j}=(1-\alpha) w_{j}, h_{j}=\frac{\alpha w}{r_{j}\left(1+\tau_{a_{j}}^{H}\right.}$.
} 
Applying the $\underline{L}$ operator to equations (47), (48), (49), (50), (56), and (57) we get:

$$
\overline{N_{j}^{m}}=\overline{N_{j}^{n}}
$$

that is, population shares within any MF stays constant. Note that

$$
\begin{aligned}
G_{j}^{m} & =\frac{G_{j}^{n}}{\sum_{j^{\prime} \in a_{j}} G_{j^{\prime}}^{n}} \sum_{j^{\prime} \in a} G_{j^{\prime}}^{n} \frac{\tau_{j^{\prime}}^{m}}{1+\tau_{j^{\prime}}^{m}} \frac{1+\tau_{j^{\prime}}^{n}}{\tau_{j^{\prime}}^{n}} \frac{N_{j^{\prime}}^{m}}{N_{j^{\prime}}^{n}} \\
& =\left[\prod_{j^{\prime} \in a_{j}} \frac{N_{j^{\prime}}^{m}}{N_{j^{\prime}}^{n}}\right]^{\frac{1}{\left|a_{j}\right|}} \frac{G_{j}^{n}}{\sum_{j^{\prime} \in a_{j}} G_{j^{\prime}}^{n}} \sum_{j^{\prime} \in a_{j}} G_{j^{\prime}}^{n} \frac{\tau_{j^{\prime}}^{m}}{1+\tau_{j^{\prime}}^{m}} \frac{1+\tau_{j^{\prime}}^{n} \frac{\bar{N}_{j^{\prime}}}{\tau_{j^{\prime}}^{n}} \frac{\bar{N}_{j^{\prime}}{ }^{n}}{\sum_{j^{\prime}}}}{\sum_{j^{\prime} \in a_{j}} G_{j^{\prime}}^{n}} \sum_{j^{\prime} \in a_{j}} G_{j^{\prime}}^{n} \frac{\tau_{j^{\prime}}^{m}}{1+\tau_{j^{\prime}}^{m}} \frac{1+\tau_{j^{\prime}}^{n}}{\tau_{j^{\prime}}^{n}}
\end{aligned}
$$

We define $X_{a}$ such as

$$
\frac{X_{a}}{G_{j}^{n}}=\frac{\sum_{j^{\prime} \in a} G_{j^{\prime}}^{n} \frac{\tau_{j^{\prime}}^{m}}{1+\tau_{j^{\prime}}^{m}} \frac{1+\tau_{j^{\prime}}^{n}}{\tau_{j^{\prime}}^{n}}}{\sum_{j^{\prime} \in a_{j}} G_{j^{\prime}}^{n}}
$$

Applying the $\underset{\sim}{L}$ operator to equations (48), (49), (50), (56), (57), (59) and (60) we get:

$$
\left[\sigma+(1-\phi) \alpha \frac{1}{\eta+1}+\phi \kappa-\phi\right] \ln \frac{\widehat{N_{j}^{m}}}{\overparen{N_{j}^{n}}}=\phi \ln \frac{\overparen{X_{a}}}{\overparen{G_{a}^{n}}}-\frac{\eta}{\eta+1}(1-\phi) \alpha \ln \frac{\widehat{1+\tau_{a}^{m}}}{\widehat{1+\tau_{a}^{n}}}
$$

Note that we have

$$
\frac{N_{j}^{m}}{N_{j}^{n}}=\frac{\overparen{N_{j}^{m}} \overline{N_{j}^{m}}}{\overparen{N_{j}^{n}} \overline{N_{j}^{n}}} \frac{\sum_{j^{\prime}} \widehat{N_{j^{\prime}}^{n}} \overline{N_{j^{\prime}}^{n}}}{\sum_{j^{\prime}} \widehat{N_{j^{\prime}}^{m}} \overline{N_{j^{\prime}}^{m}}}
$$

With equations (56),(58), (59), (60), (61), (62) and (57) — in this order - we get $\tau_{j}^{m}, N_{j}^{m}$ and $G_{j}^{m}$.

Finally:

$$
\begin{aligned}
& v_{j}^{m}-v_{j}^{n}=\phi \delta \ln \frac{G_{j}^{m}}{G_{j}^{n}}+\phi \frac{1-\delta}{\left|a_{j}\right|} \sum_{j \in a_{j}} \ln \frac{G_{j^{\prime}}^{m}}{G_{j^{\prime}}^{n}}-\left[(1-\phi) \alpha \frac{1}{\eta+1}+\phi \kappa \delta^{2}\right] \ln \frac{N_{j}^{m}}{N_{j}^{n}} \\
& -\phi \kappa \frac{1-\delta^{2}}{\left|a_{j}\right|} \sum_{j^{\prime} \in a_{j}} \ln \frac{N_{j^{\prime}}^{m}}{N_{j^{\prime}}^{n}}-\frac{\eta}{\eta+1}(1-\phi) \alpha \ln \left(\frac{1+\tau_{a_{j}}^{m}}{1+\tau_{a_{j}}^{n}}\right)
\end{aligned}
$$

\section{D.3 Welfare Comparison}

We define social welfare as

$$
\mathrm{W}=\mathbb{E}\left[\max _{j}\left(v_{j}+\mu_{i j}\right)\right]
$$


Since idiosyncratic tastes are distributed Extreme Value Type-I, we have ${ }^{33}$

$$
\mathrm{W}=\sigma \zeta+\sigma \ln \left(\sum_{j} \exp \left(v_{j} / \sigma\right)\right)
$$

hence

$$
\mathrm{W}^{o}=\sigma \zeta+\sum_{j} \frac{v_{j}^{o}}{J}+\sigma \ln \left(\sum_{j} \exp \left(\frac{v_{j}-\sum_{j} \frac{v_{j}^{o}}{J}}{\sigma}\right)\right)
$$

Note that $\check{N}_{j}^{n}=\exp \left(\frac{\widehat{v_{j}^{n}}}{\sigma}\right)$ therefore

$$
\mathrm{W}^{n}=\sigma \zeta+\sum_{j} \frac{v_{j}^{n}}{J}+\sigma \ln \left(\sum_{j} \check{N}_{j}^{n}\right)
$$

and

$$
\mathrm{W}^{m}=\sigma \zeta+\sum_{j} \frac{v_{j}^{n}}{J}+\sigma \ln \left[\sum_{j} \check{N}_{j}^{n} \exp \frac{v_{j}^{m}-v_{j}^{n}}{\sigma}\right]
$$

Eventually

$$
\mathrm{W}^{m}-\mathrm{W}^{n}=\sigma \ln \left(\frac{\sum_{j} \check{N}_{j}^{n} \exp \frac{v_{j}^{m}-v_{j}^{n}}{\sigma}}{\sum_{j} \check{N}_{j}^{n}}\right)
$$

\section{D.4 Welfare Estimation}

For the estimation of welfare change, we use parameters estimates of Section 6 and their estimated variance-covariance structure. As we have as many parameters estimates as we have moment specifications, we take the average across specifications for each parameter. We compute Monte Carlo standard errors by simulating 10,000 new values for each parameter using the estimated variancecovariance matrix. We then estimate the welfare impact of a reform for each of these simulated set of parameters and compute percentile-based standard errors. In our baseline scenario, we take $\eta=0.2$ and $\alpha=0.3$.

\footnotetext{
${ }^{33} \zeta$ is the Euler constant.
} 